\title{
Una nueva rana de huesos verdes del género Scinax (Anura: Hylidae) asociada a los bosques subandinos de la cuenca del río Magdalena, Colombia
}

\author{
A new frog with green bones of the genus Scinax (Anura: Hylidae), associated \\ with the sub-Andean forests of the Magdalena River basin, Colombia
}

\section{Andrés R. Acosta-Galvis}

\section{Resumen}

Como resultado de la exploración de áreas en postconflicto enmarcada en el proyecto Colombia BIO, se realizó la descripción de una nueva especie de Scinax con huesos verdes, asignable al clado de $S$. ruber. Esta nueva especie es endémica de los bosques subandinos periféricos del valle medio del río Magdalena en Colombia. Esta entidad biológica fue previamente identificada en la literatura científica como Scinax "A" y se caracteriza por su tamaño mediano $(28,6-31,1 \mathrm{~mm})$, su patrón cromático y su vocalización, similar al balido de una cabra, con una duración de 0,21-0,47 s, y frecuencia dominante entre 2184-3218 Hz. Sus características larvales en conjunto, permiten diferenciarla claramente de otras especies del género en la región transinterandina de Colombia. Con esta, ascienden a 18 las especies de Scinax documentadas en el territorio colombiano.

Palabras clave. Amphibia. Bioacústica. Renacuajos. Scinaxinae. Taxonomía.

\begin{abstract}
As a result of the exploration of post-conflict areas in the Colombia BIO project, a new species of green bones frog of the genus Scinax, assignable to the clade Scinax ruber, is described. The species is endemic to the peripheral sub-Andean forests of the middle Magdalena valley in Colombia. This biological entity was previously identified in the scientific literature as Scinax "A". The new species is recognizable by its average size $28.6-31.1 \mathrm{~mm}$, chromatic pattern and its particular mating call that is similar to the sound of a goat bleating; each vocalization has a duration of 0.21-0.47 s, with a dominant frequency between 2184-3218 Hz.; its larval characteristics were evaluated, which altogether made it possible to clearly differentiate it from other species in the genus in the trans-Andean region of Colombia. With the description of this species, 18 frogs of the genus Scinax are currently recognized in the Colombian territory.
\end{abstract}

Keywords. Amphibia. Bioacustics. Tadpoles. Scinaxinae. Taxonomy.

\section{Introducción}

El género Scinax Wagler, 1830 agrupa un importante número de ranas, reconocibles morfoló- gicamente a priori por la ausencia o reducción de la membrana interdigital pedial entre los dedos 
I-II que por lo general no se extiende más allá del tubérculo subarticular del dedo I, la cabeza deprimida, vientre inmaculado y el rostro subacuminado en vista dorsal (Faivovich et al., 2005; Duellman et al., 2016). Este género neotropical en la actualidad está representado por 70 especies (Araujo-Vieira et al., 2016; Duellman et al., 2016; http:/ / research.amnh.org/vz/herpetology/ amphibia/) que se distribuyen desde el sureste de Méjico hasta el oriente de Argentina (Faivovich, 2002, Nunes et al.; 2010, Cruz et al.; 2011, Nunes y Pombal, 2011; Lourenço et al., 2013; Sturaro y Peloso, 2014; Araujo-Vieira et al., 2016). Propuestas contemporáneas basadas en hipótesis filogenéticas fundamentadas en datos morfológicos y moleculares reconocen la validez del clado Scinax junto con otros tres géneros que conforman la subfamilia Scinaxinae (Duellman et al., 2016). Al interior del género Scinax, el grupo $S$. rostratus es bien soportado, mientras que un número significativo de especies no han sido asignadas a un grupo en particular (Faivovich, 2002; Faivovich et al., 2005; Araujo-Vieira et al., 2016; Duellman et al., 2016). En Colombia se encuentran 17 especies nominales de este género (www.batrachia.com); de ellas, 5 pertenecen al grupo de Scinax rostratus (S. sugillatus, S. kennedyi, S. garbei, S. boulengeri y $S$. rostratus) y las 12 restantes (S. blairi, S. cruentommus, S. elaeochrous, S. funereus, S. ictericus, S. karenanneae, S. lindsayi, S. manriquei, S. quinquefasciatus, S. ruber, S. wandae y $S . x$-signatus) no han sido atribuidas a algún grupo de especies (Faivovich et al., 2005; Duellman et al., 2016).

Geográficamente, la mayor parte de las especies de este género en Colombia se restringen a las tierras bajas. De ellas tres especies son exclusivas de la región del Pacífico: Scinax elaeochrous (Cope, 1876) que ocupa entre los 30-1500 m s.n.m., S. quinquefasciatus (Fowler, 1913) por debajo de los 500 m s.n.m., y S. sugillatus (Duellman, 1973) con distribuciones altitudinales entre 30-500 m s.n.m. Otras 3 especies son endémicas de la cuenca del Orinoco: S. blairi (Fouquette y Pyburn, 1972) entre los 200-500 m s.n.m., S. kennedyi (Pyburn, 1973) que ocupa los 155-200 m s.n.m. (erróneamente incluida en la región Amazónica por Sturaro y Peloso, 2014) y S. wandae (Pyburn y Fouquette, 1971) que habita entre los $200-880$ m s.n.m. Seis especies están confinadas en la región Amazónica: Scinax cruentommus (Duellman, 1972) que habitan entre los 50-150 m s.n.m., S. funereus (Cope, 1874) sobre los 100 m s.n.m., S. garbei (Miranda-Ribeiro, 1926) entre 50-300 m s.n.m., S. ictericus (Duellman y Wiens, 1993) cercano a los 300 m s.n.m., S. karenanneae (Pyburn, 1993) que habita sobre los 170 m s.n.m. y S. lindsayi (Pyburn, 1992), sobre los 100 m s.n.m. Por otra parte, Scinax manriquei (Barrio-Amorós, Orellana y Chacón, 2004), una especie asociada a la región andina nororiental en los límites entre Colombia y Venezuela a una altitud de 1400-1500 m s.n.m. Las restantes cuatro especies conocidas para el país presentan distribuciones generalistas (Figura 1) que ocupan, a su vez, varias ecorregiones; estas son: $S$. boulengeri (Cope, 1877) con reportes entre 0-20 m s.n.m., S. rostratus (Peters, 1863) 30-1100 m s.n.m., S. ruber (Laurenti, 1768) 0-1700 m s.n.m. y S. x-signatus (Spix, 1824) 40-2200 m s.n.m. Se presume que estos cuatro taxones envuelven diversidad críptica a nivel de especies (Fouquet et al., 2007).

Con base a evidencia morfológica, Nieto-Castro (1999) señala la existencia de varias poblaciones colombianas de Scinax correspondientes a especies no descritas; entre ellas, una denominada Scinax " $A$ ", que ha sido históricamente confundida con Scinax elaeochrous debido a sus huesos verdes. No obstante, sus características acústicas y morfológicas permiten definirla como una nueva especie.

Una serie de expediciones en las estribaciones andinas circundantes a la cuenca media del valle del río Magdalena, en los departamentos de Antioquia (en el marco de las expediciones Colombia BIO), Caldas en la cordillera Central y en el departamento de Cundinamarca en la cordillera Oriental, permitieron obtener más especímenes a los ya previamente tipificados, a partir de los cuales se describe aquí la nueva especie. 


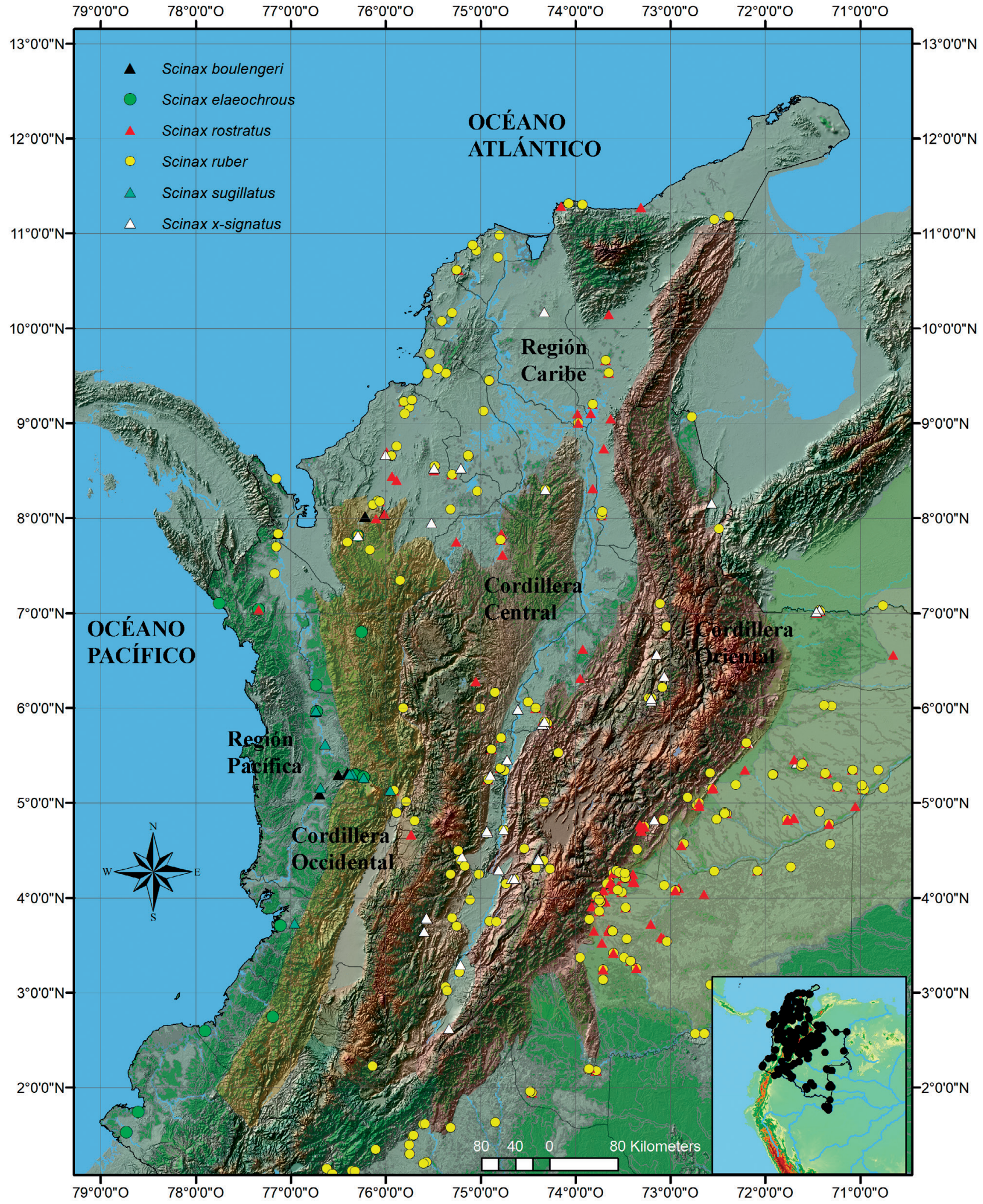

Figura 1. Distribución de los registros de las especies transinterandinas del género Scinax en Colombia. 


\section{Materiales y métodos}

Trabajo de campo y colecciones de referencia. Los ejemplares provienen de cuatro localidades de las estribaciones andinas circundantes del valle central del Magdalena (Figura 2) entre los 9351100 m s.n.m. Localidad 1: Inspección de Policía Guadualito (053' $31^{\prime \prime} \mathrm{N}$ y $\left.74^{\circ} 18^{\prime} 32^{\prime \prime} \mathrm{O}\right)$, municipio de Yacopí, departamento de Cundinamarca, Colombia, 1 de octubre de 1995. Localidad 2: Vereda Bellavista $\left(05^{\circ} 19^{\prime} 53,2^{\prime \prime} \mathrm{N}\right.$ y $\left.74^{\circ} 55^{\prime} 15^{\prime \prime} \mathrm{O}\right)$, municipio La Victoria, departamento de Caldas, 17 de diciembre de 2007. Localidad 3: Centro Ecológico y de Vacaciones San Felipe $\left(05^{\circ} 01^{\prime} 44,6^{\prime \prime}\right.$ $\mathrm{N}$ y $\left.74^{\circ} 22^{\prime} 9,7^{\prime \prime} \mathrm{O}\right)$, municipio de La Vega, departamento de Cundinamarca, 16 de julio de 2011 en Colombia. Localidad 4: caserío Escuela El Porvenir, vereda El Porvenir (05 $53^{\prime} 18^{\prime \prime} \mathrm{N}$ y751'15" O), municipio de Carmen de Viboral, departamento de Antioquia, entre el 30 de noviembre y el 4 de diciembre de 2016.

Las localidades estudiadas corresponden a agrosistemas de la ecorregión denominada bosques del valle del Magdalena (Dinerstein et al., 1995; Olson y Dinerstein, 2002). Las coordenadas geográficas y sus elevaciones correspondientes fueron obtenidas directamente en los sitios de colecta con un GPS Garmin GPSMAP 60CSx (datum WGS 84). Los datos de colecta y aspectos de historia natural se basaron en las notas de campo identificadas con la siguiente abreviatura: ARA=Andrés Acosta. Los especímenes fueron sacrificados siguiendo la propuesta metodológica de Chen y Combs (1999) y su posterior fijación se realizó en una solución de formol de calidad analítica al $10 \%$, preservados en etanol al $70 \%$ y depositados en las colecciones biológicas del Instituto de Investigación de Recursos Biológicos Alexander von Humboldt, Villa de Leyva, Boyacá, Colombia (IAvH-Am), del Instituto de Ciencias Naturales de la Universidad Nacional de Colombia, sede Bogotá (ICN-MHN) y la Pontificia Universidad Javeriana, sede Bogotá (MUJ). Especies adicionales examinadas son listadas en el Anexo 1.
Morfología de los adultos. La definición, diagnosis y descripción siguen a Savage y Heyer (1967) Duellman (1970), Myers y Duellman (1982), Duellman (1986), De la Riva (1993), Napoli y Caramaschi (1998), Guayasamin et al. (2006), Cisneros-Heredia y McDiarmid (2007). Las medidas de los ejemplares fueron realizadas con un calibrador digital (Mitutoyo $0.1 \mathrm{~mm}$ ); siguiendo a Duellman (1970): LRC (longitud rostro cloacal), AC (anchura cefálica, a nivel de la base mandibular), LC (longitud cefálica desde el extremo del rostro hasta la base mandibular, DIN (distancia internarinas), DIO (distancia interorbital), DO (diámetro del ojo), DON (distancia ojo-narina), DT (diámetro del tímpano), AP (anchura del párpado), LR (distancia entre el borde anterior del ojo hasta el extremo de rostro) AR (anchura del rostro), LT (longitud tibial), LF (longitud femoral), LPd (longitud pedial), LMn (longitud manual), Lab (longitud del antebrazo), IIIDm (diámetro del disco del tercer dedo manual) y IVDp (diámetro del disco del cuarto dedo pedial). El promedio y la desviación estándar de estas variables son reportados. Para identificar el sexo y la madurez sexual se realizó la observación macroscópica directa de los caracteres sexuales secundarios, se empleó un estereoscopio digital Nikon SMZ-1B con iluminación de alta intensidad NI-150 Nikon. Los machos adultos fueron identificados por la presencia de un saco gular y cojinetes nupciales. Las fotografías de los hábitats y especímenes fueron realizadas mediante varios equipos ópticos que incluyen in situ una cámara digital Canon EOS 70D y en ex situ empleando una cámara Canon EOS 5D Mark II al interior de una caja de iluminación Photo Safe-box con luces LED de 5500 kelvin.

Morfología de las larvas. Tres lotes de renacuajos fueron colectados y fijados en una solución de formol al $10 \%$ y de calidad analítica. A estos tres lotes fueron asignados los siguientes números de catálogo: IAvH 14565 (n= 6), IAvH 14566 (n=14) e IAvH14570 (n=2). La caracterización de los estadios 


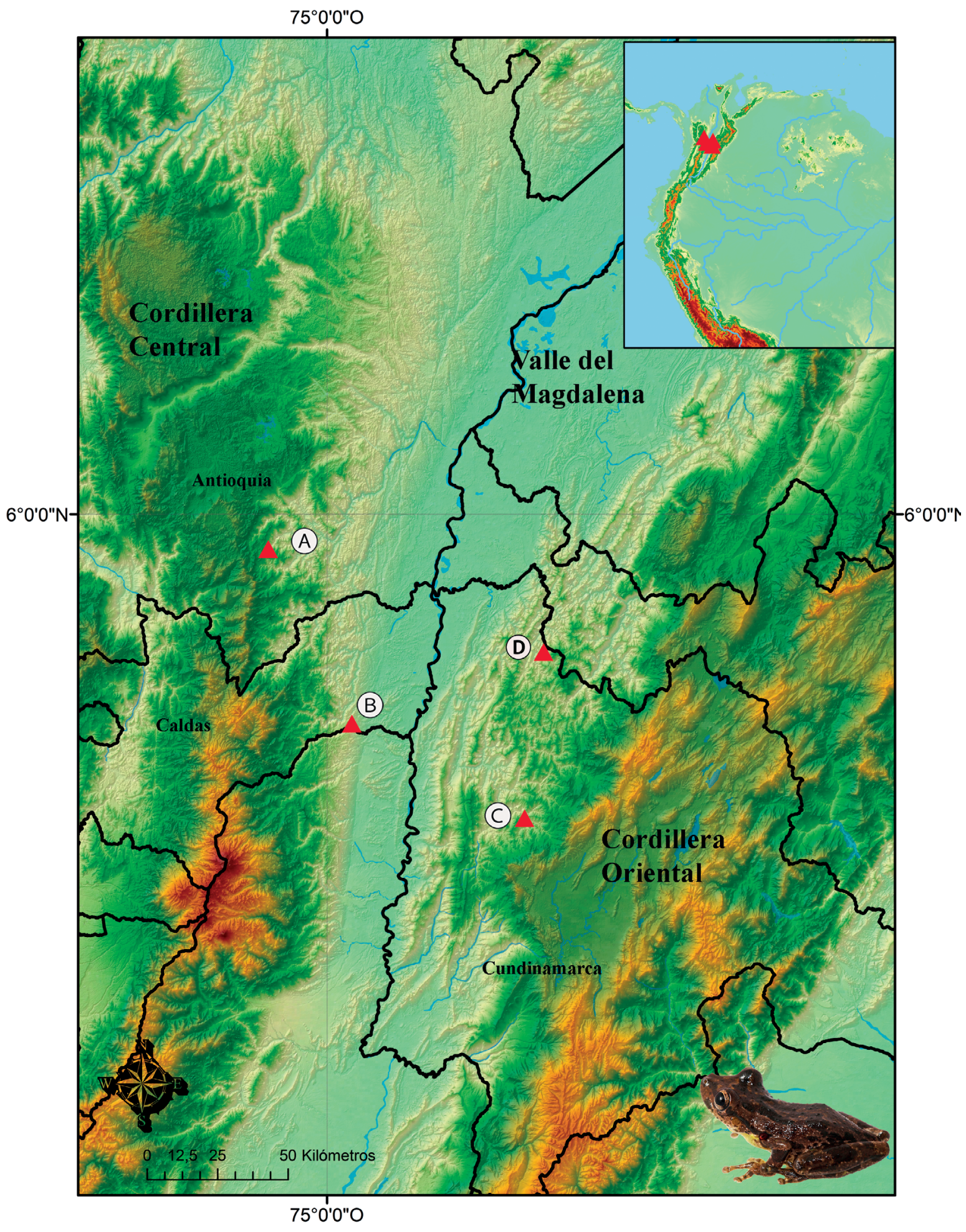

Figura 2. Registros geográficos (triángulos rojos) de Scinax caprarius sp. nov. A. Municipio El Carmen de Viboral en el departamento de Antioquia. B. Municipio La Victoria, departamento de Caldas. C. Localidad típica, municipio La Vega, departamento de Cundinamarca. D. Inspección de Policía Guadualito, municipio Yacopí, departamento de Cundinamarca. 
larvales observados (28-34) sigue la clasificación de Gosner (1960); para la descripción de los caracteres morfológicos (disco oral y morfología del cuerpo) se siguió a Altig y McDiarmid (1999), McDiarmid y Altig (1999) y Lannoo (1987). Otros criterios específicos sobre la morfología del género Scinax siguen propuestas contemporáneas (Faivovich, 2002; Silva-Soares et al,. 2010; Lourenço et al., 2013; Guimaraes et al., 2014). Las estructuras morfológicas fueron observadas y documentadas mediante un estereoscopio digital Leica MC 190HD. El color in vivo fue descrito a partir de las fotografías y notas de campo.

Las medidas estándar registradas para los renacuajos son las siguientes: LT (longitud total desde el extremo del rostro hasta la punta de la cola); LC (longitud del cuerpo desde el extremo del rostro hasta la base de la musculatura caudal); LCD (longitud caudal desde la base de la musculatura caudal hasta el extremo apical de la cola); AlCo (altura máxima del cuerpo), AnCo (ancho máximo del cuerpo) ACf (anchura cefálica a nivel de los ojos), Mcd (altura de la musculatura caudal en la base de la cola), Amcd (anchura muscular en la base de la cola), MxAcd (altura máxima de la cola), O-N (distancia ojo-narina), DR-N (distancia desde el extremo del rostro hasta la porción anterior de la narina), DIN (distancia internarinas), DIO (distancia interorbital) y DO (diámetro del ojo).

Bioacústica. Las vocalizaciones de dos especímenes colectados fueron grabadas entre 0,20-1 m de distancia. El ejemplar: IAvH-Am-14421 (BSA15985) fue grabado $(0,50 \mathrm{~m})$ el 30 de noviembre de 2016 en reservorios de agua asociados con áreas de potrero a las 19:53 horas, temperatura ambiental de $24{ }^{\circ} \mathrm{C}$ y una humedad relativa de $68 \%$, en el caserío El Porvenir, municipio de El Carmen de Viboral, departamento de Antioquia. El ejemplar MUJ-7509 (BSA-15989) fue grabado el 18 de diciembre de 2007 en una laguna, a las 19:30 horas, con una temperatura ambiental de
$21,3{ }^{\circ} \mathrm{C}$ y una humedad relativa de $85 \%$, en la vereda Bellavista, del municipio de La Victoria en el departamento de Caldas. Las grabaciones fueron realizadas empleando una grabadora digital Marantz PMD670 Digital Recorder con un micrófono unidireccional Sennheiser MKH 60 P48 y con una grabadora Sony HI-MD-Linear PCM, y una grabadora digital HI-MD Recorder MZ-M10 con un micrófono Sony F-V5. Los análisis acústicos fueron realizados mediante el programa Raven Pro 1,5 (Charif et al., 2010) con una frecuencia de muestreo de $44,1 \mathrm{KHz}$ y 16 bit de resolución; la temperatura y humedad relativa fueron obtenidas con termo-higrómetro marca EXTECH. Los siguientes parámetros, que incluyen variables espectrales y temporales, siguen diferentes propuestas (Duellman y Pyles, 1983; Cocroft y Ryan, 1995; De Carvalho et al., 2015; Köhler et al., 2017) que incluyen: llamado (unidad acústica principal en una vocalización; un llamado está separado de otro por silencio), duración de la llamada (es la duración de una sola llamada, independientemente de si está compuesta por una o varias notas), nota (subunidades más pequeñas, casi siempre separadas por intervalos de silencio, el llamado se suele dividir en notas), número de notas por llamada (número de señales acústicas reconocibles en una llamada), duración de una nota (duración de una nota dentro de una llamada; medida desde el principio hasta el final de la nota), duración de los intervalos entre notas, pulso (ráfagas de sonido dentro de una nota), número de pulsos por nota, oscilaciones (número de ondas de sonido contenidas en cada nota), número de armónicos (número de armónicos presente en una llamadas), espectro de frecuencia (el intervalo que representa todo el espectro de frecuencia en el cual están contenidos los armónicos) y la frecuencia dominante (la frecuencia de mayor energía). Las grabaciones fueron depositadas en el Banco de Sonidos Ambientales (BSA), del Instituto Humboldt y las URL con las vocalizaciones están disponibles en http://colecciones.humboldt.org. $\mathrm{co} / \mathrm{rec} /$ sonidos. 


\section{Resultados}

\author{
Scinax caprarius sp. nov. \\ urn:Isid:zoobank.org:act:179A9F3E-AF39- \\ 40F2-9C2A-82B2107578B8
}

Scinax "A" Nieto-Castro 1999:345, Tabla 2.

Scinax sp. Restrepo et al. 2017:214, Figura 5H, Tabla 1.

Holotipo (Figura 3): macho adulto, IAvHAm-11363 (Número de Campo ARA 6029), colectado por Andrés Acosta el 16 de julio de 2011, y depositado en la Colección de Anfibios del Instituto de Investigación de Recursos Biológicos Alexander von Humboldt Colombia, Villa de Leyva, Boyacá, Colombia.

Localidad típica. Carretera entre La Vega y Villeta, a $4 \mathrm{~km}$ al occidente del casco urbano de la Vega, Centro Ecológico y de Vacaciones San Felipe $\left(05^{\circ} 01^{\prime} 44,6^{\prime \prime} \mathrm{N}\right.$ y $74^{\circ} 22^{\prime} 9,7^{\prime \prime} \mathrm{O}, 935 \mathrm{~m}$ s.n.m.), municipio La Vega, departamento de Cundinamarca, flanco occidental de la cordillera Oriental de Colombia.
Paratipos. (Figuras 4 y 5): machos adultos: IAvHAm-11360-11362 colectados con el holotipo el 16 de Julio de 2011, por Andrés Acosta. Machos adultos IAvH-Am-14417-14422, colectados en el caserío Escuela El Porvenir, vereda El Porvenir, municipio de El Carmen de Viboral, Colombia, departamento de Antioquia, flanco oriental de la cordillera Central de Colombia, (0553'19,7' N y 75¹1'18" O; 1065 m s.n.m.), por Andrés Acosta y Yair Orozco entre el 28 de noviembre y el 4 de diciembre de 2016; machos adultos, ICN-MHN 37042, ICN-MHN 37047, ICN-MHN 37050, ICNMHN 37052-37055, ICN-MHN 37059, ICN-MHN 37061, ICN-MHN 37063, ICN-MHN 37068, ICNMHN 37070 colectados en la Inspección de Policía Guadualito, municipio Yacopí, departamento de Cundinamarca $\left(05^{\circ} 33^{\prime} 31^{\prime \prime} \mathrm{N}\right.$ y $74^{\circ} 18^{\prime} 32^{\prime \prime} \mathrm{O}$; $1050 \mathrm{~m}$ s.n.m.), por José Vicente Rueda Almonacid, el 1 de octubre de 1995.

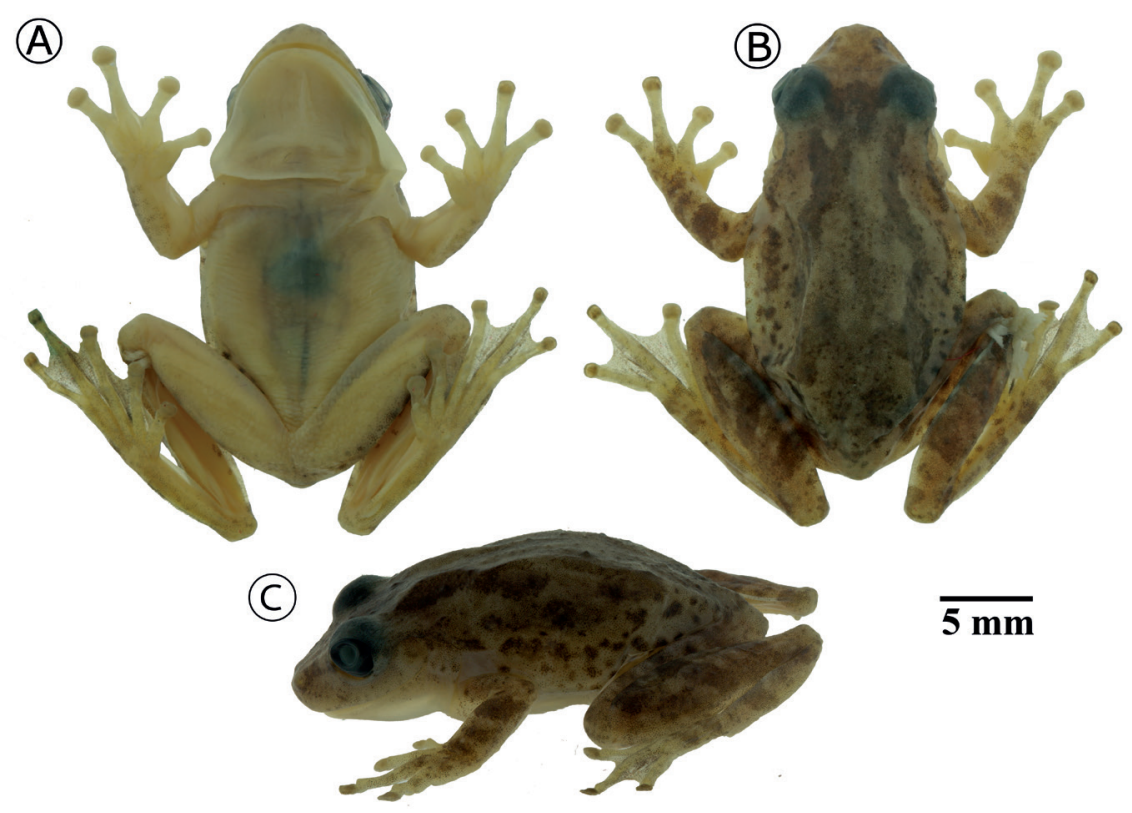

Figura 3. Scinax caprarius sp. nov. Holótipo IAvH-Am-11363, macho adulto preservado en etanol $70 \%, \mathrm{LRC}=29.6 \mathrm{~mm}$. A. Vista ventral. B. Vista dorsal. C. Vista laterales. Escala $=5 \mathrm{~mm}$. Fotos: Andrés Acosta. 
(A)
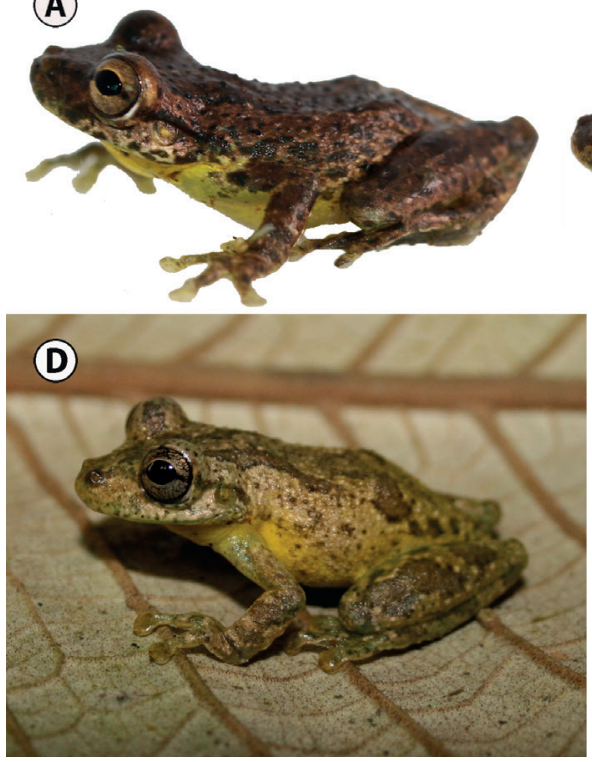

(B)
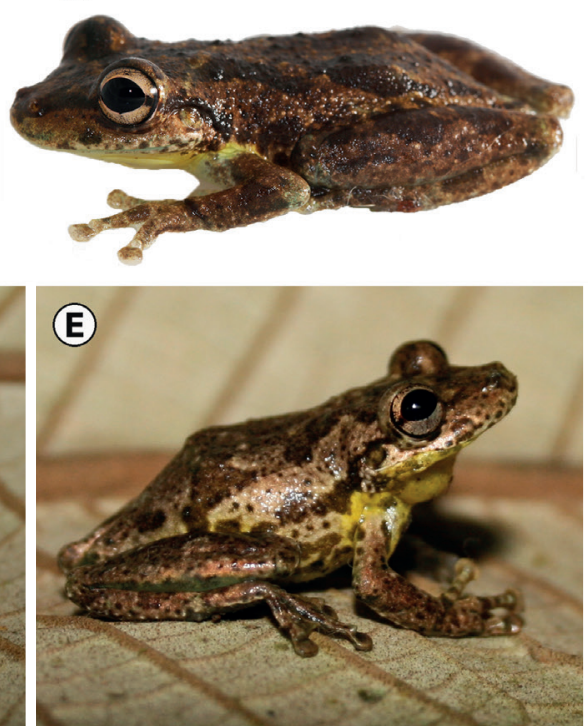

(C)
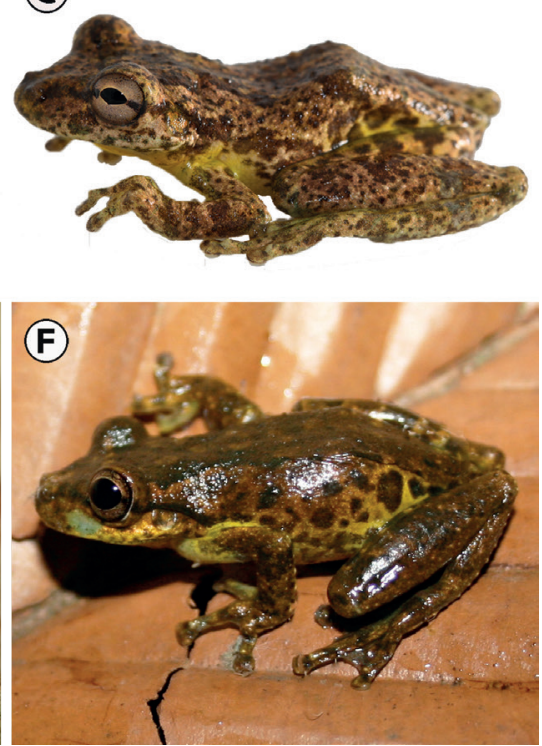

Figura 4. Variación cromática en machos adultos de Scinax caprarius sp. nov.: departamento de Antioquia A. IAvH-Am-14418 (ARA 7376). B. IAvH-Am-14419 (ARA 7391). C. IAvH-Am-14420 (ARA 7392), departamento de Caldas. D. MUJ 7583 (ARA 4489). E. MUJ 7504 (ARA 4490). F. MUJ 7509 (ARA 4500). Fotos: Andrés Acosta.
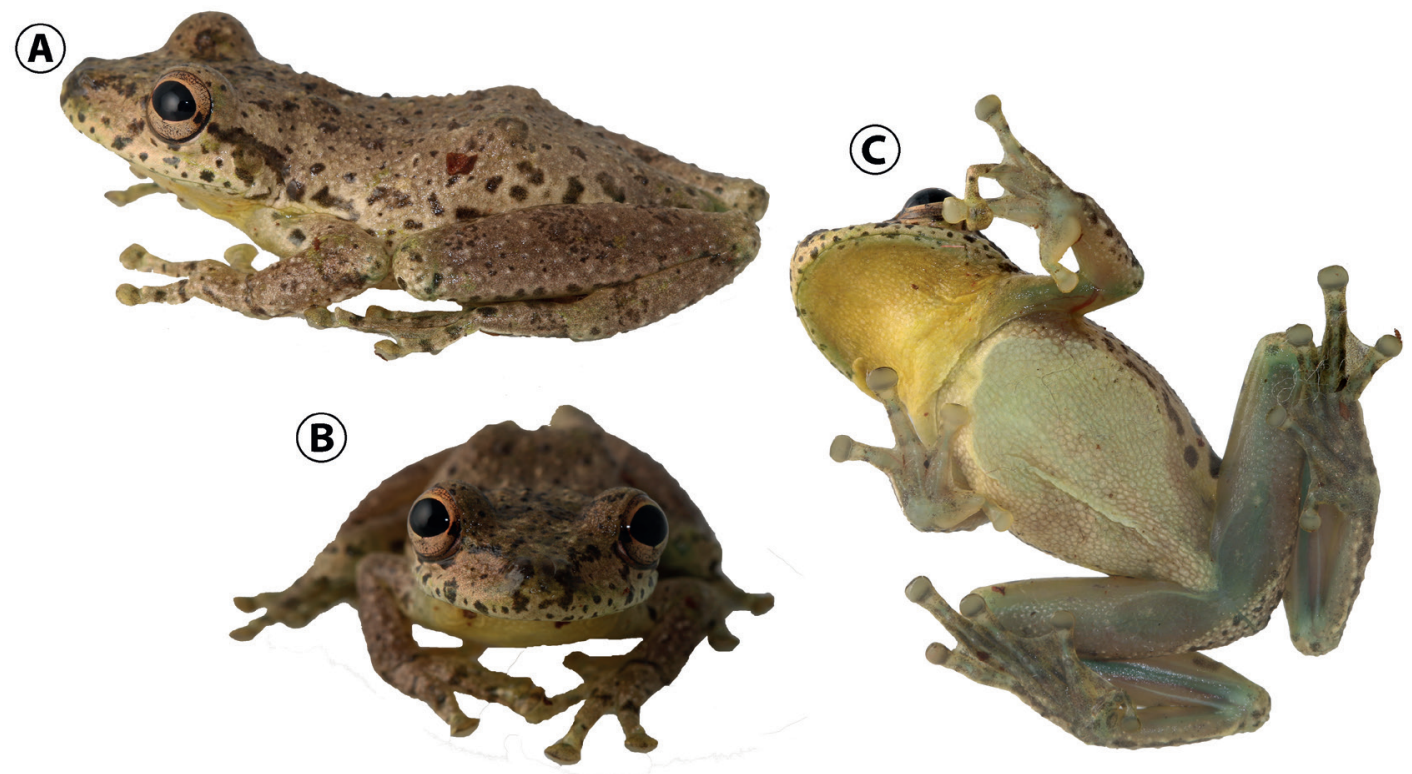

Figura 5. Scinax caprarius sp. nov: Paratipo IAvH-Am-14421 (con grabación BSA15985), macho adulto (LRC $=29,0 \mathrm{~mm}$.). A. Vista lateral. B. Vista frontal. C. Vista ventral. Fotos: Andrés Acosta. 
Ejemplares referidos. Macho adulto MUJ 7503, colectado en la vereda Bellavista, municipio La Victoria $\left(05^{\circ} 19^{\prime} 53,2^{\prime \prime} \mathrm{N}\right.$ y $74^{\circ} 55^{\prime} 15^{\prime \prime} \mathrm{O} ; 1040 \mathrm{~m}$ s.n.m.), departamento de Caldas, flanco oriental de la cordillera Central de Colombia, el 15 de diciembre de 2007, por Andrés Acosta (Figura 4).

Etimología. El epíteto específico hace alusión a la vocalización que emiten los machos de esta especie, similar a la vocalización de una cabra. Del latín caprarius (masculino) es una segunda declinación del latín capra.

Definición. A partir de sus rasgos morfológicos es identificado como un anuro del género Scinax debido a que la membrana interdigital pedial entre los dedos I-II no se extiende más allá del tubérculo subarticular del dedo I pedial y vientre inmaculado. El nuevo taxón es asignable al clado Scinax ruber (sensu Faivovich et al., 2005) y definido por la siguiente combinación de caracteres: 1) tamaño moderado, machos adultos (LRC $=28,5-$ $31,7 \mathrm{~mm}) ; 2$ ) color de las superficies dorsales in vivo (Figuras 4 y 5) café claro a café rojizo con manchas irregulares, algunas de ellas fusionadas en forma de reticulaciones café oscuro; coloración de la región axilar, ingle, parte anterior y posterior de los muslos amarillo pálido a brillante con manchas irregulares de color café oscuro; porción supralabial, desde el ojo hasta el tímpano, de color café pálido hasta amarillo brillante, con pequeñas manchas irregulares café; saco gular amarillo y vientre inmaculado (Figura $5 \mathrm{C}$ ); 3) rostro corto, redondeado en vistas dorsal y lateral; 4) huesos verdes (Figura $5 \mathrm{C}$ ); 5) superficies dorsales con tubérculos dispersos que se distribuyen de manera uniforme; superficies de los flancos del cuerpo, axila, ingle, y partes anterior y posterior del muslo, lisas; superficies ventrales areoladas; 6) iris café con pequeñas reticulaciones negras hacia la margen externa de la órbita y unas manchas negras en la región anterior y posterior del iris que forman una banda longitudinal (Figura 6 A); 7) superficie posterior del muslo con manchas irregulares oscuras, algunas forman reticulaciones; 8) vocalización compuesta entre 4-7 notas, con una duración de 0,21-0,47 s y frecuencia dominante entre 2184-3218 Hz. (Figura 11);9) Tubo proctodeal en los renacuajos no sobrepasa el margen de la aleta ventral (Figura 10) y su región caudal posee poca pigmentación (Figura 9); 10) membrana interdigital pedial con fórmula $\mathrm{I}(2)$ $\left(2^{+}-2\right) \operatorname{II}\left(1^{+}-1\right)-\left(2-2^{-}\right) \operatorname{III}\left(1^{+}-1^{-}\right)-\left(2-2^{-}\right) \operatorname{IV}\left(2^{-}\right)-\left(1^{-}\right) \mathrm{V}$.

Diagnosis. Scinax caprarius sp. nov. es una especie transinterandina y endémica del valle medio del Magdalena, que difiere de las especies del grupo de Scinax rostratus presentes en esta área geográfica de Colombia (S. sugillatus, S. boulengeri y S. rostratus; caracteres entre paréntesis) por presentar manchas irregulares en la superficie posterior del muslo (patrón de barras transversas en las tres especies) y por la ausencia de una marca triangular entre la región interorbital (presente en las tres especies).
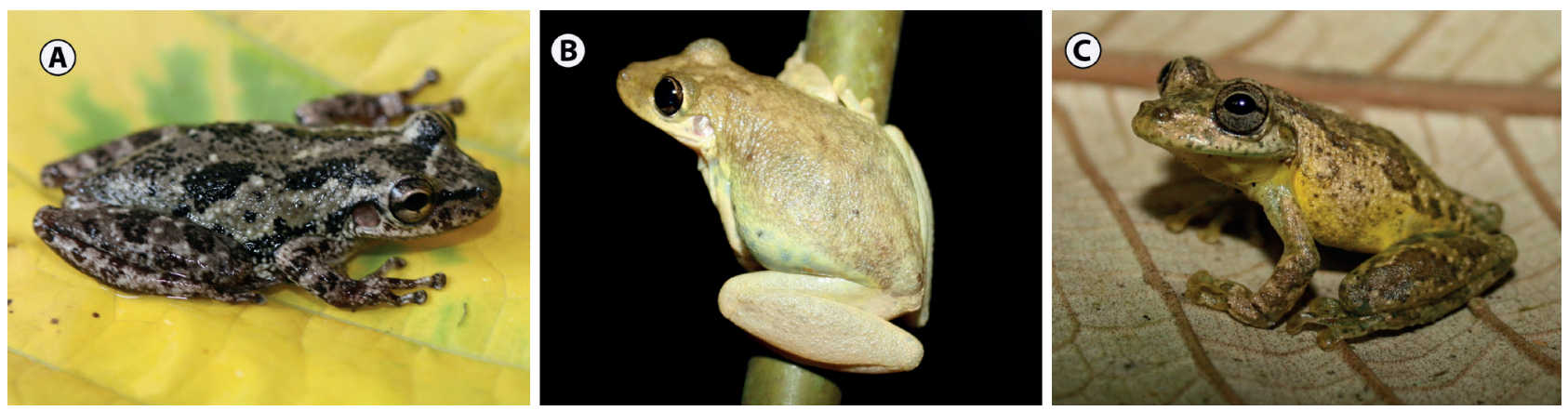

Figura 6. Especies del clado Scinax ruber presentes en la región del valle del Magdalena, Colombia. A. Scinax $x$-signatus IAvH-Am-11444, departamento del Tolima. B. Scinax ruber IAvH-Am-10547, departamento de Santander, municipio Sabana de Torres. C. Scinax caprarius sp. nov. MUJ 7503, departamento de Caldas. Fotos: Andrés Acosta. 
De forma comparativa, con las restantes especies del género Scinax (caracteres entre paréntesis) que se distribuyen en la región transinterandina (Figura 6 y 7), Scinax caprarius sp. nov. presenta huesos verdes (huesos blancos en $S$. ruber y S. x-signatus), las superficies dorsales son café rojizo a dorado (superficies dorsales variables café a amarillo); los renacuajos en los estados 2836 presentan poca pigmentación en la cola (con moteaduras irregulares en las aletas dorsales y ventrales en $S$. ruber y $S$. $x$-signatus [Suárez y Lynch 2011]); la aleta dorsal se inicia en la mitad del cuerpo (a nivel del borde posterior de los ojos en S. x-signatus [Suárez y Lynch 2011]); vocalización con un promedio de 5.8 notas por cada llamado (1.9 notas por llamado en Scinax ruber [Duellman y Pyles 1983], la duración de cada llamado es mayor, con 0,21-0,47 s (0,14-0,16 s en Scinax ruber [Duellman y Pyles 1983]) y posee una frecuencia dominante entre 2184-3218 Hz (1248-1785 Hz en Scinax ruber, [Duellman y Pyles 1983]).

Scinax caprarius sp. nov. comparte la presencia de huesos verdes (Figura 5) con Scinax elaeochrous, la cual se distribuye en las tierras bajas de la región de Pacífico, pero difiere de ella por presentar el dorso tubercular (usualmente liso o con tubérculos pequeños en Scinax elaeochrous, Figura 7), la parte posterior del muslo con un patrón de manchas irregulares que en algunos casos conforman retículos (sin de patrón cromático en Scinax elaeochrous) y una frecuencia dominante entre 2184-3218 Hz. (1248-1560 Hz en Scinax elaeochrous [Duellman y Pyles 1983]).

Descripción de la serie típica (Figura 4, Tabla 1). La descripción se basa en 10 machos adultos y su variación morfométrica es presentada en la tabla 1. Machos adultos entre 28,5-31,7 mm (28,8 $\pm 1,00$; $\mathrm{n}=10$ ) de la LRC. Piel de las superficies dorsales y laterales en la región cefálica, parpados y la porción anterior granular; piel de las superficies ventrales con saco de la gula liso y vientre areolado; tubérculos cloacales ausentes.

La anchura cefálica equivale al 31,4-36,3\% de la longitud rostro cloacal, y al 87,3-97,8 \% de su longitud cefálica. Distancia interorbital equivale al 32,6-39,8 \% de la anchura cefálica. Rostro corto, redondeado en vista dorsal y redondeado con una pequeña proyección en la punta, en vista lateral. Canthus rostralis apenas perceptible y redondeado. Región loreal con una débil concavidad que se inclina hacia la parte externa del labio superior que es protuberante. Ojos protuberantes, su diámetro equivale al 28,6-33,1\% de la longitud cefálica. Membrana palpebral translúcida y su margen superior con una banda longitudinal oscura. Distancia del ojo a la narina equivale al 58,4 $72,6 \%$ de la longitud del rostro, y al 92,5-112,8 \% del diámetro del ojo. Narinas externas protuberantes, ovoides y orientadas postero-dorsalmente. Anillo timpánico casi circular, visible y su porción dorsal recubierta de un pliegue prominente, su diámetroequivaleal46,1-62,4\% deldiámetrodelojo. Dientes presentes en los arcos maxilar y mandibular. Saco vocal simple, medial, subgular, visible a los lados de la mandíbula y en vista ventral no se extiende más allá de la región pectoral; hendiduras vocales situadas diagonalmente al eje longitudinal de la boca, dispuestas a los lados de la lengua. Lengua subovoide algo granular y en su región posterior con una muesca apenas perceptible. Dientes vomerinos localizados en paralelo a las coanas, dispuestos en dos series cada una entre 7-11 dientes pedicelados (izquierda) y 7-10 dientes (derecha).

Membrana axilar ausente; miembros anteriores esbeltos, la longitud del antebrazo equivale al 17,2$19,5 \%$ de la LRC y al 56,6-65,8 \% de su longitud manual. Tubérculos ulnares ausentes. La longitud manual equivale al 27,7-32,3\% de su LRC. Dedos manuales, cortos, delgados y moderadamente expandidos; discos de los dedos elípticos, más anchos que largos; la anchura de la falange adyacente al dedo manual III equivale al 44,4$60,8 \%$ del disco del dedo III. Rebordes dérmicos presentes en los dedos manuales. Dedo manual I más corto, que el dedo II. El disco del dedo manual II sobrepasa el tubérculo subarticular medio del dedo III; el disco del dedo manual IV sobrepasa el último tubérculo subarticular dista del dedo III. Longitud relativa de los dedos manuales III $>$ IV $>$ II $>$ I. 

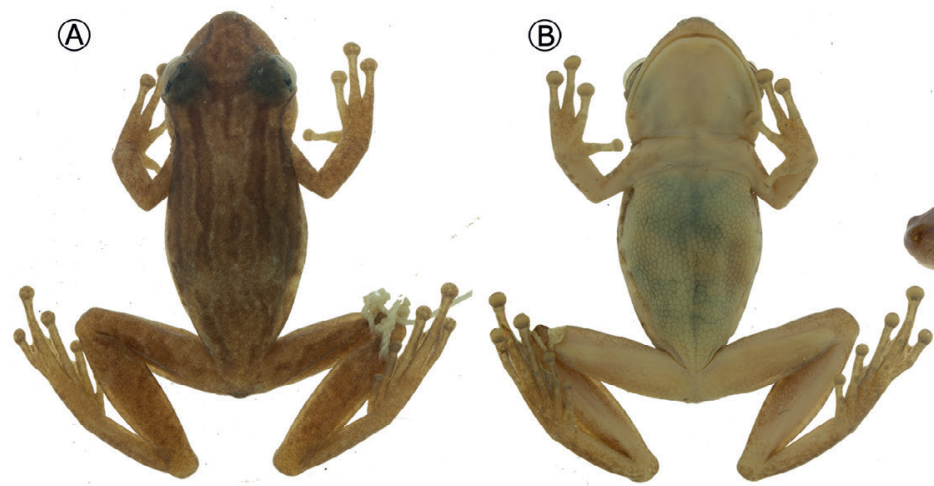

(C)

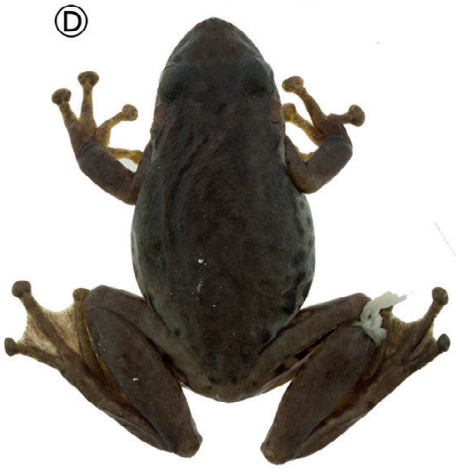

(E)

(F)

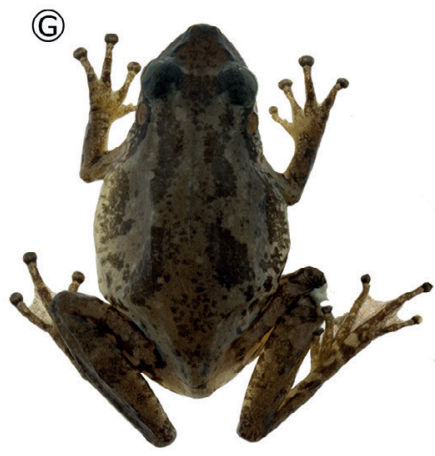

(1)

(1)
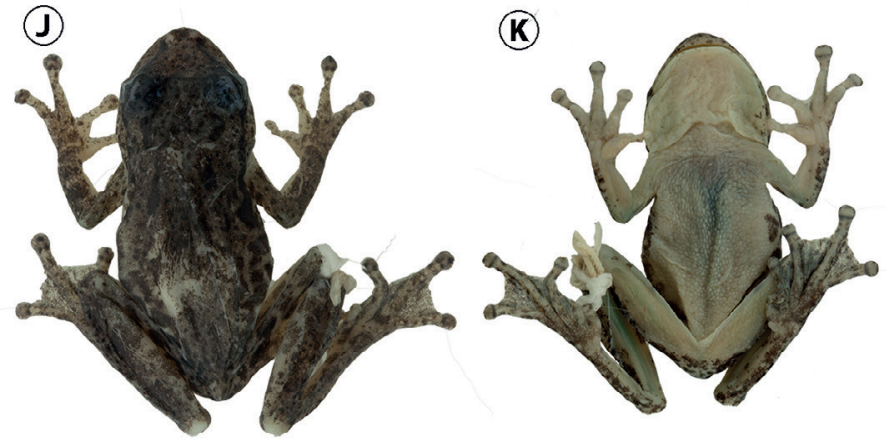

(L)
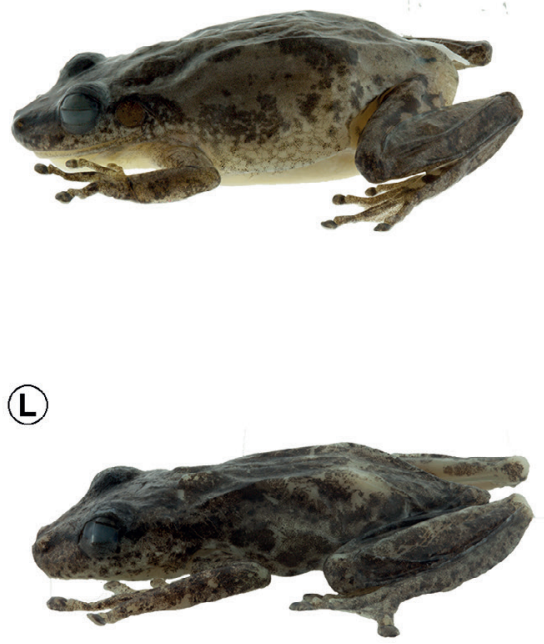

Figura 7. Especies del clado de Scinax ruber (preservados etanol 70 \%) reportados de la región transinterandina de Colombia. A-C. Scinax elaeochrous IAvH-Am-6847, departamento del Cauca, municipio de Guapi. D-F. Scinax ruber IAvH-Am-10547 departamento de Santander, municipio Sabana de Torres. G-I. Scinax $x$-signatus IAvH-Am-11444, departamento del Tolima. J-L. Scinax caprarius sp. nov. IAvH-Am-14419, departamento de Antioquia, municipio de El Carmen de Viboral. Fotos Andrés Acosta. 
Tabla 1 Variación morfométrica (en $\mathrm{mm}$ ) de Scinax caprarius sp. nov. Para definición de las variables morfométricas empleadas, véase sección de Métodos: morfología de los adultos.

\begin{tabular}{cc}
\hline Variable & Machos $(n=10)$ \\
\hline LRC & $28,8 \pm 1,00(28,5-31,7)$ \\
\hline AC & $10,1 \pm 0,50(9,5-11,0)$ \\
\hline LC & $11,1 \pm 0,30(10,6-11,6)$ \\
\hline DIN & $2,3 \pm 0,23(2,0-2,7)$ \\
\hline DIO & $3,5 \pm 0,22(3,1-3,8)$ \\
\hline DO & $3,4 \pm 0,17(3,2-3,7)$ \\
\hline DON & $3,4 \pm 0,25(3,0-3,7)$ \\
\hline DT & $1,8 \pm 0,15(1,6-2,1)$ \\
\hline AP & $2,7 \pm 0,21(2,3-3,0)$ \\
\hline LR & $5,2 \pm 0,32(4,7-5,9)$ \\
\hline AR & $4,5 \pm 0,52(3,8-5,4)$ \\
\hline Lt & $15,8 \pm 0,69(14,6-17,1)$ \\
\hline LF & $13,3 \pm 1,00(12,1-15,1)$ \\
\hline Lp & $12,7 \pm 0,73(11,2-13,6)$ \\
\hline Lm & $9,0 \pm 0,45(8,4-9,6)$ \\
\hline Lab & $5,5 \pm 0,26(5,1-5,8)$ \\
\hline IIIDM & $1,6 \pm 0,10(1,4-1,7)$ \\
\hline IVDP & $0,9 \pm 0,13(0,7-1,2)$ \\
\hline
\end{tabular}

Tubérculos subarticulares redondeados y cónicos, siendo el tubérculo subarticular del dedo manual IV el de mayor tamaño. Tubérculos supernumerarios pequeños y redondeados, apenas conspicuos; tubérculo tenar ovoide; tubérculo palmar bilobulado y algo prominente; la relación entre el tubérculo palmar y tenar es equivalente en diámetro. Membrana interdigital manual con fórmula variable, $\mathbf{I}-\mathbf{I I}\left(2-2^{-}\right)-\left(3-3^{+}\right) \mathbf{I I I}\left(3^{-1 / 2}\right)-\left(2^{+}\right) \mathbf{I V}$. Almohadilla nupcial, gruesa ensanchada, no pigmentada, cubriendo la región medial del tubérculo metacarpal I (Figura 8).

Miembros posteriores esbeltos, la longitud tibial equivale al $48,8-57,3 \%$ de la LRC y la longitud pedial equivale al 37,4-45,9 \% de la LRC. Membrana interdigital pedial opaca, ligeramente punteada y con manchas irregulares basales entre los dedos IIIII-IV; rebordes dérmicos evidentes en la margen externa de los dedos pediales. Longitud relativa de los dedos pediales: IV $>$ V $>$ III $>$ II $>$ I; disco pedial III alcanza el tubérculo subarticular medio del dedo IV; el disco del dedo V entra en contacto con el penúltimo tubérculo subarticular del dedo IV pedial. Membrana interdigital pedial con fórmula

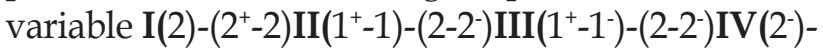
$\left(1^{-}\right) \mathrm{V}$, discos de los dedos pediales moderadamente expandidos, la anchura de la falange adyacente al dedo pedial IV, equivale al 53,0-77,2 \% en el disco del dedo IV. Tubérculos subarticulares pediales 


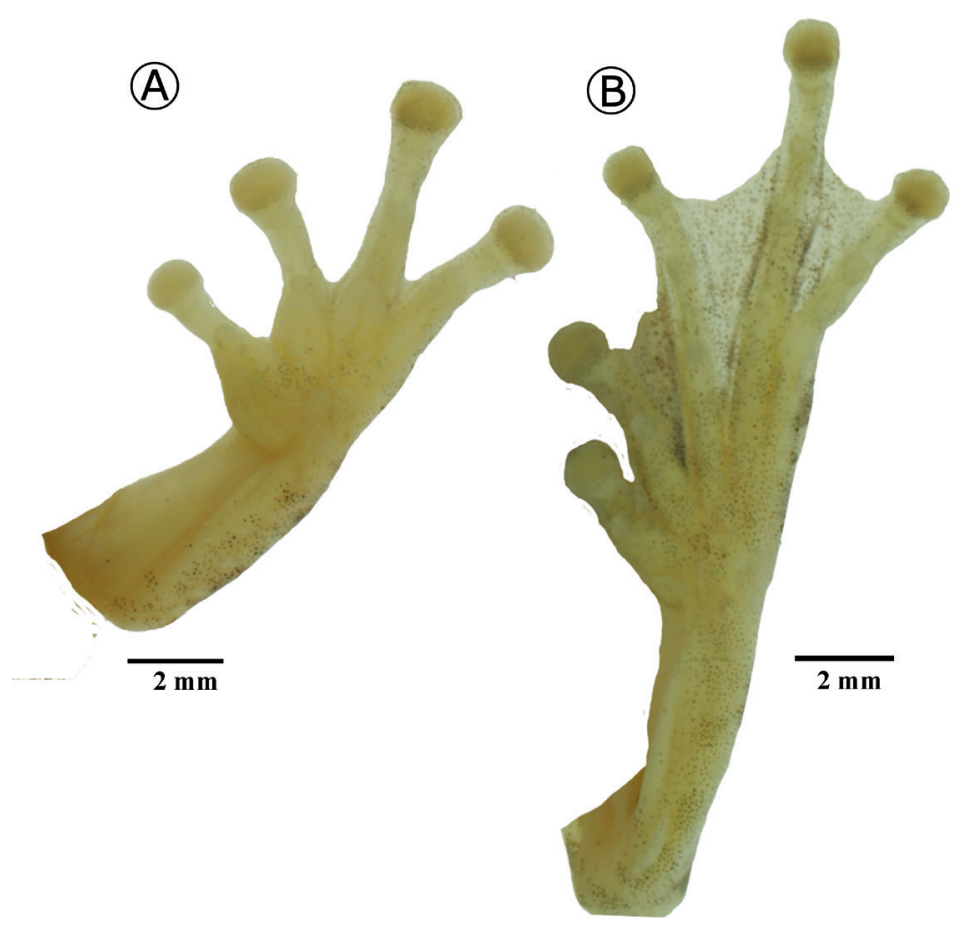

Figura 8. Scinax caprarius sp. nov. Holotipo IAvH-Am-11363. A. Palmeadura manual. B. Palmeadura pedial, Escala $=5$ mm. Fotos: Andrés Acosta.
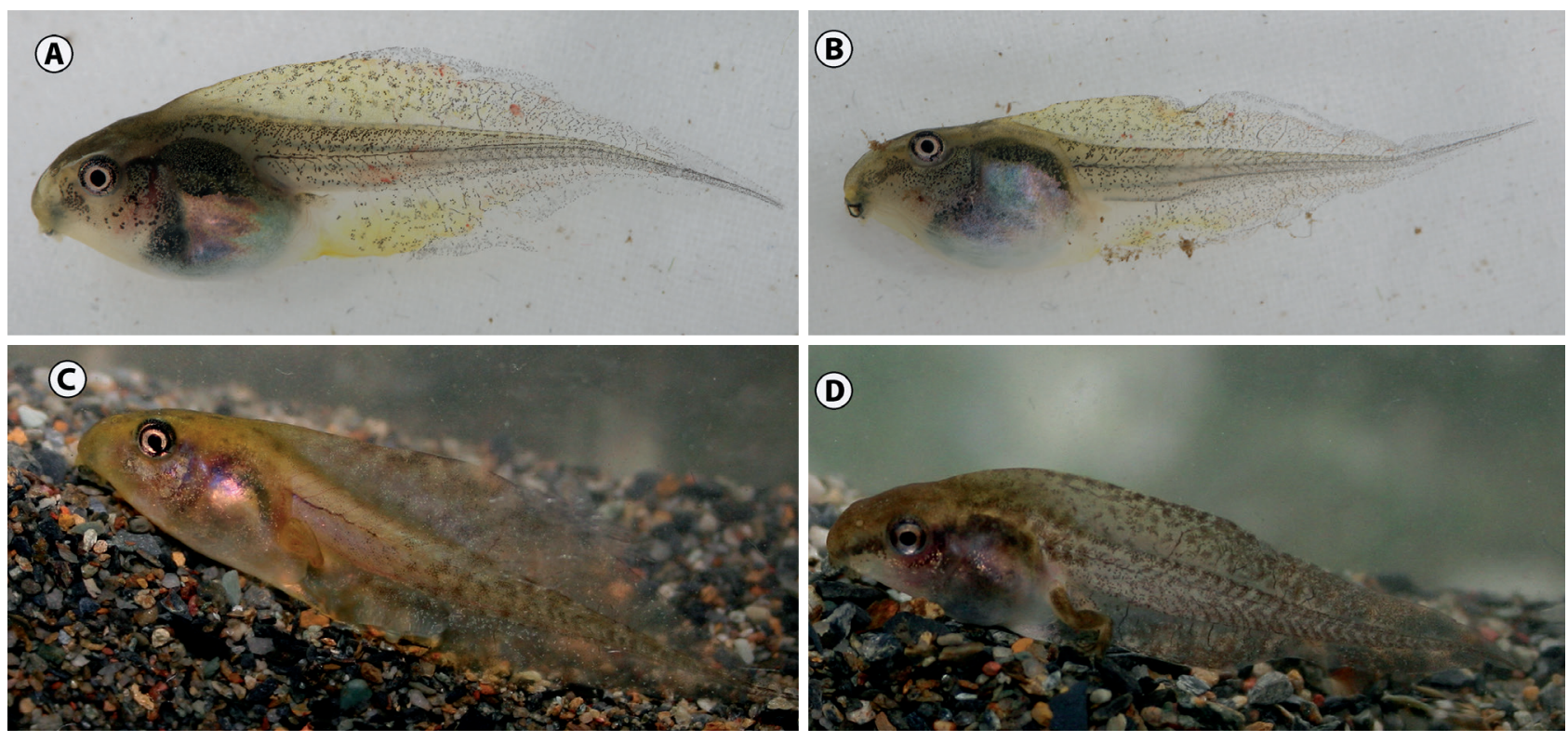

Figura 9. Renacuajos de Scinax caprarius sp. nov. in vivo. A. Vista lateral (en lote IAvH-Am -14566, estadio sensu 34 Gosner [1960], departamento de Antioquia. B. Vista ventrolateral IAvH-Am 14566, estadio 34 de sensu Gosner [1960], departamento de Antioquia. C. Vista lateral (en lote ARA 4487, estadio 39 sensu Gosner [1960]), departamento de Caldas. D. Vista Lateral (en lote ARA 4487, estadio 40 de Gosner), departamento de Caldas. Fotos: Andrés Acosta. 
1-1-2-3-1. Tubérculos plantares supernumerarios circulares, muy reducidos, apenas perceptibles; tubérculo metatarsiano interno ovoide; tubérculo metatarsiano externo subcircular, más pequeño que el tubérculo metatarsiano interno; en algunos ejemplares apenas perceptible. El diámetro del tubérculo metatarsiano externo equivale al 32,7-61,3 \% del tubérculo metatarsiano interno; tubérculo tarsiano externo ausente; tubérculo tarsiano interno basal, prominente y elongado a manera de pliegue.

Dimensiones del holotipo (en $\mathrm{mm}$ ). Longitud rostro-cloacal 29,6; longitud manual 4,5; longitud tibial 15,8; longitud pedial 13,6; anchura cefálica 10,3; longitud cefálica 11,0; diámetro del ojo 3,4; distancia ojo-narina 3,4 ; distancia internarinas 2,6; longitud rostral 5,9; distancia interorbital 3,5; diámetro del tímpano 2,1 y longitud del antebrazo 5,6.

Color en vivo (Figuras 4 y 5): color de fondo de las superficies dorsales de café claro a café rojizo (Figura 4), con manchas irregulares más oscuras, algunas fusionadas entre sí; flanco cefálico con el mismo patrón del dorso, con una banda irregular (algunas veces discontinua) café oscuro que se extiende a lo largo de la región loreal, desde el extremo del rostro hasta la región posterior del tímpano. La porción anterior de la región supralabial del mismo color del dorso, y a la altura de la margen infraorbital se torna más clara con pequeñas manchas café conformando una banda que se extiende hasta la comisura bucal. Anillo timpánico dorado. Iris café claro con pequeñas reticulaciones café oscuro hacia la región periorbital y una mancha café oscuro en la porción medial que forman con la pupila una banda media horizontal en el ojo; membrana palpebral translúcida. Flanco troncal más claro que el color de las superficies dorsales con manchas irregulares de color café, más notables. Superficies ocultas (axila, ingle y superficie posterior del muslo) de color amarillo pálido a amarillo brillante con reticulaciones café oscuro; superficies ventra-les de la región gular amarilla pálido a brillante, pecho y vientre de color crema inma- culado (Figura 5); superficie dorsal de los discos de los dedos amarillo pálido; membrana interdigital pedial café claro con algunas punteaduras y manchas irregulares café más oscuro.

Color en preservación (etanol 70 \%) (Figura 3). La coloración de las superficies dorsales se torna café con reticulaciones de color crema; las superficies ventrales y superficies ocultas se tornan de color crema; las manchas oscuras se tornan café; la membrana interdigital pedial opaca con algunas punteaduras y manchas irregulares de color café.

Descripción de las larvas. Los renacuajos (Tabla 2) en vista dorsal y lateral son de cuerpo ovoide, deprimido hacia la región cefálica. Rostro redondeado en vista dorsal y lateral; elementos condrocraneales visibles (Figura 10A). En algunos especímenes los neuromastos del sistema de línea lateral son evidentes (bajo el estereoscopio), siendo las líneas infraorbital y el medial corporal (sensu Lannoo, 1987) apenas visibles. Distancia internarinas 2,0-2,8 mm $(2,3 \pm 0,2), 74-97 \%$ de la distancia interorbital; distancia interorbital 2,0-3,6 $\mathrm{mm}(2,6 \pm 0,4), 41-61 \%$ de la anchura del cuerpo. Ojos en posición lateral 1,0-1,7 mm $(1,3 \pm 0,1)$, su diámetro equivale al $34-57 \%$ de la distancia interorbital. La masa intestinal visible (Figura 10D) orientada longitudinalmente (estado 0 sensu Faivovich, 2002). Espiráculo siniestro, corto, simple y cónico, orientado longitudinalmente, situado por debajo de la línea media horizontal del cuerpo y ligeramente posterior a la línea media vertical del cuerpo, distancia desde el rostro a la abertura del espiráculo 4,0-11,2 mm $(5,8 \pm 1,5)$ equivalente al 49-103 \% de la longitud del cuerpo. Tubo cloacal corto, medial, distalmente libre, orientado posterolateralmente y unido al lado izquierdo de la aleta ventral, su longitud equivale al 5-28 \% de la longitud del cuerpo; Peritoneo visceral translúcido con intestinos visibles en la región central (Figura 10). La longitud caudal $7,8-15,4 \mathrm{~mm}(10,9 \pm 2,3)$ equivale al $47-65 \%$ de su longitud total. Musculatura caudal inserta hasta la porción media del cuerpo (en vista dorsal) con miotomos visibles que se reducen gradualmente hasta el extremo caudal (Figura 9 y Figura 10C- 
D); la altura de la musculatura caudal entre 2,0$3,7 \mathrm{~mm}(2,7 \pm 0,4)$ equivale al $38-66 \%$ de la altura del cuerpo. La aleta dorsal se origina en porción media del cuerpo, siendo de mayor altura hacia la región medial caudal y de forma apical en su extremo más distal; la altura máxima de la cola entre 3,8-7,6 mm $(5,9 \pm 0,8)$, su altura equivale al $82-117 \%$ de la altura del cuerpo.

Disco oral triangular no emarginado, orientado anteroventralmente; su anchura es de 1,0-2,8 mm $(2,3 \pm 0,5)$, y equivale al $18-52 \%$ de la anchura del cuerpo. Papilas marginales cortas y cónicas, dispuestas en dos hileras en la región labial anterior; papilas submarginales abundantes recubriendo las superficies laterales en el labio posterior; picos córneos superior e inferior, pigmentados, redondeados y aserrados en su margen libre. Fórmula dental $2 / 3$ hilera de dientes A-1 es continua y medialmente en forma de $\mathrm{V}$ invertida (Figura 10), la hilera A-2 es interrumpida medialmente, asemejando dos hileras separadas. Todas las hileras de dientes de labio posterior completas y de longitud similar (P-1= P-2= P-3).

Tabla 2. Variación morfométrica (en $\mathrm{mm}$ ) de los renacuajos de Scinax caprarius sp. nov. Para definición de las variables morfométricas empleadas, véase sección de Métodos: Morfología de las larvas.

\begin{tabular}{|c|c|c|c|c|c|c|}
\hline Medida & $\begin{array}{c}\text { Estadio } 28 \\
(n=10)\end{array}$ & $\begin{array}{c}\text { Estadio } 29 \\
(\mathrm{n}=3)\end{array}$ & $\begin{array}{c}\text { Estadio } 30 \\
\quad(n=3)\end{array}$ & $\begin{array}{l}\text { Estadio } 32 \\
\quad(n=2)\end{array}$ & $\begin{array}{l}\text { Estadio } 33 \\
\quad(n=1)\end{array}$ & $\begin{array}{c}\text { Estadio } 34 \\
\quad(n=2)\end{array}$ \\
\hline LT & $\begin{array}{c}18,8 \pm 2,18 \\
(14,2-20,5)\end{array}$ & $\begin{array}{c}18,8 \pm 4,49 \\
(14,5-23,5) \\
\end{array}$ & $\begin{array}{c}18,8 \pm 0,48 \\
(18,3-19,3) \\
\end{array}$ & $\begin{array}{c}23,3 \pm 2,3 \\
(21,7-25,5) \\
\end{array}$ & 18,8 & $\begin{array}{c}23,5 \pm 3,8 \\
(20,8-26,3)\end{array}$ \\
\hline LC & $\begin{array}{l}8,0 \pm 0,80 \\
(6,3-9,0)\end{array}$ & $\begin{array}{l}8,1 \pm 1,55 \\
(6,7-9,8)\end{array}$ & $\begin{array}{l}8,9 \pm 0,59 \\
(8,4-9,5)\end{array}$ & $\begin{array}{l}9,4 \pm 0,48 \\
(9,1-9,7)\end{array}$ & 8,2 & $\begin{array}{c}10,5 \pm 0,61 \\
(10,7-10,9)\end{array}$ \\
\hline LCD & $\begin{array}{l}10,2 \pm 1,50 \\
(7,9-12,1)\end{array}$ & $\begin{array}{l}10,6 \pm 4,1 \\
(7,8-15,4)\end{array}$ & $\begin{array}{l}9,9 \pm 0,11 \\
(9,7-9,9)\end{array}$ & $\begin{array}{c}13,9 \pm 1,8 \\
(12,6-15,2)\end{array}$ & 10,5 & $\begin{array}{c}10,0 \pm 3,75 \\
(10,7-15,4)\end{array}$ \\
\hline AlCo & $\begin{array}{l}5,8 \pm 0,77 \\
(4,2-6,7)\end{array}$ & $\begin{array}{l}5,5 \pm 1,50 \\
(3,8-6,6)\end{array}$ & $\begin{array}{l}5,9 \pm 0,41 \\
(5,5-6,4)\end{array}$ & $\begin{array}{l}6,1 \pm 0,39 \\
(5,8-6,4)\end{array}$ & 5,98 & $\begin{array}{l}7,0 \pm 0,80 \\
(6,4-7,6)\end{array}$ \\
\hline AnCo & $\begin{array}{l}5,2 \pm 0,58 \\
(4,3-5,9)\end{array}$ & $\begin{array}{l}5,0 \pm 0,92 \\
(4,5-6,1)\end{array}$ & $\begin{array}{l}5,4 \pm 0,37 \\
(5,1-5,8)\end{array}$ & $\begin{array}{l}5,8 \pm 0,5 \\
(5,5-6,2)\end{array}$ & 5,74 & $\begin{array}{l}6,2 \pm 0,02 \\
(6,2-6,3)\end{array}$ \\
\hline ACf & $\begin{array}{c}4,5 \pm 0,3 \\
(3,9-5,1)\end{array}$ & $\begin{array}{l}4,5 \pm 0,82 \\
(3,6-5,3)\end{array}$ & $\begin{array}{l}5,1 \pm 0,05 \\
(5,1-5,2)\end{array}$ & $\begin{array}{l}5,6 \pm 0,11 \\
(5,6-5,7)\end{array}$ & 5,02 & $\begin{array}{l}5,8 \pm 0,17 \\
(5,7-6,0)\end{array}$ \\
\hline Mcd & $\begin{array}{l}2,7 \pm 0,3 \\
(2,3-3,3) \\
\end{array}$ & $\begin{array}{l}2,4 \pm 0,40 \\
(2,0-2,8) \\
\end{array}$ & $\begin{array}{l}2,3 \pm 0,21 \\
(2,1-2,5) \\
\end{array}$ & $\begin{array}{l}2,9 \pm 0,11 \\
(2,9-3,0)\end{array}$ & 3,51 & $\begin{array}{c}3,48 \pm 0,35 \\
(3,2-3,7)\end{array}$ \\
\hline Amcd & $\begin{array}{l}1,6 \pm 0,25 \\
(1,0-1,9)\end{array}$ & $\begin{array}{l}1,7 \pm 0,25 \\
(1,5-2,0)\end{array}$ & $\begin{array}{l}1,7 \pm 0,26 \\
(1,5-2,0)\end{array}$ & $\begin{array}{l}2,1 \pm 0,21 \\
(1,9-2,2)\end{array}$ & 1,8 & $\begin{array}{l}2,4 \pm 0,20 \\
(2,3-2,5)\end{array}$ \\
\hline MxAcd & $\begin{array}{l}5,8 \pm 0,96 \\
(4,3-6,9)\end{array}$ & $\begin{array}{l}5,4 \pm 1,31 \\
(3,9-6,3)\end{array}$ & $\begin{array}{c}6,7 \pm 0,9 \\
(5,9-7,7)\end{array}$ & $\begin{array}{l}6,6 \pm 1,31 \\
(5,7-7,5)\end{array}$ & 5,1 & $\begin{array}{c}7,36 \pm 0,96 \\
(6,6-8,0)\end{array}$ \\
\hline $\mathrm{O}-\mathrm{N}$ & $\begin{array}{l}0,7 \pm 0,09 \\
(0,5-0,9)\end{array}$ & $\begin{array}{l}1,0 \pm 0,11 \\
(0,9-1,2)\end{array}$ & $\begin{array}{l}0,9 \pm 0,14 \\
(0,8-1,0)\end{array}$ & $\begin{array}{l}1,2 \pm 0,12 \\
(1,1-1,3)\end{array}$ & 0,9 & $\begin{array}{c}1,1 \pm 0,04 \\
(1,13-1,19)\end{array}$ \\
\hline DR-N & $\begin{array}{l}1,5 \pm 0,43 \\
(0,8-2,3) \\
\end{array}$ & $\begin{array}{l}1,4 \pm 0,72 \\
(0,6-2,6)\end{array}$ & $\begin{array}{l}1,4 \pm 0,60 \\
(1,0-2,1) \\
\end{array}$ & $\begin{array}{l}1,9 \pm 0,16 \\
(1,8-2,0)\end{array}$ & 1,81 & $\begin{array}{l}2,0 \pm 0,32 \\
(1,7-2,2) \\
\end{array}$ \\
\hline DIN & $\begin{array}{l}2,1 \pm 0,12 \\
(2,0-2,3)\end{array}$ & $\begin{array}{l}2,4 \pm 0,16 \\
(2,2-2,6)\end{array}$ & $\begin{array}{l}2,3 \pm 0,30 \\
(2,0-2,6)\end{array}$ & $\begin{array}{l}2,7 \pm 0,14 \\
(2,6-2,8)\end{array}$ & 2,4 & $\begin{array}{l}2,5 \pm 0,09 \\
(2,4-2,6)\end{array}$ \\
\hline DIO & $\begin{array}{l}2,4 \pm 0,21 \\
(2,1-2,8)\end{array}$ & $\begin{array}{l}2,4 \pm 0,41 \\
(2,0-2,8)\end{array}$ & $\begin{array}{l}2,7 \pm 0,37 \\
(2,3-3,1)\end{array}$ & $\begin{array}{l}3,5 \pm 0,18 \\
(3,4-3,6)\end{array}$ & 2,6 & $\begin{array}{l}3,3 \pm 0,24 \\
(3,1-3,5)\end{array}$ \\
\hline DO & $\begin{array}{l}1,2 \pm 0,10 \\
(1,0-1,4)\end{array}$ & $\begin{array}{l}1,2 \pm 0,24 \\
(1,0-1,5)\end{array}$ & $\begin{array}{l}1,3 \pm 0,09 \\
(1,2-1,4)\end{array}$ & $\begin{array}{l}1,3 \pm 0,05 \\
(1,2-1,3)\end{array}$ & 1,3 & $\begin{array}{l}1,5 \pm 0,18 \\
(1,4-1,7)\end{array}$ \\
\hline
\end{tabular}


(A)

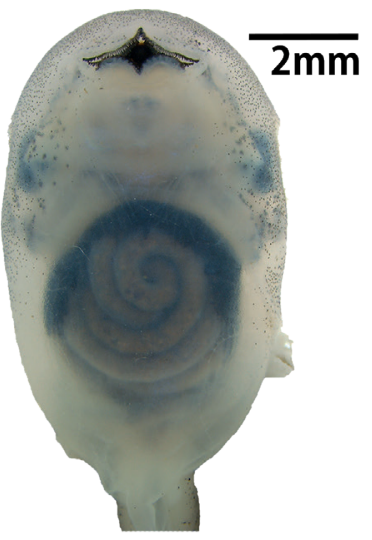

(C)

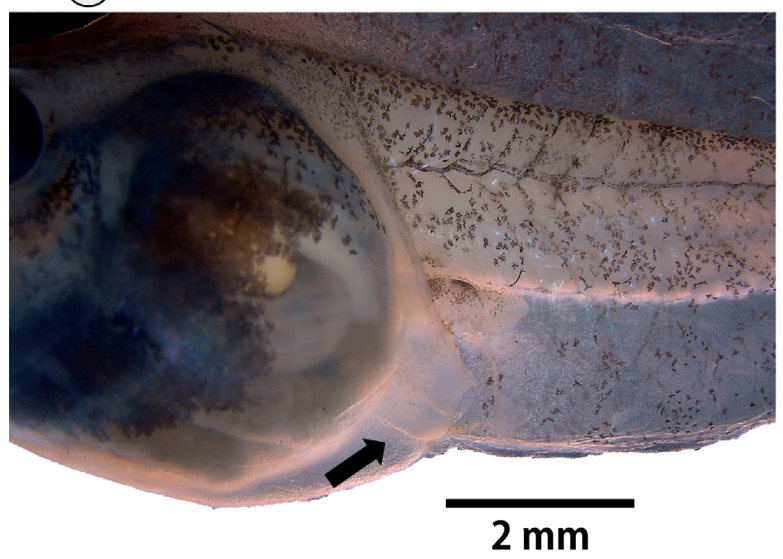

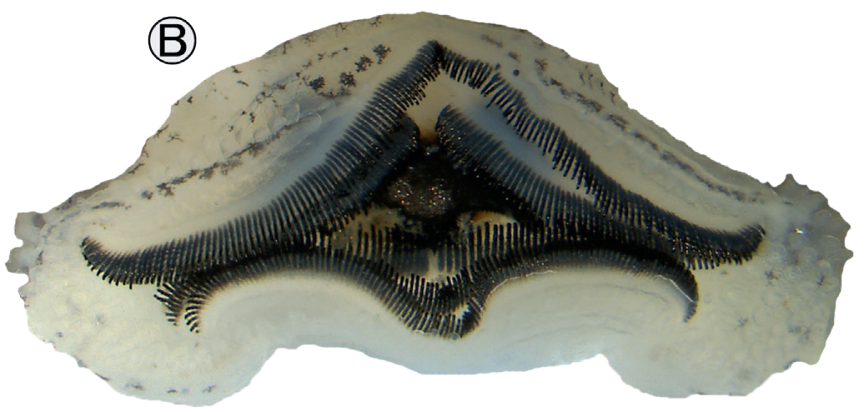

$0.2 \mathrm{~mm}$

(D)

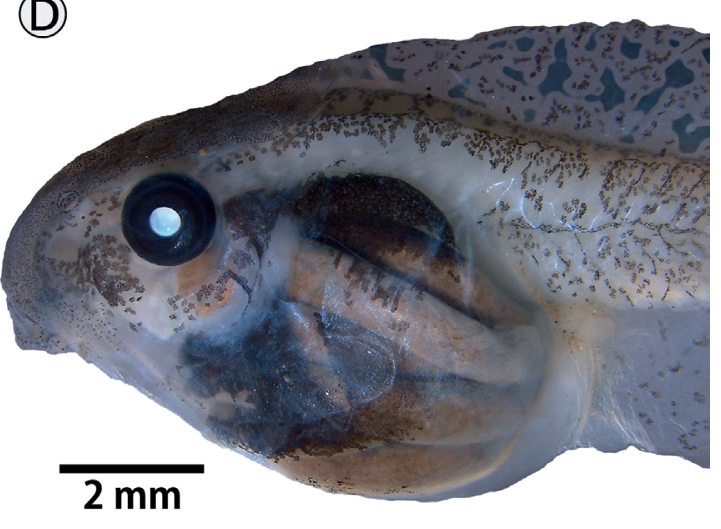

Figura 10. Renacuajos preservados de Scinax caprarius sp. nov. (lote IAvH-Am-14566). A. vista ventral de la región corporal en estadio 34; se observa el peritoneo intestinal translúcido. B. detalle del disco oral, en estadio 32. C. vista lateral de la región abdominal en estadio 32, la flecha indica el tubo proctodeal. D. vista lateral en estadio 30, exhibiendo la posición de la masa intestinal. Fotos: Andrés Acosta.

Color en vivo de los renacuajos (Figura 9). Superficies dorsales de la región cefálica café oscuro. Las superficies laterales hacia la región preorbital, de color crema con pigmento café que forman manchas irregulares; las regiones anteriores y dorsolateral del abdomen de color café y la región ventrolateral de color crema. Las superficies ventrales de color crema, con el peritoneo abdominal translúcido que deja ver el intestino. La musculatura caudal es crema con punteaduras de color café, siendo más denso hacia la región dorsolateral; las aletas dorsal y ventral translúcidas, con moteaduras café y amarillo pálido en las porciones anterior $\mathrm{y}$ medial, mientras que la porción posterior y la región apical son translúcidas con punteaduras café apenas visible. En el estadio 40 de Gosner el pigmento de la región caudal se torna en motas café con algunas reticulaciones y en la región loreal aparece una banda longitudinal café.

Color en preservación de los renacuajos (formol $10 \%$ ). La coloración dorsal se torna café al igual que los pigmentos distribuidos a lo largo del cuerpo, mientras que en la región caudal se torna crema. En la región abdominal, las aletas dorsal y ventral se tornan translúcidas. 
Vocalizaciones. El llamado de Scinax caprarius sp. nov. incluye entre $4-7$ notas $(5,8 \pm 0,90 ; n=25)$, con una duración que varía entre 0,21-0,47 s $(0,37$ $\pm 0,08 ; n=25)$ y la duración de los intervalos entre llamados es entre 2,3-33,0 $(17,9 \pm 8,73 ; n=23)$ (Figura 11). La duración de una nota individual varía entre $0,04-0,08 \mathrm{~s}(0,06 \pm 0,009 ; n=30)$ y la duración de los intervalos entre notas es entre $0,018-0,027$ $(0,022 \pm 0,002 ; n=31)$. La segunda y tercera notas incrementan ligeramente su amplitud con respecto a las restantes (Figura 12). El número de ondas de sonido (oscilaciones) contenidas en cada nota varía entre $42-63(51,3 \pm 5,54 ; n=37)$. La estructura espectral de cada nota (Figura 12) consiste entre 3 a 5 armónicos, y con una frecuencia dominante entre $2184-3218 \mathrm{~Hz}(2728 \pm 292 ; n=65)$.

Distribución. Scinax caprarius sp. nov. es conocida de los bosques subandinos en el valle medio del Magdalena, abarcando los departamentos de Antioquia, Caldas y Cundinamarca, sobre elevaciones de 935-1065 m s.n.m (Figura 13). Esta especie se encuentra reportada en áreas asociadas con gradientes de alta humedad en el valle del río Magdalena entre 2800-5000 $\mathrm{mm}$ anuales de pluviosidad (Figura 2).

Historia natural. Scinax caprarius sp. nov. es una especie nocturna, conspicua únicamente durante la estación lluviosa, y asociada a ambientes acuáticos lénticos, que incluyen pequeñas lagunas naturales y reservorios de agua artificiales; su microhábitat preferencial corresponde a la vegetación arbustiva que circunda estos ambientes. Es una especie resiliente a los ambientes intervenidos y se localiza en agrosistemas; sin embargo, su distribución geográfica está asociada con ambientes montanos de bosque subandino conservados, con alta humedad relativa, en las estribaciones del valle medio del Magdalena. En esta región el clima es tetraestacional (con 2 picos de lluvias); uno de menor intensidad entre abril y mayo con una precipitación que alcanza los 4000 $\mathrm{mm}$ anuales y un segundo pico entre septiembrediciembre con $5000 \mathrm{~mm}$.
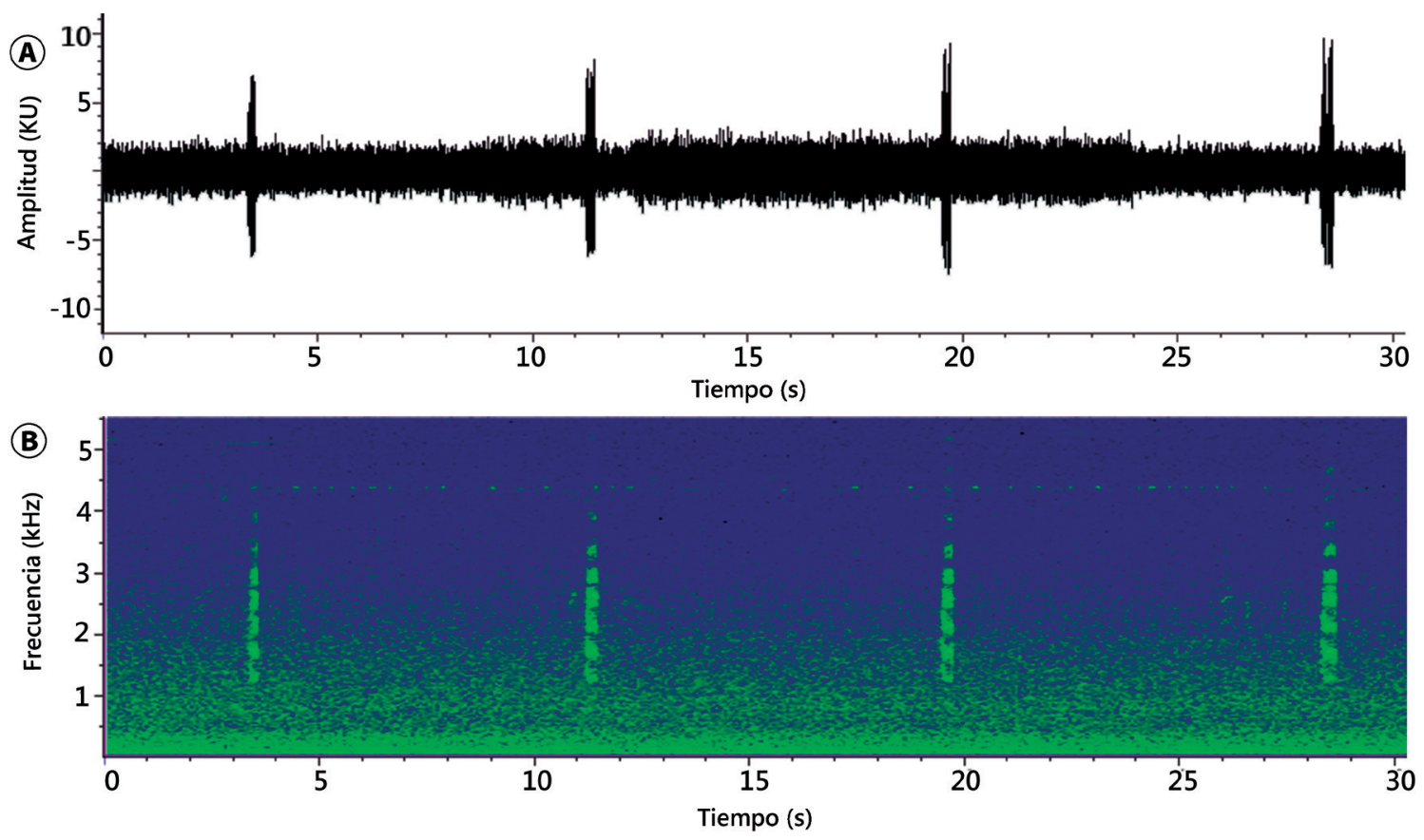

Figura 11. Serie de cuatro llamados de Scinax caprarius sp. nov. Ejemplar IAvH-Am-14421 (BSA-15985), (Figura 5), http://colecciones.humboldt.org.co/rec/sonidos/BSA-15985/. Grabación del 30 de noviembre de 2016 a las 19:53 horas, $24{ }^{\circ} \mathrm{C}$ y una humedad relativa de 68 \%; El Porvenir, municipio de El Carmen de Viboral, departamento de Antioquia. A. oscilograma. B. espectrograma. 

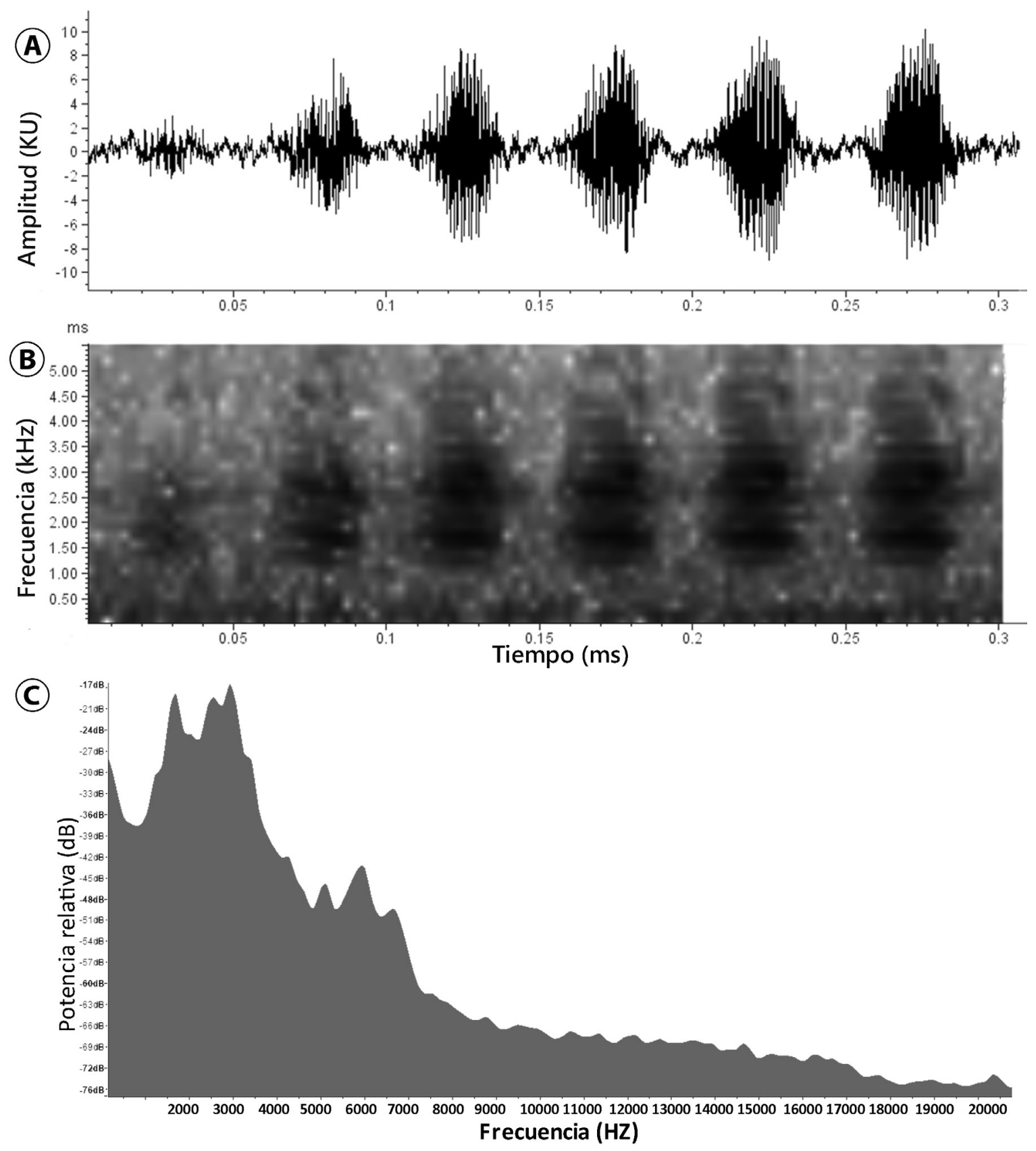

Figura 12. Detalle de un llamado de Scinax caprarius sp. nov. en el que se observan cinco notas. A. Oscilograma. B. Espectrograma. C. Espectro de poder. Ejemplar IAvH-Am-14421 (BSA15985), http:/ / colecciones.humboldt.org.co /rec/sonidos/BSA-15985/, (Figura 5). Grabación del 30 de noviembre de 2016 a las 19:53 horas, $24{ }^{\circ} \mathrm{C}$ y una humedad relativa de 68 \%; localidad El Porvenir, municipio de El Carmen de Viboral, departamento de Antioquia. 

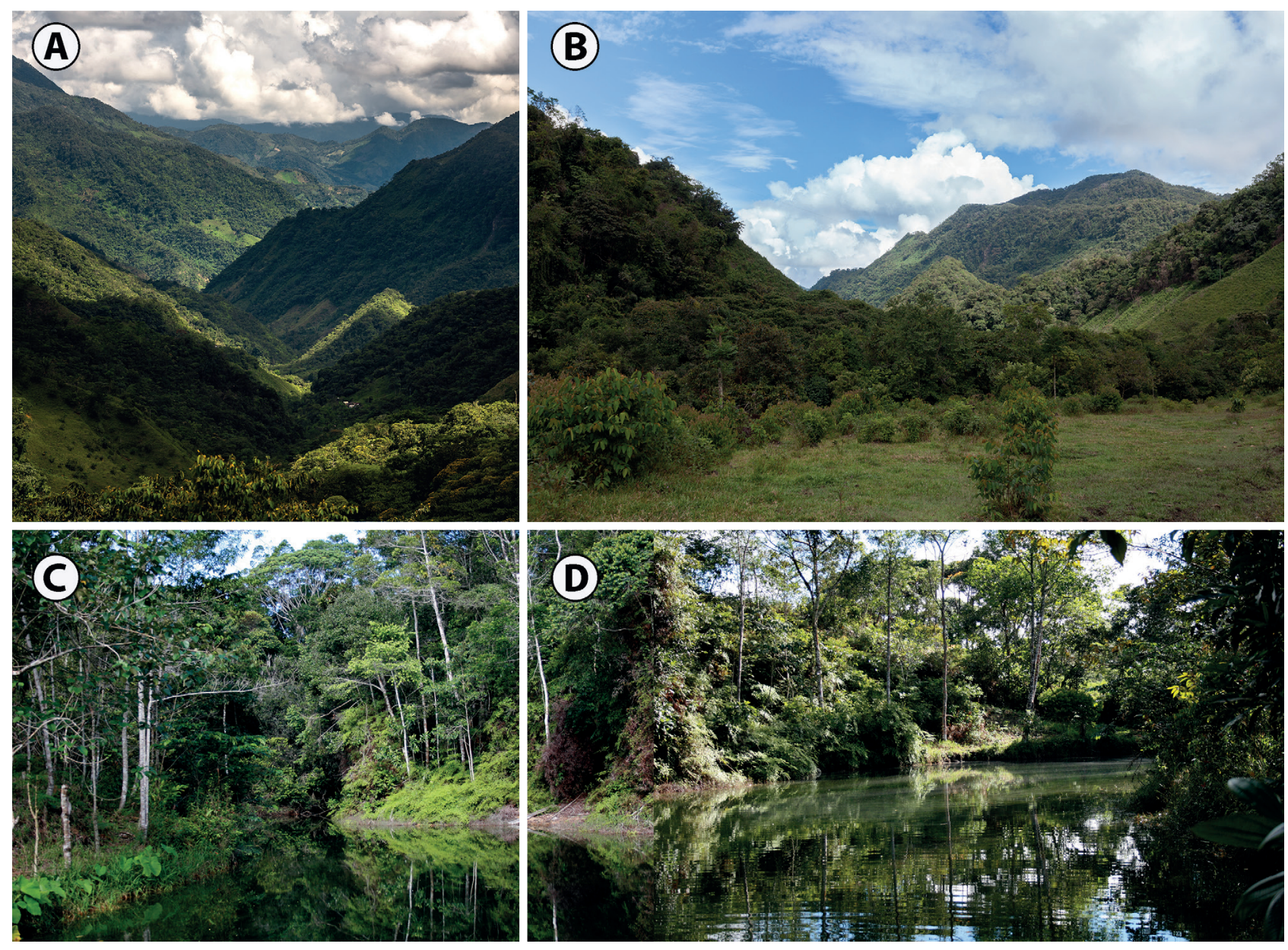

Figura 13. Panorámica general de los bosques subandinos donde habita Scinax caprarius sp. nov. A. Estribaciones de la cordillera Central, El Porvenir, municipio de El Carmen de Viboral, departamento de Antioquia. Foto: Andrés Romero ("Chino”). B. Hábitat en áreas abiertas, El Porvenir, municipio de El Carmen de Viboral, departamento de Antioquia. Foto: Felipe Villegas. C-D. Lagunas en la vereda Bellavista, del municipio de La Victoria en el departamento de Caldas. Fotos: Andrés Acosta.

Los machos de Scinax caprarius sp. nov. vocalizan ocultos entre 0,1-0,5 metros de altura del suelo, en la vegetación arbustiva que circunda estanques y lagunas. Los renacuajos son de tipo exotrófico, léntico y nectónico (clase ecomorfológica II, A, 2 sensu McDiarmid y Altig, [1999]) siendo registrados en pequeños grupos en las zonas perimetrales (entre 1-2 metros de distancia de la orilla) de lagunas o estanques pequeños que varían entre 2-10 metros de diámetro y de fondo fangoso con vegetación emergente. Estos cuerpos de agua se asocian a las áreas abiertas cercanas a bosques naturales, y tienen profundidades que varían entre $0,5-1,5 \mathrm{~m}$.
Grado de amenaza. La evaluación de las cuatro poblaciones estudiadas abarca una distribución de $318 \mathrm{~km}^{2}$, que, sumado al estado de conservación de sus hábitats y las abundancias relativas halladas, sugiere categorización a Scinax caprarius sp. nov. como de Preocupación Menor (LC, por sus siglas en inglés en la clasificación de la UICN [2001]). Esto es soportado por que las poblaciones detectadas de esta especie son estables, con densidades altas (a pesar de su fácil detección, aun cuando la obtención de especímenes es compleja), no se evidencian reducciones en las poblaciones estudiadas y sus hábitats están asociados a ambientes antropizados con altos grados de 
fragmentación. Su distribución potencial puede hacerse extensiva a otras localidades más al norte del valle medio del río Magdalena.

\section{Discusión}

Las líneas de evidencia que apoyan la delimitación de esta nueva especie, incluyen algunos rasgos morfológicos (en adultos y larvas) y bioacústicos, que a nivel supraespecífico han sido empleadas en aproximaciones previas y recientes del género (Araujo-Vieira et al., 2015, 2016; Brusquettti et al., 2014; Conte et al., 2016; Faivovich et al., 2005; Juncá et al., 2015; Lourenço et al., 2013, 2016; Sturaro y Peloso, 2014). Por otra parte, Suárez y Lynch (2011) indican que uno de los rasgos larvales para la distinción de Scinax $x$-signatus frente a $S$. ruber es la relación del sitio de inserción (inicio) de la aleta dorsal con el cuerpo, la cual se inicia a la altura del borde posterior de los ojos en Scinax $x$-signatus, mientras que en $S$. ruber se inicia en la mitad del cuerpo; este último rasgo es compartido con $S$. caprarius sp. nov.

En lo que concierne a las especies colombianas de clado Scinax ruber no asignadas a un grupo de especies en particular (sensu Faivovich, 2002) y que presentan huesos verdes como la aquí descrita, solo una especie, Scinax elaeochrous, presenta distribuciones en la región transinterandina (región del Pacífico de Colombia), mientras que las restantes especies con esta condición se distribuyen a la región amazónica. La utilidad de este rasgo en sus relaciones filogenéticas no ha sido evaluada, pero en el contexto taxonómico permite una clara separación de las especies.

Los parámetros acústicos son útiles para la valoración cuantitativa de algunas variables y permiten establecer claras separaciones taxonómicas, como se evidencia entre lo registrado para los cantos de $S$. caprarius sp. nov. y lo publicado por Duellman y Pyles (1983) para S. elaeochrous y $S$. ruber. De la misma manera, la exploración a priori de las vocalizaciones de varias especies colombianas del género orienta a nivel interespecífico diferencias a nivel de sus variables espectrales y temporales. Este sería el caso de la duración de las vocalizaciones, así como la amplitud y frecuencia, que permiten sumar evidencia adicional para establecer criterios en la resolución taxonómica (Figura 14).

Durante la descripción de esta especie, la evaluación de varios ejemplares adultos identificados en la colección de referencia bajo el nombre Scinax ruber ( $\mathrm{n}=243$ ) evidencia la existencia de una amplia variación policromática y morfológica dentro de este taxón putativo. Este aspecto sugiere dos alternativas: que haya errores de identificación (ejemplares confundidos en algunos casos con Scinax $x$-signatus) o la existencia de un complejo de especies que requiere someterse a diversas líneas de evidencia (p. ej. morfología de los estados adultos y larvales, bioacústica y datos moleculares) siendo este último aspecto, previamente evidenciado en las poblaciones del nororiente de Suramérica (Fouquet et al., 2007).

Finalmente, al evaluar la distribución geográfica de Scinax caprarius sp. nov. en el valle medio del río Magdalena, es notable resaltar que esta área geográfica contiene ambientes heterogéneos que involucran franjas longitudinales de bosques subandinos, selvas húmedas tropicales, hasta bosque seco tropical, que albergan un limitado número de especies de Scinax. Entre las tres especies reportadas en esta región, dos ( $S$. ruber y $S$. $x$-signatus) pueden ser consideradas generalistas en función de que sus distribuciones abarcan diversos ambientes desde bosques secos y sistemas de humedales, hasta reservorios de agua presentes en localidades con intervención antropogénica y baja pluviosidad (1000-2800 $\mathrm{mm}$ anuales). En contraste, S. caprarius sp. nov. ocupa aquellas franjas más húmedas (2800-5000 $\mathrm{mm}$ anuales), que involucran áreas boscosas con algún grado de intervención, siendo este un patrón reconocido para varias especies de anfibios considerados endémicos de esta franja del valle del Magdalena, como son Bolitoglossa lozanoi, Pristimantis viejas, Rheobates palmatus, Rulyrana susatamai y Sachatamia punctulata, entre otras especies de anfibios. 

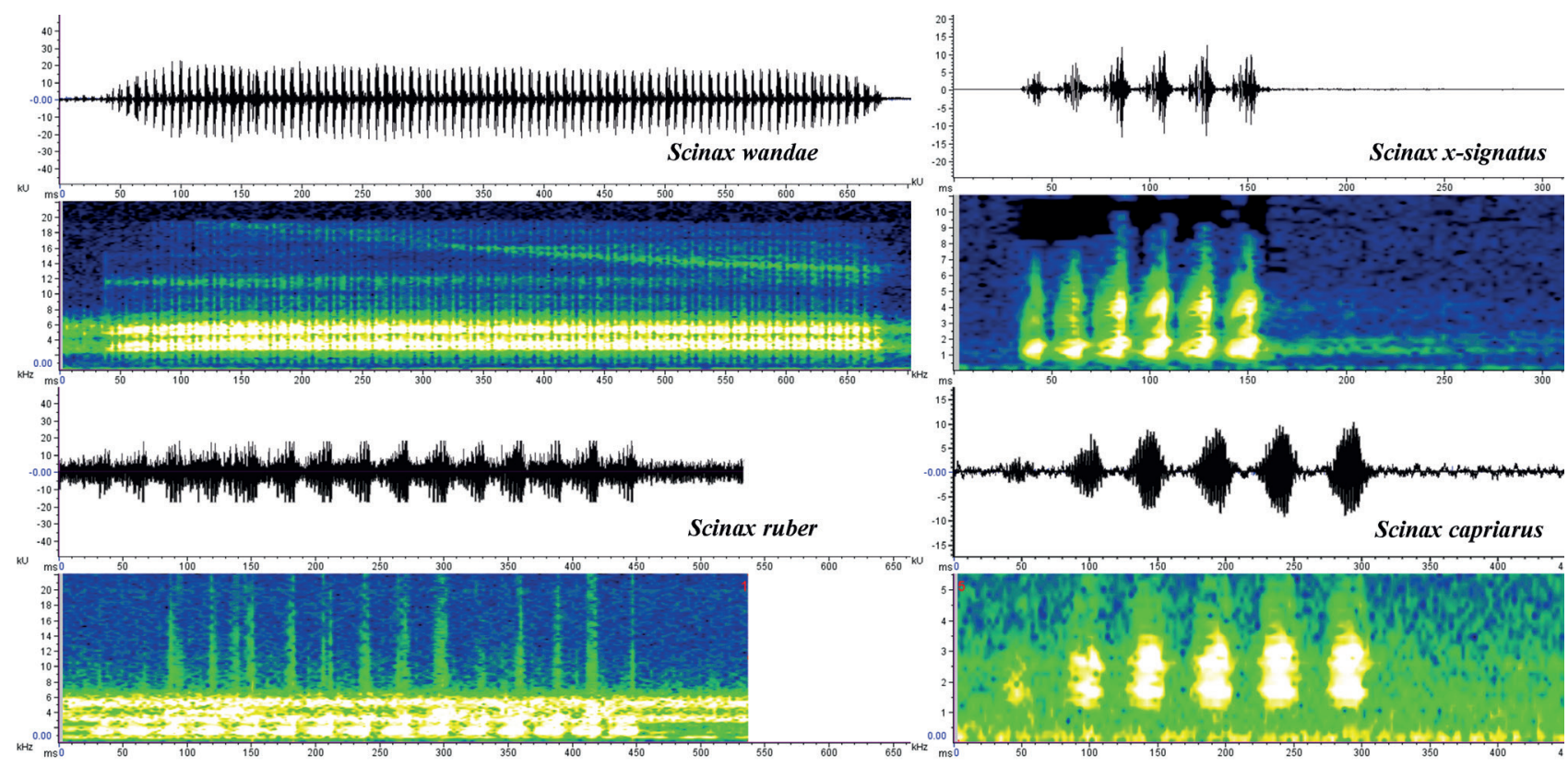

Figura 14. Comparación de Scinax caprarius sp. nov. con algunos de sus consespecíficos del grupo Scinax ruber, en oscilogramas (gráficos superiores) y espectrogramas (gráficos inferiores) de hasta 650 milisegundos de una nota simple. A. Scinax wandae, grabado a las 23:02 horas, $22,9{ }^{\circ} \mathrm{C}$, y $87 \%$ de humedad relativa, municipio San Martín, vereda Montebello, finca Tocancipá, departamento del Meta, MUJ 6164 (BSA-15980, http://colecciones.humboldt.org.co/rec/sonidos/BSA-15980/). B. Scinax $x-$ signatus, grabado a las 20:50 horas, $31,3{ }^{\circ} \mathrm{C}$, y 55 \% Humedad relativa, en el municipio Guayabal, corregimiento Méndez, Reserva de La Sociedad Civil, hacienda Jabirú, IAvH-Am-11444 (BSA-15982, http://colecciones.humboldt.org.co/rec/sonidos/BSA-15982/). C. Scinax ruber, municipio San Martín, vereda Montebello, finca Tocancipá, departamento del Meta, Colombia (BSA-15990, http:// colecciones.humboldt.org.co/rec/sonidos/BSA-15990/). D. Scinax caprarius sp. nov., grabado a las 19:53 horas, $24{ }^{\circ} \mathrm{C}$ y $68 \%$ de una humedad relativa, El Porvenir, municipio de El Carmen de Viboral, departamento de Antioquia, IAvH-Am-14421 (BSA-15985, http://colecciones.humboldt.org.co/rec/ sonidos/BSA-15985/).

\section{Agradecimientos}

Extendemos nuestros más sinceros agradecimientos a los habitantes de la vereda El Porvenir en el municipio de El Carmen de Viboral, en el departamento de Antioquia, especialmente a nuestro guía local Yair Orozco por su incondicional apoyo a lo largo de los trabajos de campo en el río Melcocho en diciembre de 2016. Esta contribución se generó en el marco del proyecto Caracterización de la diversidad para el fortalecimiento de las colecciones científicas y la generación de información genética de la diversidad colombiana bajo el programa Colombia BIO, convenio especial de colaboración ColcienciasIAvH, FP44842-109-2016 y en el marco del POA 2017 de la subdirección de investigaciones, línea

de las colecciones biológicas del Instituto de Investigación de Recursos Biológicos Alexander von Humboldt. Quiero extender mi gratitud a Javier Barriga y Johann Cárdenas por la organización logística en el trabajo decampo. Felipe Villegas y Andrés Romero ("Chino") realizaron parte de las fotografías de los ambientes. Sergio Córdoba y Kevin Borja permitieron el depósito de las vocalizaciones en la colección de sonidos ambientales del BSA. Finalmente, quiero expresar mi infinito reconocimiento a los evaluadores anónimos que con sus invaluables contribuciones permitieron aclarar y actualizar varios conceptos relevantes. 


\section{Referencias}

Altig, R. y McDiarmid, R.W. (1999). Body plan: development and morphology. En McDiarmid, R. W. y Altig, R. (Eds.). Tadpole: The Biology of Anuran Larvae. London: The University of Chicago Press. 458 pp.

Araujo-Vieira, K., Brandão, R. A. y do C. Faria, D. C. (2015). A new species of rock-dwelling Scinax Wagler (Anura: Hylidae) from Chapada dos Veadeiros, central Brazil. Zootaxa, 3915 (1): 52-66.

Araujo-Vieira, K., Valdujo, P. H. y Faivovich, J. (2016). A new species of Scinax Wagler (Anura: Hylidae) from Mato Grosso, Brazil. Zootaxa, 4061 (3): 261-273.

Barrio-Amorós, C. L., Orellana, A. y ChacónOrtiz., A. (2004). A new species of Scinax (Anura: Hylidae) from the Andes of Venezuela. Journal of Herpetology, 38: 105-112.

Brusquetti, F., Jansen, M., Barrio-Amorós, C. L., Segalla M. V.y Haddad, C. F. B. (2014). Taxonomic review of Scinax fuscomarginatus (Lutz, 1925) and related species (Anura; Hylidae). Zoological Journal of the Linnean Society, 171: 783-821.

Charif, R., Waack, A. y Strickman, L. (2010). Raven Pro 1.4. Ithaca, NY: Cornell Lab of Ornithology.

Chen, H. M. y Combs, C. A. (1999). An alternative anesthesia for amphibians: ventral application of benzocaine. Herpetological Review, 30 (1): 34.

Cisneros-Heredia, D. F. y Mcdiarmid R. W. (2007). Revision of the characters of Centrolenidae (Amphibia: Anura: Athesphatanura), with comments on its taxonomy and the description of new taxa of glassfrogs. Zootaxa, 1572: 1-82.

Cocroft, R. B. y Ryan, M. J. (1995). Patterns of advertisement call evolution in toads and chorus frogs. Animal Behaviour, 49 (2): 283-303.

Conte, C. E., Araujo-Vieira, K., Crivellari, L. B. y Berneck, B.V. (2016). A new species of Scinax Wagler (Anura: Hylidae) from Paraná, Southern Brazil. Zootaxa, 4193 (2): 245-265.

Cruz, C. A. G., Nunes, I. y Lima M. (2011). A new Scinax Wagler belonging to the $S$. catharinae clade
(Anura: Hylidae) from the State of Alagoas, northeastern Brazil. Zootaxa, 3096: 18-26.

De Carvalho, T. R., Martins L. B. y Giaretta A. A. (2015). The complex vocalization of Scinax cardosoi (Anura: Hylidae), with comments on advertisement calls in the $S$. ruber Clade. Phyllomedusa: Journal of Herpetology, 14 (2): 127137.

De La Riva, I. (1993). A new species of Scinax (Anura, Hylidae) from Argentina and Bolivia. Journal of Herpetology, 27 (1): 41-46.

Dinerstein, E., Olson, D. M., Graham, D. J., Webster, Primm, A. L. S. A., Bookbinder M. P., Ledec G. y Young. K. R. (1995). A conservation assessment of the terrestrial ecoregions of Latin America and the Caribbean. Washington D. C.: World Bank. 174 pp.

Duellman, W. E. (1970). Hylid frogs of Middle America. Monographs of the Museum of Natural History, University of Kansas, 1-2: 1-753.

Duellman, W. E. (1972). A new species of Hyla from Amazonian Ecuador. Copeia, 1972: 265-271.

Duellman, W. E. (1973). Descriptions of new hylid frogs from Colombia and Ecuador. Herpetologica, 29: 219-227.

Duellman, W. E. (1986). Two new species of Ololygon (Anura: Hylidae) from the Venezuelan Guyana. Copeia, 1986: 864-870.

Duellman, W. E. y Pyles, R. A. (1983). Acoustic resource partitioning in anuran communities. Copeia, 639-649.

Duellman, W. E. y Wiens, J. J. (1993). Hylid frogs of the genus Scinax Wagler, 1830, in Amazonian Ecuador and Peru. Occasional Papers of the Museum of Natural History, University of Kansas, 153: 1-57.

Duellman, W. E., Marion, A. B. y Hedges, S. B. (2016). Phylogenetics, classification, and biogeography of the treefrogs (Amphibia: Anura: Arboranae). Zootaxa, 4104 (1): 1-109.

Faivovich, J. (2002). A cladistic analysis of Scinax (Anura: Hylidae). Cladistics, 18 (4): 367-393. 
Faivovich, J., Haddad, C. F., Garcia, P. C., Frost, D. R., Campbell, J. A. y Wheeler, W. C. (2005). Systematic review of the frog family Hylidae, with special reference to Hylinae: phylogenetic analysis and taxonomic revision. Bulletin of the American Museum of Natural History, 294: 1-240.

Fouquette Jr., M. J. y Pyburn, W. F. (1972). A new Colombian treefrog of the Hyla rubra complex. Herpetologica, 28: 176-181.

Fouquet, A., Vences, M., Salducci, M. D., Meyer, A., Marty, C., Blanc, M., y Gilles, A. (2007). Revealing cryptic diversity using molecular phylogenetics and phylogeography in frogs of the Scinax ruber and Rhinella margaritifera species groups. Molecular phylogenetics and evolution, 43 (2): 567-582.

Gosner, K. L. (1960). A simplified table for staging anuran embryos and larvae with notes on identification. Herpetologica, 16 (3): 183-190.

Guayasamin, J. M., Lehr, E., Rodríguez, D. y Aguilar, C. (2006). A new species of glass frog (Centrolenidae: Cochranella ocellata Group) from central Peru. Herpetologica, 62 (2): 163-172.

Guimaraes, C. S., Peixoto, M. A. A., Lacerda, J. V. A. y Feio, R. N. (2014). The tadpole of Scinax cosenzai (Anura: Hylidae). Salamandra, 50 (2): 99104.

Juncá, F. A., Napoli M. F., Nunes, I., de A. Mercês, E. y de Abreu, R. O. (2015). A new species of the Scinax ruber clade (Anura, Hylidae) from the Espinhaço Range, northeastern Brazil. Herpetologica, 71 (4): 299-309.

Köhler, J., Jansen, M., Rodríguez, A., Kok, P. J. R., Toledo, L. F., Emmrich, M., Glaw, F., Haddad, C. F. B., Rödel M. O. y Vences, M. (2017). The use of bioacoustics in anuran taxonomy: theory, terminology, methods and recommendations for best practice. Zootaxa, 4251 (1): 1-124

Lannoo, M. J. (1987). Neuromast topography in anuran amphibians. Journal of Morphology, 191 (2): 115-129.

Lourenço, A., Carvalho, A., Baeta, D., Pezzuti, T. L. y Leite, F. (2013). A new species of the Scinax catharinae group (Anura, Hylidae) from Serra da Canastra, southwestern state of Minas Gerais, Brazil. Zootaxa, 3613 (6): 573-588.

Lourenco, A. C. C., Zina, J., Catroli, G. F., Kasahara, S., Faivovich, J. y Haddad, C. F. (2016). A new species of the Scinax catharinae group (Anura: Hylidae) from southeastern Brazil. Zootaxa, 4154 (4): 415-435.

McDiarmid, R. W. y Altig, R. (Eds.). (1999). Tadpoles: the biology of anuran larvae. University of Chicago Press. 458 pp.

Myers, C. y Duellman, W. (1982). A New Species of Hyla from Cerro Colorado, and other tree frog records and geographical notes from western Panama. American Museum Novitates, 2752: 1-32.

Napoli, N. F. y Caramaschi, U. (1998). Duas novas espécies de Hyla Laurenti, 1768 do Brasil central afins de $H$. tritaeniata Bokermann, 1965 (Amphibia, Anura, Hylidae). Boletim do Museu Nacional, Nova Série, Zoologia, 391: 1-12.

Nieto-Castro, M. (1999). Estudio preliminar de las especies del género Scinax (Amphibia: Anura: Hylidae) en Colombia. Revista de la Academia Colombiana de Ciencias Exactas, Físicas y Naturales, 23 (Suplemento Especial): 339-346.

Nunes, I., Carvalho Jr., R. R. y Pereira, E.G. (2010). A new species of Scinax Wagler (Anura: Hylidae) from Cerrado of Brazil. Zootaxa, 2514: 24-34.

Nunes, I. y Pombal, Jr., J. P. (2011). A new snouted treefrog of the speciose genus Scinax Wagler (Anura, Hylidae) from northeastern Brazil. Herpetologica, 67 (1): 80-88.

Olson, D. M. y Dinerstein, E. (2002). The Global 200: Priority ecoregions for global conservation. Annals of the Missouri Botanical Garden, 89: 199-224.

Pyburn, W. F. (1973). A new hylid from the Llanos of Colombia. Journal of Herpetology, 7: 297-301.

Pyburn, W. F. (1992). A new tree frog of the genus Scinax from the Vaupes River of northwestern Brazil. Texas Journal of Science, 44: 405-411.

Pyburn, W. F. (1993). A new species of dimorphic tree frog, genus Hyla (Amphibia: Anura: 
Hylidae), from the Vaupés River of Colombia. Proceedings of the Biological Society of Washington, 106: 46-50.

Pyburn, W. F. y Fouquette, Jr., M. J. (1971). A new striped treefrog from central Colombia. Journal of Herpetology, 5: 97-101.

Restrepo, A., Molina-Zuluaga, C., Hurtado, J. P., Marín C. M. y Daza J. M. (2017). Amphibians and reptiles from two localities in the northern Andes of Colombia. Check List, 13 (4): 203-237.

Savage, J. M. y Heyer W. R.. (1967) Variation and distribution in the tree-frog genus Phyllomedusa in Costa Rica, Central America. Beitrage zur Neotropischen Fauna, 5: 111-131.

Silva-Soares, T., Costa, P. N., Ferreira, R. B. y Weber, L. N. (2010). The tadpole of the hylid frog Scinax belloni (Anura: Hylidae). Zootaxa, 2727: 63-68.

Sturaro, M. J. y Peloso, P. L. V. (2014). A new species of Scinax Wagler, (1830) (Anura: Hylidae) from the middle Amazon River basin, Brazil. Papéis Avulsos de Zoologia, 54 (2): 9-23.

Suarez, A. y Lynch J. D. (2011). Clave ilustrada de los renacuajos en las tierras bajas al oriente de los Andes, con énfasis en Hylidae. Caldasia, 33 (1): 235-270.

UICN. (2001). Categorías y criterios de la lista roja de la UICN: Versión 3.1. Comisión de Supervivencia de Especies de la UICN. UICN, Gland, Suiza y Cambridge, Reino Unido. ii + 33 pp.

\section{Anexo 1.}

Ejemplares examinados. Scinax blairi: COLOMBIA, departamento de Arauca, municipio Arauca, Hato El Venero, IAvH-Am-3901; departamento de Casanare, municipio Paz de Ariporo, vereda San Esteban, $5^{\circ} 37^{\prime} 14.53^{\prime \prime} \mathrm{N}$ y 70²' 24.95"O, 114 m s.n.m., IAvH-Am-14247; departamento del Meta, desembocadura del caño Cabra, Parque Nacional Natural Sierra de La Macarena, IAvH-Am-2410, IAvH-Am-2413, IAvH-Am-2418, IAvH-Am-2420; río Cafre, cabaña Raudal bajo, Parque Nacional Natural Sierra de La Macarena, IAvH-Am-2506.

Scinax boulengeri. COLOMBIA, departamento de Antioquia, municipio de Carepa, vereda La Cinco, Escuela Rural 19 de enero IAvH-Am-11138-9; departamento de Caldas, municipio La Dorada, Hacienda La Española, cerca al río Purnio, $5^{\circ} 22^{\prime} 2.9^{\prime \prime} \mathrm{N}$ y $74^{\circ} 47^{\prime} 36.6^{\prime \prime} \mathrm{O}, 266$ m s.n.m., IAvHAm-13043-4; departamento de Chocó, municipio Acandí, Cerro El Tolo, IAvH-Am-4060-8; departamento de Sucre, Sucre, IAvH-Am-1168.
Scinax cruentommus: COLOMBIA, departamento de Amazonas, municipio de Leticia, Cabaña de Matamata y alrededores, Parque Nacional Natural Amacayacu, IAvH-Am-2094; departamento de Caquetá, municipio de Solano, vía Chiribiquete, Parque Nacional Natural Serranía de Chiribiquete, IAvH-Am-8746.

Scinax elaeochrous: COLOMBIA, departamento de Bolívar, San Cristóbal, IAvH-Am-0540; departamento del Chocó, Bellavista, río Atrato, IAvH-Am-5364-6; departamento del Cauca, municipio de Guapi, Casco Urbano, IAvHAm-4370-1, IAvH-Am-6846-7.

Scinax garbei: COLOMBIA, departamento de Amazonas, municipio de Leticia, alrededores de Leticia, IAvH-Am-4799; Cabaña de Matamata y alrededores, Parque Nacional Natural Amacayacu, IAvH-Am-2093, IAvH-Am-4637, IAvH-Am-5143; Leticia, IAvH-Am-3911; departamento de Caquetá, Quebrada del Yavilla, 
cerca de las bocas en zona pantanosa, IAvHAm-0456; departamento de Cauca, municipio de Santa Rosa, vereda Nabueno, finca El Diamante, 270 m s.n.m., IAvH-Am-5748.

Scinax kennedyi: COLOMBIA, departamento de Arauca, municipio de Cravo Norte, Lejanías del Juriepe, $6^{\circ} 14^{\prime} 2,15^{\prime \prime} \mathrm{N}$ y $69^{\circ} 42^{\prime} 59,45^{\prime \prime} \mathrm{O}, 100 \mathrm{~m}$ s.n.m., IAvH-Am-10615-7, IAvH-Am-10624-7; departamento de Casanare, municipio Orocué, vereda Cumaco, Bloque Cachicamo, Morichal, 225 m s.n.m., IAvH-Am-11799; Paz de Ariporo, vereda San Esteban, 5³7'14.53"N y 7042'24.95"O 14 m s.n.m., IAvH-Am-14024; departamento del Meta, municipio, Puerto Gaitán, vereda Fundación, Hacienda El Brasil, $4^{\circ} 19^{\prime} 44^{\prime \prime} \mathrm{N}$ y 71²3`54.1”O, 204 m s.n.m., IAvH-Am-11656, IAvH-Am-11663, IAvH-Am-116; departamento del Vichada, municipio Cumaribo, Corregimiento de Santa Rita, río Tomo, Parque Nacional Natural El Tuparro, 5²1'48'N y 6751'36"O, 240 m s.n.m., IAvH-Am-7511-13; Caño Peinilla, Parque Nacional Natural El Tuparro, $5^{\circ} 21^{\prime} 20^{\prime \prime} \mathrm{N}$ y $68^{\circ} 1^{\prime} 28^{\prime \prime} \mathrm{O}, 240$ m s.n.m., IAvH-Am-7557; Zurales, Parque Nacional Natural El Tuparro, $5^{\circ} 20^{\prime} 3^{\prime \prime} \mathrm{N}$ y $67^{\circ} 52^{\prime} 15^{\prime \prime} \mathrm{O}, 240$ m.s.n.m., IAvH-Am-7573; municipio La Primavera, Finca La Florida, $5^{\circ} 48^{\prime} 15,4^{\prime \prime} \mathrm{N}$ y $68^{\circ} 51^{\prime} 24,9^{\prime \prime} \mathrm{O}, 81$ m s.n.m., IAvH-

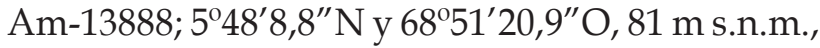
IAvH-Am-13889; municipio Puerto Carreño, vereda Caño Negro, Reserva Natural Privada de la Sociedad Civil La Pedregoza, margen derecha del río Bita, $6^{\circ} 0.5^{\prime} 39.6^{\prime \prime} \mathrm{N}$ y $67^{\circ} 43^{\prime} 34.1^{\prime \prime} \mathrm{O}$, 35 m s.n.m., IAvH-Am-11579; finca la Rampa, $5^{\circ} 44^{\prime} 16,9^{\prime \prime} \mathrm{N} \quad$ y $68^{\circ} 28^{\prime} 9,7^{\prime \prime} \mathrm{O}, 52$ m s.n.m., IAvHAm-13887; municipio Santa Rosalía, vereda Pavanay, hacienda La Navidad, 59'22.9"N y 7045'10.1"O, 115 m s.n.m. IAvH-Am-11581-3.

Scinax lindsayi: COLOMBIA, departamento de Vaupés, corregimiento Miraflores, meseta de Diana, Parque Nacional Natural Serranía de Chiribiquete, IAvH-Am-5463.

Scinax rostratus: COLOMBIA, departamento de Arauca, municipio Arauca, vereda La Pastora, Finca La Barquereña, $6^{\circ} 48^{\prime} 22.2^{\prime \prime} \mathrm{N}$ y
7059'10.8”O, 134 m s.n.m., IAvH-Am-10228, vereda Caño Salas, finca La Tormenta, $6^{\circ} 49^{\prime} 5.1^{\prime \prime} \mathrm{N}$ y $71^{\circ} 04^{\prime} 20.6^{\prime \prime} \mathrm{O}, 136$ m s.n.m., IAvH-Am-10231; municipio de Cravo Norte, vereda Juriepe, Caño Araguato, Zona Avioneta, $6^{\circ} 27^{\prime} 17.3^{\prime \prime} \mathrm{N}$ y $69^{\circ} 46^{\prime} 1.35^{\prime \prime} \mathrm{O}, 84 \mathrm{~m}$ s.n.m., IAvH-Am-14372; vereda Normandía, 6³4'4,0" $\mathrm{N}$ y $71^{\circ} 9^{\prime} 16,59^{\prime \prime} \mathrm{O}$, IAvH-Am-10657; municipio Támara, vereda Quebrada honda, quebrada La Vinagrera, $5^{\circ} 45^{\prime} 30.8^{\prime \prime} \mathrm{N}$ y $72^{\circ} 06^{\prime} 29.8^{\prime \prime} \mathrm{O}$, IAvH-Am-12994; Paz de Ariporo, vereda Varsovia, 6 ${ }^{\circ} 5^{\prime} 39.89^{\prime \prime} \mathrm{N}$ y 709'17.94"O, 108 m s.n.m., IAvH-Am-14022; 6 5'35.01"N y 70 9'31.54" O, 105 m s.n.m., IAvHAm-14023; municipio Pore, vereda La Plata, Finca

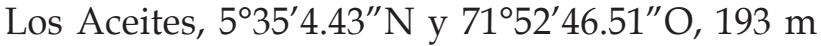
s.n.m., IAvH-Am-12218; municipio Tame, vereda San Joaquín, finca El Santuario, 6 ${ }^{\circ} 12^{\prime} 46.34^{\prime \prime} \mathrm{N}$ y $71^{\circ} 34^{\prime} 6.19^{\prime \prime} \mathrm{O}, 176 \mathrm{~m}$ s.n.m., IAvH-Am-12212; $6^{\circ} 13^{\prime} 27.52^{\prime \prime} \mathrm{N}$ y $71^{\circ} 33^{\prime} 58.98^{\prime \prime} \mathrm{O}, 174$ m s.n.m., IAvH-Am-12213; vereda San Salvador, finca La Guaira, $6^{\circ} 14^{\prime} 26.23^{\prime \prime} \mathrm{N}$ y $71^{\circ} 34^{\prime} 50.11^{\prime \prime} \mathrm{O}, 173$ $\mathrm{m}$ s.n.m., IAvH-Am-12214-5; 6014'15.96"N y 71'34'52.23"O, 174 m s.n.m., IAvH-Am-12216; $6^{\circ} 13^{\prime} 8.13^{\prime \prime} \mathrm{N}$ y $71^{\circ} 35^{\prime} 55.42^{\prime \prime} \mathrm{O}, 176$ m s.n.m., IAvHAm-12217, IAvH-Am-12477, IAvH-Am-12480; finca La Envidia, bosque Puna Puna, 6 $19^{\prime} 50.9^{\prime \prime} \mathrm{N}$ y $71^{\circ} 46^{\prime} 23.2^{\prime \prime} \mathrm{O}, 283$ m s.n.m. IAvH-Am-12992; río Negro y Caribabare, $6^{\circ} 16^{\prime} 55.3^{\prime \prime} \mathrm{N}$ y $71^{\circ} 46^{\prime}$ 36.7"O, 278 m s.n.m. IAvH-Am-12993; vereda Bocas del Tocoragua, finca San José, $6^{\circ} 16^{\prime} 11,1^{\prime \prime} \mathrm{N}$ y 7151'53,6”'O, IAvH-Am-12995; departamento de Caquetá, municipio de San Vicente de Caguán, vereda La Siberia, IAvH-Am-4703; departamento de Casanare, municipio de Hato Corozal, vereda La Chapa, complejo de humedales de Hato Corozal, Caño El Oso-Aricaporo, 554'24.32” N y 71'28'47.76"O, 167 m s.n.m., IAvH-Am-10908-9; vereda La Manga, Finca La Providencia, $6^{\circ} 12^{\prime} 2.16^{\prime \prime} \mathrm{N}$ y $71^{\circ} 36^{\prime} 0.99^{\prime \prime} \mathrm{O}, 180$ m s.n.m., IAvHAm-12208; municipio Maní, vereda El Viso, finca El Caracaro, $4^{\circ} 53^{\prime} 19.8^{\prime \prime} \mathrm{N}$ y $72^{\circ} 21^{\prime} 56.6^{\prime \prime} \mathrm{O}, 191 \mathrm{~m}$ s.n.m., IAvH-Am-11721-4; municipio de Nunchía, IAvH-Am-7725, vereda Piedecuesta, finca Las Canarias, 450 m s.n.m. IAvH-Am-7009-11; municipio de Orocué, vereda Palmarito, Caño Canacabare, hacienda El Samán, 4 ${ }^{\circ} 50^{\prime} 27.1^{\prime \prime} \mathrm{N}$ y $71^{\circ} 0.42^{\prime}$ 9.4"O, IAvH-Am-11793-7; vereda Brisas 


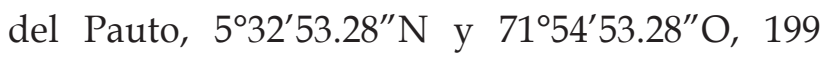
m s.n.m., IAvH-Am-12209-11; 5³2'54.61"N y 71054'35.54"O,196, m s.n.m., IAvH-Am-12464; municipio de Tauramena, vereda Yaguaros desembocadura entre las Quebradas El Aceite y El Tesoro, $4^{\circ} 0.5^{\prime} 44.4^{\prime \prime} \mathrm{N}$ y $72^{\circ} 43^{\prime} 44^{\prime \prime} \mathrm{O}$, IAvHAm-11160; municipio de Yopal, Morichal, $380 \mathrm{~m}$ s.n.m., IAvH-Am-7726-7; departamento de Cesar, municipio Chimichagua, Ecce-Homo-La Calera, $9^{\circ} 17^{\prime} 06^{\prime \prime} \mathrm{N}$ y $73^{\circ} 46^{\prime} 48^{\prime \prime} \mathrm{O}, 135$ m s.n.m., IAvHAm-11274; departamento de Cundinamarca, municipio Paratebueno, finca Palumea, sector Tres Caños, $4^{\circ} 20^{\prime} 50.7^{\prime \prime} \mathrm{N}$ y $73^{\circ} 11^{\prime} 21.67^{\prime \prime} \mathrm{O}, 238 \mathrm{~m}$ s.n.m., IAvH-Am-9610; departamento del Meta, municipio de Villavicencio, El Edén, Piscifactoría, IAvH-Am-0520; vereda La Cunsia, kilómetro 8 Villavicencio-Acacias, IAvH-Am-4668-4670; departamento de Santander, municipio de Sabana de Torres, vereda Diamante, límite veredal cruce robledo, $7^{\circ} 23^{\prime} 32,07^{\prime \prime} \mathrm{N}$ y $73^{\circ} 27^{\prime} 19,58^{\prime \prime} \mathrm{O}$, 192 m s.n.m., IAvH-Am-10444; departamento de Sucre, municipio Colosó, vereda El Sereno Alto, Quebrada El Sereno, arriba de la estación, $9^{\circ} 31^{\prime} 49.7^{\prime \prime} \mathrm{N}$ y $75^{\circ} 21^{\prime} 18^{\prime \prime} \mathrm{O}, 300$ m s.n.m., IAvHAm-8041.

Scinax ruber: COLOMBIA, departamento de Amazonas, municipio de Leticia, casco urbano de Leticia, IAvH-Am-0014, IAvH-Am-0601, IAvH-Am-3907, IAvH-Am-0806-13; isla Santa Sofía, IAvH-Am-0190-206, IAvH-Am-0253, IAvH-Am-3404; isla Santa Sofía II a $20 \mathrm{~km}$ al noroeste de Leticia, IAvH-Am-3437-8, IAvHAm-7963; baño de la cabaña en la isla de Mike Tsalickis, IAvH-Am-0278-81; Tarapacá, km 3-4, IAvH-Am-0479; Trocha a Calderón, aprox. 35-40 km de Leticia, IAvH-Am-0646; Cabaña Matamata, alrededores Parque Nacional Natural Amacayacu, IAvH-Am-2081, IAvH-Am-2087-8, IAvH-Am-2099, IAvH-Am-2106, IAvH-Am-2126, $\mathrm{IAvH}-\mathrm{Am}-2217$, IAvH-Am-2219, IAvH-Am-2310; Cabañas bocas de Amacayacu, Parque Nacional Natural Amacayacu, IAvH-Am-3883; centro de visitantes, Parque Nacional Natural Amacayacu, IAvH-Am-5380-3; Quebrada Tucuchira, IAvHAm-3909; corregimiento La Pedrera, IAvHAm-2562; río Mirití - Paraná (Puerto Rastrojo),
IAvH-Am-4513; corregimiento La Chorrera, frente a la Caja Agraria, IAvH-Am-6287; municipio Puerto Nariño, sector Lagos de Tarapoto, trocha comunidad Tarapoto Norte a $1 \mathrm{~km}$ del Aguajal, $3^{\circ} 46^{\prime} 44,3^{\prime \prime} \mathrm{S}$ y $70^{\circ} 25^{\prime} 51,2^{\prime \prime} \mathrm{O}$, IAvH-Am-10575; Boyahuasú, 347'23.3"S y 70³7'13.6”O, 94 m s.n.m., IAvH-Am-11424; departamento de Arauca, municipio de Arauca, IAvH-Am-3503; municipio de Arauquita, vereda Normandía, $6^{\circ} 34^{\prime} 4,08^{\prime \prime} \mathrm{N} \quad \mathrm{y}^{7} 1^{\circ} 9^{\prime} 16,59^{\prime \prime} \mathrm{O}$, IAvH-Am-10649; municipio Cravo Norte, vereda Juriepe, finca La Palmira, 96 m s.n.m., IAvH-Am-14371; municipio Tame, vereda San Joaquín, finca El Santuario,

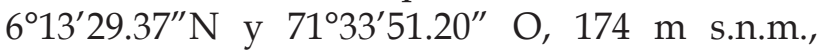
IAvH-Am-12250; vereda San Salvador, finca La Guaira, 6 6 $13^{\prime} 6.33^{\prime \prime}$ y $71^{\circ} 35^{\prime} 57.19^{\prime \prime} \mathrm{W}, 176 \mathrm{~m}$ s.n.m., IAvH-Am-12252-3, IAvH-Am-12474-6; $6^{\circ} 14^{\prime} 26.23^{\prime \prime} \mathrm{N}$ y $71^{\circ} 34^{\prime} 50.11^{\prime \prime} \mathrm{O}, 173$ m s.n.m., IAvH-Am-12472; 6013'8.13"N y 71'35'56.12" O, 176 m s.n.m., IAvH-Am-12473; 6 $13^{\prime} 8.13^{\prime \prime} \mathrm{N}$ y 71'35'55.42"O, 176 m s.n.m., IAvH-Am-12479; $6^{\circ} 13^{\prime} 10.13^{\prime \prime} \mathrm{N}$ y $71^{\circ} 35^{\prime} 55.79^{\prime \prime} \mathrm{O}, 176$ m s.n.m., IAvH-Am-12481-2; bosque finca La Fortuna, $6^{\circ} 16^{\prime} 54.5^{\prime \prime} \mathrm{N}$ y $71^{\circ} 46^{\prime} 36.6^{\prime \prime} \mathrm{O}, 302$ m s.n.m., IAvHAm-12989; vereda Sabana la Vieja, laguna La Vieja, $6^{\circ} 21^{\prime} 25,3^{\prime \prime} \mathrm{N}$ y $71^{\circ} 49^{\prime} 18,7^{\prime \prime} \mathrm{O}$, IAvH-Am-12990; $6^{\circ} 21^{\prime} 25,5^{\prime \prime} \mathrm{N}$ y $71^{\circ} 49^{\prime} 19,4^{\prime \prime} \mathrm{O}$, IAvH-Am-12991; departamento de Bolívar, Puerto Chocó, Puerto Chacho, IAvH-Am-6632; departamento de Boyacá, "municipio Duitama", Camino Belén Encino, IAvH-Am-9534-8; departamento de Cauca, municipio de Santa Rosa, vereda El Carmen o El Pozo Miraflor, Finca El Triunfo, 380 m s.n.m. IAvH-Am-5720, IAvH-Am-5722, IAvHAm-5724, IAvH-Am-5728; vereda El Carmen, Pozo Miraflor, finca El Triunfo, orilla río Tambor, 380 m s.n.m., IAvH-Am-5735, IAvH-Am-5746-7, IAvH-Am-5774; vereda Nabueno, Mary II, 270 m s.n.m. IAvH-Am-5749-2, IAvH-Am-5759, IAvHAm-5765, IAvH-Am-5767; Finca El Diamante, 270 m s.n.m., IAvH-Am-5775; vereda San Pablo, 270 m s.n.m., IAvH-Am-5776; departamento del Casanare, municipio de Nunchía, alrededores de Nunchía, 380 m s.n.m., IAvH-Am-7731; hato Venecia, IAvH-Am-4898-910; municipio Hato Corozal, vereda La Manga, finca La Providencia, $6^{\circ} 12^{\prime} 2.16^{\prime \prime} \mathrm{N}$ y $71^{\circ} 36^{\prime} 0.99^{\prime \prime} \mathrm{O}, 180$ m s.n.m., IAvH- 
Am-12237; municipio Pore, Brisas del Pauto, $5^{\circ} 31^{\prime} 44.30^{\prime \prime} \mathrm{N}$ y $71^{\circ} 53^{\prime} 53.08^{\prime \prime} \mathrm{O}, 195$ m s.n.m., IAvH-Am-12238-39; vereda La Plata, finca

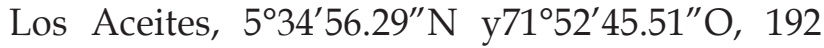
$\mathrm{m}$ s.n.m. IAvH-Am-12240, IAvH-Am-12249; $5^{\circ} 35^{\prime} 1.48^{\prime \prime} \mathrm{N}$ y $71^{\circ} 52^{\prime} 34.87^{\prime \prime} \mathrm{O}, 196$ m s.n.m., IAvH-Am-12247-9; finca Japón, 5³4’35.24"N y 71'52'31.73"O, 194 m s.n.m., IAvH-Am-12244-6, vereda Matapalo, 531'2.73"N y $71^{\circ} 51^{\prime} 15.66^{\prime \prime} \mathrm{O}$, 192 m s.n.m. IAvH-Am-12241-3; vereda Santa María, complejo de humedales Hato Corozal, laguna de rebalse o inundación El Encanto, $6^{\circ} 0^{\prime} 24.95^{\prime \prime} \mathrm{N} \quad 71^{\circ} 33^{\prime} 54.01^{\prime \prime} \mathrm{O}, 176$ m s.n.m., $\mathrm{IAvH}-\mathrm{Am}-10895,6^{\circ} 0^{\prime} 28.67^{\prime \prime} \mathrm{N} \quad \mathrm{y}^{\circ} 1^{\circ} 33^{\prime} 52.81^{\prime \prime} \mathrm{O}$; 182 m s.n.m. IAvH-Am-10896-7, 600'28.67" N y 713'52.81"O, 182 m s.n.m., IAvH-Am-10917; vereda La Chapa, complejo de humedales Hato Corozal, caño Los Aceites, 5०56'2.97”N y 71²9'14.37"O, 174 m s.n.m., IAvH-Am-10898; complejo de humedales Hato Corozal, caño El Oso/Aricaporo, $5^{\circ} 54^{\prime} 24.32^{\prime \prime} \mathrm{N}$ y $71^{\circ} 28^{\prime} 47.76^{\prime \prime} \mathrm{O}$, 167 m s.n.m., IAvH-Am-10899-900; municipio Maní, vereda El Viso, casa de la Finca Guaralito, $4^{\circ} 54^{\prime} 33.70^{\prime \prime} \mathrm{N}$ y $72^{\circ} 22^{\prime} 39.40^{\prime \prime} \mathrm{O}, 191 \mathrm{~m}$ s.n.m., IAvH-Am-11744-6, vereda Santa María, hacienda Corocito, $4^{\circ} 38^{\prime} 8.7^{\prime \prime} \mathrm{N}$ y $72^{\circ} 0.5^{\prime} 34.8^{\prime \prime}$ O, 150 m s.n.m., IAvH-Am-11741-3; municipio Orocué, vereda Palmarito, caño Canacabare,

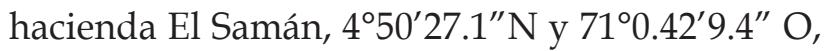
IAvH-Am-11798; municipio Tauramena, vereda Chaparral, Bosque Pozo Buenos Aires (BAX-30), atrás del Campamento de Equion, $4^{\circ} 59^{\prime} 31.1^{\prime \prime} \mathrm{N}$ y 7243'1.8” O, 372 m s.n.m., IAvH-Am-11159, IAvH-Am-11175; municipio Yopal, Morichal, 380 m s.n.m. IAvH-Am-7728-30; departamento de Caquetá, Las Islas, río Caquetá, IAvHAm-0458; municipio de San Vicente del Caguán, vereda La Siberia, IAvH-Am-4701-2; municipio de San José del Fragua, vereda La Esmeralda, alto río Yurayaco, $2^{\circ} 58^{\prime} 1^{\prime \prime} \mathrm{N}$ y $78^{\circ} 11^{\prime} 1^{\prime \prime} \mathrm{O}, 1000$ m s.n.m., IAvH-Am-6834-5; departamento de Cesar, Chimichagua, Ecce-Homo-La Calera, 9¹7'06"N y 7346 $48^{\prime \prime}$ O, 141 m s.n.m., IAvHAm-11277; departamento del Chocó, municipio Acandí, vereda La Playona, IAvH-Am-4069-70; municipio de Riosucio, vereda Cacarica, Parque Nacional Natura Los Katios, IAvH-Am-1988-94,
IAvH-Am-2259; departamento de Córdoba, alto río Sinú, campamento Urra 2, confluencia río Esmeralda con el río Sinú, IAvH-Am-2009; municipio de Ayapel, IAvH-Am-5102, IAvHAm-5107, IAvH-Am-5109; departamento del Magdalena, municipio de Santa Marta, sector Cañaveral, Parque Nacional Natural Tayrona, IAvH-Am-2033-6, IAvH-Am-2039-40, IAvHAm-2061; Pueblito, Parque Nacional Natural Tayrona, IAvH-Am-2500; departamento del Meta, municipio de Cubarral, cabaña Las Mirlas, Parque Nacional Natural Sumapaz, 710 m s.n.m. , IAvHAm-9040; municipio La Macarena, caño Cerrillo, Parque Nacional Natural Sierra de La Macarena, 460 m s.n.m., IAvH-Am-7105; municipio de Lomalinda, $5^{\circ} 14^{\prime} \mathrm{N}$ y $67^{\circ} 51^{\prime} \mathrm{O}$, IAvH-Am-7583; municipio Vista Hermosa, cabaña Caño Cabra, río Guayabero, Parque Nacional Natural Sierra de La Macarena, IAvH-Am-1067; departamento de Risaralda, municipio de Pereira, Cuenca del Río Otún, IAvH-Am-9038-9; departamento del Santander, municipio de Sabana de Torres, Hacienda Brisas del Mar, 7¹7'11,4"Ny 73³3'41,3" O, 295 m s.n.m, IAvH-Am-10547; departamento de Sucre, municipio Colosó, vereda El Sereno Bajo, $1 \mathrm{~km}$ al sur de la Estación Primatológica, $9^{\circ} 31^{\prime} 22^{\prime \prime} \mathrm{N}$ y $75^{\circ} 21^{\prime} 13.4^{\prime \prime}, 176$ m s.n.m., IAvHAm-8151. municipio San Benito Abad, vereda La Caimanera, sector de la Caimanera, $9^{\circ} 27^{\prime} 1^{\prime \prime} \mathrm{N}$ y

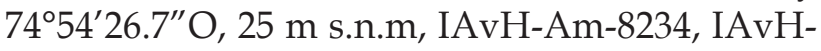
Am-8262-71, IAvH-Am-8281; municipio de San Marcos, Ciénaga de Gamboa, Estación San Marcos -INDERENA, 41 m s.n.m., IAvH-Am-5336, IAvHAm-5339-40, ciénaga Gamboa, 25 m s.n.m. IAvHAm-7769-3; municipio Tolú Viejo, hacienda La Estanzuela, sector el Bobo, IAvH-Am-1165; Casa del INDERENA, IAvH-Am-3510-2; departamento de Putumayo, municipio de Puerto Leguízamo, IAvH-Am-3912-5; Cabaña La Paya, Parque Nacional Natural La Paya, $1^{\circ} 36^{\prime} 47^{\prime \prime} \mathrm{N}$ y $76^{\circ} 6^{\prime} 2$.1 $^{\prime \prime} \mathrm{O}$, 330 m s.n.m. IAvH-Am-7114-5; Parque Nacional Natural La Paya, Cabaña Viviano Cocha, $0^{\circ} 7^{\prime} S$

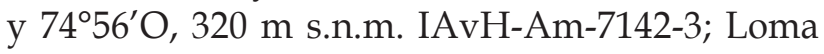
Alta, Parque Nacional Natural La Paya, $0^{\circ} 6^{\prime} \mathrm{S}$ y 745ㅇ' O, 350 m s.n.m., IAvH-Am-10397-8; departamento del Tolima, municipio de Prado, Represa Hidroprado, IAvH-Am-0554, IAvH- 
Am-6178; municipio de Melgar, IAvH-Am-1010; municipio Carmén de Apicalá, IAvH-Am-3145; municipio de Honda, vereda el Triunfo, hacienda El Triunfo, quebrada Lubebi, 5009'06.3" y 7447'59.6", 290 m s.n.m., IAvH-Am-11443; departamento de Vaupés, Caño Arara, sobre piedras cerca de orillas del río, IAvH-Am-0274; Timbo, IAvH-Am-0636; Estación Biológica Mosiro - Itajura (Caparú), IAvH-Am-5674, IAvHAm-5684， IAvH-Am-5687-8， IAvH-Am-5691, IAvH-Am-5695, IAvH-Am-5697; departamento del Vichada, Santa Rosalía, vereda Pavanay, hacienda La Navidad, 59'22.9' $\mathrm{N}$ y $70^{\circ} 45^{\prime} 10.1^{\prime \prime} \mathrm{O}$, 115 m s.n.m., IAvH-Am-11577.

Scinax wandae: COLOMBIA, departamento de Arauca, municipio Arauca, Puerto Rondón, vereda Ele-Perocero, 6³2' 45,41" Ny 7050'30,10"O,IAvHAm-10672; municipio Cravo Norte, vereda Juriepe, 103 m s.n.m., IAvH-Am-14374-6; municipio de Tame, vereda El Banco, finca el Romance, $6^{\circ} 16^{\prime}$ 00,3" N y 7154' 57,4'”, IAvH-Am-13017; vereda Sabana de La Vega, finca Casirba, $6^{\circ} 22^{\prime} 8.27^{\prime \prime} \mathrm{N}$ y $71^{\circ} 55^{\prime} 19.25^{\prime \prime} \mathrm{O}, 778 \mathrm{~m}$ s.n.m. IAvH-Am-10165, IAvH-Am-10173; 6 ${ }^{\circ} 22^{\prime} 55.95^{\prime \prime} \mathrm{N}$ y $71^{\circ} 55^{\prime} 14.04^{\prime \prime} \mathrm{O}$, 762 m s.n.m., IAvH-Am-10191，6 622'42.53"N y 71 ${ }^{\circ} 55^{\prime} 58.59^{\prime \prime} \mathrm{O}, 976$ m s.n.m., IAvH-Am-10197, IAvH-Am-10199-200, IAvH-Am-10204-18; río Negro y Caribabare, $6^{\circ} 16^{\prime} 55.3^{\prime \prime} \mathrm{N}$ y $71^{\circ} 46^{\prime}$ 36.7" O 278 m s.n.m., IAvH-Am-13018-9; vereda Sabana la Vieja, Laguna la Vieja, $6^{\circ} 21^{\prime} 25,5^{\prime \prime} \mathrm{N}$ y 7149' 19,4'” O, IAvH-Am-13020-1; departamento de Casanare, municipio Hato Corozal, vereda Santa María, complejo de humedales Hato Corozal, laguna de rebalse o inundación El Encanto, 559'55.47"N y $71^{\circ} 33^{\prime} 8.85^{\prime \prime} \mathrm{O}, 174 \mathrm{~m}$ s.n.m., IAvH-Am-10910, vereda La Chapa, complejo de humedales Hato Corozal, Estero El

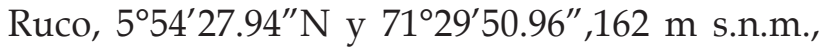
IAvH-Am-1091, Bijagual Mararabe, 554' 44.59"N y $71^{\circ} 28^{\prime} 54.60^{\prime \prime} \mathrm{O}, 162 \mathrm{~m}$ s.n.m., IAvH-Am-10912;

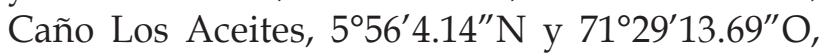
174 m s.n.m., IAvH-Am-10913, 556'2.97"N y 71²9'14.37" O, 174 m s.n.m., IAvH-Am-10914-6; municipio de Maní, vereda El Viso, finca El Caracaro $4^{\circ} 53^{\prime} 19.8^{\prime \prime} \mathrm{N}$ y $72^{\circ} 21^{\prime} 56.6^{\prime \prime} \mathrm{O}, 191$ m s.n.m. , IAvH-Am-11818, IAvH-Am-11771-4; vereda Santa María, hacienda Corocito, $4^{\circ} 38^{\prime} 37.3^{\prime \prime}$ N y 720.5'4.4" O, 150 m s.n.m., IAvH-Am-11945; municipio Nunchía, alrededores de Nunchía, 380 m s.n.m., IAvH-Am-7762-6; hato Venecia, IAvH-Am-4911; vereda Vega del Tacare, finca La Esperanza, vega del río Tocaría, 450 m s.n.m., IAvH-Am-7018; municipio de Orocué, vereda Cumaco, 225 m s.n.m. ,IAvH-Am-11817, IAvHAm-11819-23; vereda Cumaco, bosque del caño Mare Mare, 225 m s.n.m., IAvH-Am-11824-8; municipio Paz de Ariporo, vereda Varsovia, $6^{\circ} 0^{\prime} 31.50^{\prime \prime} \mathrm{N}$ y $70^{\circ} 13^{\prime} 36.59^{\prime \prime} \mathrm{O}, 100$ m s.n.m., IAvHAm-14236; vereda San Esteban, 5³7'11.64"N y $70^{\circ} 41^{\prime} 11.65^{\prime \prime} \mathrm{O}, 114 \mathrm{~m}$ s.n.m., IAvH-Am-14241; $5^{\circ} 37^{\prime} 21.17^{\prime \prime} \mathrm{N}$ y $70^{\circ} 41^{\prime} 10.09^{\prime \prime} \mathrm{O}, 116$ m s.n.m., IAvH-Am-14242; 5³7'14.53" N y 7042'24.95" O, 114 m s.n.m., IAvH-Am-14244; municipio Pore, vereda La Plata, finca Japón, $5^{\circ} 34^{\prime} 35.24^{\prime \prime} \mathrm{N}$ y 71 52'31.73"O, 194 m s.n.m., IAvH-Am-12456-62; 5³5'7.53" N y 71 52'43.04"O,194 m s.n.m., IAvHAm-12471, IAvH-Am-12484; vereda San Joaquín, finca El Santuario, 6² $13^{\prime} 27.52^{\prime \prime} \mathrm{N}$ y $71^{\circ} 33^{\prime} 58,98^{\prime \prime} \mathrm{O}$, 174 m s.n.m., IAvH-Am-12463, IAvH-Am-12465; vereda Brisas del Pauto, $5^{\circ} 32^{\prime} 54,61^{\prime \prime} \mathrm{N}$ y 7154'35.54"O, 196 m s.n.m., IAvH-Am-12466-7; vereda La Plata, finca Los Aceites, $5^{\circ} 34^{\prime} 56.29^{\prime \prime} \mathrm{N}$ y 71'52'45.51"O, 192 m s.n.m., IAvH-Am-12468-70, 5³4'47.17"N y 7152'30.12" O, 191 m s.n.m, IAvHAm-12483; municipio Támara, finca los Pantanos, Quebrada Volcana, 545'39,6"N y 72²'3,7"O, 556 m s.n.m., IAvH-Am-13016; departamento de Cundinamarca, municipio de Paratebueno, finca Palumea, sector tres caños, $4^{\circ} 20^{\prime} 19.91^{\prime \prime} \mathrm{N}$ y $73^{\circ} 12^{\prime} 3.61^{\prime \prime} \mathrm{O}, 251 \mathrm{~m}$ s.n.m., IAvH-Am-9609; departamento del Meta, municipio Villavicencio, vereda La Cunsia, kilómetro 8 VillavicencioAcacias, IAvH-Am-4671-8. municipio Mesetas, Vereda La Curia, Cabaña Cerrillo, Parque Nacional Natural Sierra de La Macarena IAvHAm-7876; municipio de Puerto Gaitán, vereda Fundación, hacienda El Brasil, $4^{\circ} 19^{\prime} 44^{\prime \prime}$ y 714354.1"O, 204 m s.n.m. IAvH-Am-11829; departamento del Vichada, río Tomo, Parque Nacional Natural El Tuparro, 250 m s.n.m. IAvHAm-7827, municipio Cumaribo, corregimiento de Santa Rita, Caño Peinilla, Parque Nacional Natural El Tuparro, $5^{\circ} 21^{\prime} 20^{\prime \prime} \mathrm{N}$ y $68^{\circ} 1^{\prime} 28^{\prime \prime} \mathrm{O}, 240$ 
m s.n.m., IAvH-Am-7556; Zurales, Parque Nacional Natural El Tuparro, $5^{\circ} 20^{\prime} 3^{\prime \prime} \mathrm{N}$ y $67^{\circ} 52^{\prime} 15^{\prime \prime}$ O, 240 m s.n.m. IAvH-Am-7574; municipio, La Primavera, vereda, Maracaná, hacienda Maracaná, caño arriba del Campamento $5^{\circ} 51^{\prime} 25.3^{\prime \prime} \mathrm{N}$ y $68^{\circ} 40^{\prime} 10^{\prime \prime} \mathrm{O}, \quad 71 \mathrm{~m}$ s.n.m., IAvH-Am-11845; finca la Florida, $5^{\circ} 47^{\prime} 28,1^{\prime \prime} \mathrm{N}$ y $68^{\circ} 50^{\prime} 19,5^{\prime \prime} \mathrm{O}$, 87 m s.n.m., IAvH-Am-13890-1; 5०48'0,8" $\mathrm{N}$ y 68 $50^{\prime} 21,8^{\prime \prime} \mathrm{O}, 57$ m s.n.m., IAvH-Am-13892; $5^{\circ} 48^{\prime} 25,6^{\prime \prime} \mathrm{N}$ y $68^{\circ} 51^{\prime} 26,8^{\prime \prime} \mathrm{O}, 61$, m s.n.m., IAvHAm-13894; municipio Puerto Carreño, vereda Caño Negro, Reserva Natural Privada de la Sociedad Civil La Pedregoza, Margen derecha

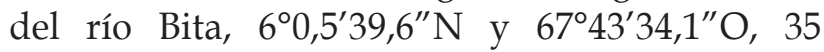
m s.n.m., IAvH-Am-11567 -9; vereda La Libertad, hacienda Mi Familia, en Morichal a 1,5 kms de la Casa, $5^{\circ} 52^{\prime} 32,3^{\prime \prime} \mathrm{N}$ y $68^{\circ} 09^{\prime} 55,3^{\prime \prime} \mathrm{O}, 62 \mathrm{~m}$ s.n.m. IAvH-Am-11846; río abajo, 5052'18.4"N y $68^{\circ} 8^{\prime} 44,5^{\prime \prime} \mathrm{O}, 60 \mathrm{~m}$ s.n.m., IAvH-Am-11898;

Andrés R. Acosta-Galvis

Colección de anfibios y reptiles, Instituto de Investigación de Recursos Biológicos Alexander von Humboldt Villa de Leyva, Boyacá, Colombia aacosta@humboldt.org.co finca la Rampa, $5^{\circ} 43^{\prime} 16,9^{\prime \prime} \mathrm{N}$ y $68^{\circ} 30^{\prime} 8,8^{\prime \prime} \mathrm{O}, 86 \mathrm{~m}$ s.n.m., IAvH-Am-13893; $5^{\circ} 45^{\prime} 22,8^{\prime \prime} \mathrm{N}$ y $68^{\circ} 29^{\prime}$ 38,8"O, 55 m s.n.m. IAvH-Am-13895; 54ㄴ $36^{\prime \prime} \mathrm{N}$ y $68^{\circ} 28^{\prime} 25,9^{\prime \prime} \mathrm{O}, 52$ m s.n.m., IAvH-Am-13896; municipio, Santa Rosalía, vereda Pavanay, hacienda La Navidad, 59'22.9” $\mathrm{N}$ y $70^{\circ} 45^{\prime} 10.1^{\prime \prime} \mathrm{O}$, 115 m s.n.m. IAvH-Am-11570-6.

Scinax $x$-signatus: COLOMBIA, departamento de Arauca, municipio Arauquita, vereda Normandia, $6^{\circ} 32^{\prime} 50^{\prime \prime} \mathrm{N}$ y $71^{\circ} 8^{\prime} 0,7^{\prime \prime} \mathrm{O}$, IAvHAm-10655; departamento del Casanare, municipio de Nunchía, vereda Vega del Tacare, finca La Esperanza, vega del río Tocaría, 450 m s.n.m. IAvH-Am-7019; departamento de Tolima, municipio Guayabal, corregimiento Méndez, Reserva de La Sociedad Civil, hacienda Jabirú, 50345.8” N y 7449³4.0”O, 289 m s.n.m., IAvH-Am-11444-6.

Una nueva rana de huesos verdes del género Scinax (Anura: Hylidae) asociada a los bosques subandinos de la cuenca del río Magdalena, Colombia

Citación del artículo: Acosta-Galvis, A. R. (2018). Una nueva rana de huesos verdes del género Scinax (Anura: Hylidae) asociada a los bosques subandinos de la cuenca del río Magdalena, Colombia. Biota Colombiana, 19 (Sup. 1): 131-159. DOI: 10.21068/c2018.v19s1a11. urn:lsid:zoobank. or g: pu b: 80 EEEE 22 - C15 A - 46 B D - B 081 EF19ABF0479F

Recibido: 10 de julio de 2017

Aprobado: 31 de octubre de 2017 


\section{Guía para autores \\ (http://revistas.humboldt.org.co/index.php/biota)}

\section{Envío del manuscrito}

El envío de un manuscrito implica la declaración explícita por parte del autor o los autores de que este no ha sido previamente publicado, ni aceptado para su publicación en otra revista u otro órgano de difusión científica. Todas las contribuciones son de la entera responsabilidad de sus autores y no del Instituto de Investigación de Recursos Biológicos Alexander von Humboldt, ni de la revista o sus editores.

Los trabajos pueden estar escritos en español, inglés o portugués, y no deben exceder las 40 páginas (párrafo espaciado a 1,5 líneas), incluyendo tablas, figuras y anexos. De particular interés para la revista son las descripciones de especies nuevas para la ciencia, nuevos registros geográficos, listados de especies temáticos o regionales, inventarios, bases de datos relacionados con biodiversidad, colecciones biológicas y reportes de muestreo.

Se reciben manuscritos que sean artículos científicos de investigación, así como notas de actualidad, reseñas, novedades bibliográficas y artículos de datos.

Los trabajos deben ser entregados a través del portal en línea (http://revistas.humboldt.org.co/index. php/biota) de la revista, siguiendo los pasos de registro como usuario. Todo el proceso editorial se desarrolla a través de esa plataforma.

\section{Evaluación del manuscrito}

Los manuscritos sometidos serán revisados por mínimo dos pares científicos calificados, cuya respuesta final de evaluación puede ser: a) publicado sin ningún cambio (se asume que no existe ningún cambio, omisión o adición al artículo, y que se recomienda su publicación en la forma actualmente presentada); b) aceptación condicional (se acepta y recomienda el artículo para su publicación solo si se realizan los cambios indicados por el evaluador, sean correcciones menores y no es necesaria una segunda re- visión o correcciones mayores y sí es necesaria una segunda revisión); y c) rechazo (cuando el evaluador considera que los contenidos o forma de presentación del artículo no se ajustan a los requerimientos y estándares de calidad de Biota Colombiana). Para proseguir con el proceso editorial para publicación, el manuscrito debe haber sido aceptado por el mínimo de dos pares científicos.

\section{Preparación del manuscrito}

Para la elaboración de los textos del manuscrito se debe usar un procesador de palabras (preferiblemente Word); los listados (a manera de tabla) deben ser elaborados en una hoja de cálculo (preferiblemente Excel). Para someter un manuscrito es necesario además anexar una carta de intención en la que se indique claramente:

1. Nombre completo del (los) autor (es), afiliaciones institucionales y direcciones para envío de correspondencia (es indispensable suministrar una dirección de correo electrónico para comunicación directa).

2. Título completo del manuscrito.

3. Nombres, tamaños y tipos de archivos suministrados.

4. Explicación concisa y clara, que no sobrepase tres líneas, explicando por qué el manuscrito en cuestión es ideal para que sea publicado en una revista como Biota Colombiana.

5. Lista mínimo de cuatro revisores sugeridos que puedan evaluar el manuscrito, con sus respectivas direcciones electrónicas.

**Para información sobre la preparación de un artículo de datos, continúe a la sección "Particularidades de los artículos de datos $\rightarrow$ Preparación de un artículo de datos" dentro de esta Guía de autores. 


\section{Lenguaje del manuscrito}

- Los manuscritos enviados a Biota Colombiana deben tener como requerimiento mínimo el uso adecuado del lenguaje en el que estén escritos, sea español, portugués o inglés, para asegurar la comunicación efectiva del artículo a los lectores.

- El estilo utilizado en el lenguaje del manuscrito enviado debe seguir las formalidades comúnmente aceptadas en escritos científicos y siempre buscar la claridad, concisión y cohesión en su expresión.

- Se sugiere utilizar guías de buena ortografía, redacción y estilo para el idioma en el que se escoja escribir.

\section{Especificaciones de formato}

- Para la presentación del manuscrito configure las páginas de la siguiente manera: hoja tamaño carta, márgenes de $2,5 \mathrm{~cm}$ en todos los lados, interlineado 1,5 y alineación hacia la izquierda (incluyendo título y bibliografía).

- Todas las páginas de texto deben numerarse en la parte inferior derecha de la hoja.

- Use letra Times New Roman o Arial, tamaño 12 puntos en todos los textos. Máximo 40 páginas, incluyendo tablas, figuras y anexos. Para tablas cambie el tamaño de la fuente a 10 puntos. Evite el uso de negritas o subrayados.

- Escriba los nombres científicos de géneros, especies y subespecies en cursiva (itálica). Proceda de la misma forma con los términos en latín (por ej. sensu, et al.). No subraye ninguna otra palabra o título. No utilice notas al pie de página.

- En cuanto a las abreviaturas y sistema métrico decimal, utilice las normas del Sistema Internacional de Unidades (SI) recordando que siempre se debe dejar un espacio libre entre el valor numérico y la unidad de medida (por ej. 16 $\mathrm{km}, 23{ }^{\circ} \mathrm{C}$ ). Para medidas relativas como $\mathrm{m} / \mathrm{seg}$., use m.seg-1.

- Escriba los números del uno al diez siempre con letras, excepto cuando preceden a una unidad de medida (por ej. $9 \mathrm{~cm}$ ) o si se utilizan como marcadores (por ej. parcela 2, muestra 7). Los números mayores a diez deben ser escritos con los símbolos numéricos arábigos. Si en el mismo párrafo se utilizan cifras menores a diez y cifras mayores a diez, se deben unificar para dejar las cifras solo con símbolos numéricos arábigos.

- No utilice punto para separar los millares, millones, etc (por ej. 54000). Utilice la coma para separar en la cifra la parte entera de la decimal (por ej. 3,1416) cuando el texto es en español. En el caso del inglés, los decimales se separan con puntos (por ej. 3.1416). Enumere las horas del día de 0:00 a 24:00.

- Exprese los años con todas las cifras sin demarcadores de miles (por ej. 1996-1998). En español los nombres de los meses y días (enero, julio, sábado, lunes) siempre se escriben con la primera letra minúscula, en inglés se escriben con la primera letra mayúscula (January, July, Saturday, Monday).

- Los puntos cardinales (norte, sur, este y oeste) en español siempre deben ser escritos en minúscula, a excepción de sus abreviaturas N, S, E, O (en inglés $W$ ), y cuando son referidos como puntos o hacen parte de un nombre propio (p.e. cordillera Oriental). La indicación correcta de coordenadas geográficas es como sigue: $02^{\circ} 37^{\prime} 53^{\prime \prime} \mathrm{N}-$ $56^{\circ} 28^{\prime} 53^{\prime \prime} \mathrm{O}$. La altitud geográfica se citará como se expresa a continuación: 1180 m s.n.m. y en inglés $1180 \mathrm{~m}$ a.s.l.

- Las abreviaturas se deben explicar la primera vez que son usadas.

- Al citar las referencias en el texto, siga las normas APA (Manual de Publicaciones de la American Psychological Association, Sexta Edición). Incluya los apellidos de los autores en caso de que sean uno o dos, y el apellido del primero seguido por et al. (en cursiva) cuando sean tres o más. En el caso de dos autores, los apellidos deben ser separados por la palabra "y" (por ej. Cochran y Goin, 1970). En inglés, los apellidos deben estar separados por " $\&$ ". Si menciona varias referencias, éstas deben ser ordenadas cronológicamente y separadas por punto y coma (por ej. Rojas, 1978; Bailey et al., 1983; Sephton, 2001, 2001). Inserte una coma después de los nombres de los autores y antes del año de la referencia (Acevedo, 2009). 
- Las referencias que son autoridad taxonómica de descripción no deben ser incluidas en la lista de referencias al final pero sí en el texto.

- Refiera las figuras (gráficas, diagramas, ilustraciones y fotografías) sin abreviación (por ej. Figura 3) al igual que las tablas (por ej. Tabla 1). Gráficos y figuras deben presentarse con tipo y tamaño de letra uniforme.

- Las figuras deben ser nítidas y de buena calidad, evitando complejidades innecesarias (por ej. tridimensionalidad en gráficos de barras, marcos o efectos tridimensionales); si es posible use solo colores sólidos en lugar de tramas. Las letras, números o símbolos de las figuras deben ser de un tamaño adecuado de manera que sean claramente legibles una vez reducidas.

- Cada figura debe estar insertada en el texto, y adicionalmente se debe enviar su archivo aparte en alta calidad en el paso de "Cargar los archivos complementarios". Para el caso de las fotografías y figuras digitales es necesario que estas sean guardadas como formato tiff, jpg o png con una resolución de 300 dpi.

- Las tablas y anexos deben ser simples en su estructura (marcos) y estar unificados. Haga las llamadas a pie de página de tabla con letras ubicadas como superíndice. Evite tablas grandes sobrecargadas de información y líneas divisorias o presentadas en forma compleja.

\section{Secciones del manuscrito}

** Para información sobre las secciones de un artículo de datos, continúe a la sección "Particularidades de los artículos de datos $\rightarrow$ Secciones de un artículo de datos" dentro de esta Guía de autores.

- Los manuscritos deben llevar el siguiente orden: título, resumen y palabras clave, abstract y keywords, introducción, materiales y métodos, resultados, discusión, conclusiones (optativo), agradecimientos (optativo) y referencias. Seguidamente, presente una página con la lista de tablas, figuras y anexos.

- Las secciones del manuscrito en el texto deben ir en negrilla, con solo la primera letra en mayúscula. Si necesita agregar subtítulos a las secciones, estos deben ir en la misma línea en la que comienza el texto del párrafo, separados por un punto del resto del texto, y en negrilla.

Título: conciso y explicativo, debe informar sobre el contenido del manuscrito.

Resumen: da un resumen de máximo 200 palabras sobre el manuscrito, en el que se debe incluir el objetivo, métodos, resultados y conclusiones principales del manuscrito. Si se presenta algo que sea novedoso o excepcional, se debe hacer mención aquí. El resumen se debe escribir en dos idiomas (español o portugués y abstract en inglés).

Palabras clave: máximo cinco palabras clave, complementarias al título del artículo, en español o portugués e inglés, separadas por un punto entre cada término. Deben presentarse en orden alfabético. Se sugiere el uso de tesauros temáticos para encontrar sinónimos y términos adecuados.

Introducción: presenta el tema y da el contexto necesario para el desarrollo del manuscrito. El propósito u objetivo principal del trabajo debe hacerse explícito en esta sección.

Materiales y métodos: hace una descripción detallada del procedimiento, incluyendo los materiales, lugar, fechas, métodos estadísticos, etc. que se utilizaron en el trabajo. Debe ser lo suficientemente completo para que otros investigadores puedan replicar el trabajo y si se usa una metodología novedosa debe explicarse y sustentarse.

Resultados: presenta los hallazgos del trabajo de manera organizada y con uso adecuado de figuras. Evitar la inclusión de tablas muy extensas en esta sección y más bien incluir como anexos si es el caso.

Discusión: se destacan los puntos más relevantes, polémicos o novedosos del trabajo y se explican los resultados principales en relación a la importancia o aportes del trabajo en su área.

Conclusiones: reflexiones finales sobre el trabajo con relación a su propósito y objetivos, frecuentemente direccionando hacia acciones e investigaciones futuras.

Agradecimientos: Párrafo sencillo y conciso entre el texto y la lista de referencias. Mencione fuentes 
de financiación o apoyo que recibió el proyecto. Evite títulos como Dr., Lic., TSU, etc.

Referencias: La revista sigue las normas de citación APA (Manual de Publicaciones de la American Psychological Association, Sexta Edición). La lista de las referencias contiene únicamente aquellas citadas en el texto. Ordénelas alfabéticamente por autores y cronológicamente para un mismo autor. Si hay varias referencias de un mismo autor(es) en el mismo año, añada las letras a, b, c, etc. al año. No abrevie los nombres de las revistas. Incluya todos los autores de la referencia. Presente las referencias al final del manuscrito.

\section{Ejemplos de citación}

\section{Artículo en revistas:}

Antonelli, A., Nylander, J. A., Persson, C. y Sanmartín, I. (2009). Tracing the impact of the Andean uplift on Neotropical plant evolution. Proceedings of the National Academy of Sciences, 106(24): 9749-9754.

\section{Libros:}

Gutiérrez, F. P. (2010). Los recursos hidrobiológicos $y$ pesqueros en Colombia. Bogotá: Instituto de Investigación de Recursos Biológicos Alexander von Humboldt. 118 pp.

\section{Tesis:}

Cipamocha, C. A. (2002). Caracterización de especies y evaluación trófica de la subienda de peces en el raudal Chorro de Córdoba, bajo río Caquetá, Amazonas, Colombia. (Trabajo de grado). Bogotá D. C.: Universidad Nacional de Colombia, Facultad de Ciencias, Departamento de Biología. 160 pp.

\section{Informes técnicos:}

Andrade, G. I. (2010). Gestión del conocimiento para la gestión de la biodiversidad: bases conceptuales y propuesta programática para la reingeniería del Instituto Humboldt. (Informe técnico). Bogotá D. C.: Instituto de Investigación de Recursos Biológicos Alexander von Humboldt. 80 pp.

\section{Capítulo en libro o en informe:}

Fernández F., Palacio, E. E. y MacKay, W. P. (1996). Introducción al estudio de las hormigas
(Hymenoptera: Formicidae) de Colombia. En Amat, G. D., Andrade, G. y Fernández, F. (Eds.). Insectos de Colombia. Estudios Escogidos. Pp: 349-412. Bogotá: Academia Colombiana de Ciencias Exactas, Físicas y Naturales y Centro Editorial Javeriano.

\section{Resumen en congreso, simposio, talleres:}

Señaris, J. C. (2001). Distribución geográfica y utilización del hábitat de las ranas de cristal (Anura; Centrolenidae) en Venezuela. Trabajo presentado en Programa y Libro de Resúmenes del IV Congreso Venezolano de Ecología, Mérida, Venezuela. p. 124.

\section{Ley o Decreto:}

Congreso de Colombia. (8 de febrero de 1994) Ley General de Educación. [Ley 115 de 1994]. DO: 41.214.

\section{Páginas web:}

No serán incluidas en la lista de referencias, sino que se señalan claramente en el texto al momento de mencionarlas.

\section{Particularidades de los artículos de datos}

Un Artículo de Datos o Data Paper es un tipo de publicación académica que surgió como un mecanismo para incentivar la publicación de datos sobre biodiversidad. Es un medio para generar reconocimiento académico y profesional adecuado a todas las personas que intervienen, de una manera u otra, en la gestión de información sobre biodiversidad, y además sirve para destacar la existencia y relevancia de los conjuntos de datos frente el resto de la comunidad científica.

Como su nombre lo sugiere, este tipo de artículos se basan en la descripción de un conjunto de datos primarios, y aunque no es una investigación científica sensu stricto, se espera que contengan información acerca de la historia del conjunto de datos (propósito del mismo, metodología sobre la toma de los datos, financiadores, coberturas taxonómicas y geográficas, etc.) y sobre su valor y utilidad (básica o aplicada) para la comunidad científica (Chavan y Penev, 2011) ${ }^{1}$. Lo novedoso y ventajoso de este mo-

\footnotetext{
${ }^{1}$ Chavan, V. y Penev, L. (2011). The data paper: The mechanism to incentivize data publishing in biodiversity science. BMC Bioinformatics 2011, 12(Sup. 15): S2
} 
delo de publicación es que el manuscrito siempre está vinculado al conjunto de datos, a través de un enlace a un repositorio web persistente y confiable, el IPT (Integrated Publishing Toolkit). Adicionalmente los metadatos que describen ese conjunto de datos y que están documentados en la misma herramienta, deben citar el artículo de datos.

Se recomienda someter un artículo de datos, cuando los datos a los que hace referencia son primarios, originales y están restringidos temporal y metodológicamente, se encuentran disponibles en agregadores de datos como el SiB Colombia y GBIF, y pueden ser estructurados con el estándar Darwin Core (DwC) como en el caso de:

- Observaciones de un proyecto particular

- Colecciones biológicas

- Listados de especies

- Datos genómicos

- Eventos de muestreo

- Inventarios

- Bases de datos

- Rasgos funcionales

Los conjuntos de datos que no cumplan estas características, no serán aceptados para publicación como artículo de datos. Tal es el caso de compilaciones de registros biológicos de fuentes secundarias (por ej., literatura).

\section{Preparación de un artículo de datos (publicación de datos y creación del manuscrito)}

Un artículo de datos busca describir todos los tipos de recursos de datos sobre biodiversidad. De esta manera, el artículo de datos siempre está enlazado al conjunto de datos que describe a través de una URL o DOI.

A continuación encontrará el procedimiento de cómo generar y someter un manuscrito para artículo de datos usando las herramientas y modelo de publicación del SiB Colombia. Cabe resaltar que la revista también recibe artículos de datos que tengan conjuntos de datos publicados en otras plataformas reconocidas, siempre y cuando cuenten con los requisitos de ser repositorios confiables y tengan un enlace IPT disponible. Igualmente, las secciones de los manuscritos enviados deben seguir las enunciadas en la Tabla 1.

Los artículos de datos, como los demás tipos de manuscritos enviados a la revista, serán sometidos a evaluación por pares y deben cumplir las mismas especificaciones de formato, normas de citación y uso del lenguaje, además de incluir una carta de intención, como se menciona en esta Guía de autores. Adicionalmente, durante la evaluación del manuscrito, los datos descritos deben estar disponibles en línea de manera abierta en un repositorio público y con una licencia robusta de atribución y uso.

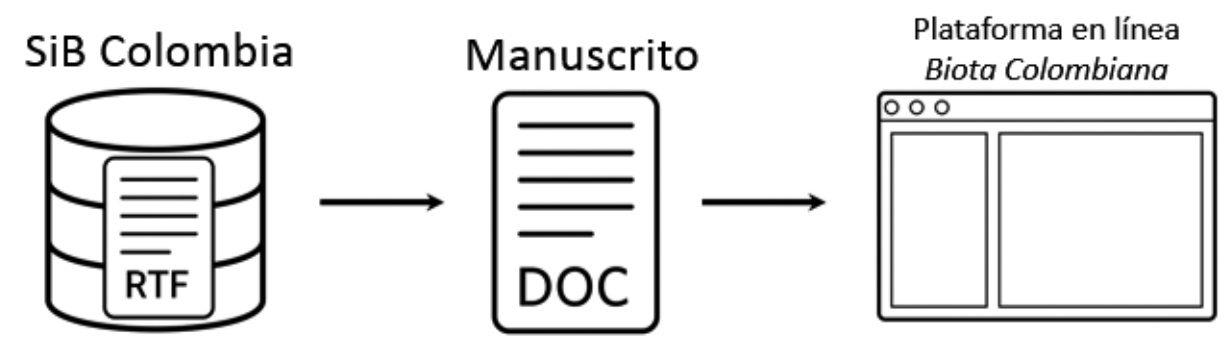

Figura 1. Proceso general de sometimiento de un artículo de datos desde el SiB Colombia a la revista Biota Colombiana. 
Paso 1.

Publicación de los datos a través del SiB Colombia

El SiB Colombia cuenta con un modelo de publicación de datos que hace uso del IPT como herramienta. Desde el IPT, es posible generar una primera versión del manuscrito a partir de los metadatos en formato de texto enriquecido (RTF), siempre $y$ cuando el conjunto de datos respectivo ya haya sido indexado por el SiB Colombia y cuente con los metadatos suficientes (el proceso de publicación de datos a través del SiB Colombia puede ser consultado en https://www.sibcolombia.net/).

A. Registro de organización. Para poder publicar a través del SiB Colombia, es necesario que la organización esté registrada como socio publicador. Se puede comprobar en este enlace si ya es así. En caso contrario, es muy sencillo hacer parte de la red de socios, solo se debe diligenciar el Formulario de Registro.

B. Estandarización de datos. Los datos se deben estructurar en una tabla plana haciendo uso del estándar Darwin Core (DwC). Para esto, se puede descargar la plantilla que se adapte a el tipo de datos o generar una plantilla a través del Generador de Plantillas Excel.

C. Calidad de sus datos. Se debe verificar y mejorar la calidad de los datos haciendo uso de herramientas para identificar, limpiar y corregir posibles errores geográficos, taxonómicos o de formato, entre otros.

D. Cargar datos en línea. El IPT es una herramienta que facilita compartir diferentes tipos de datos relacionados con la biodiversidad siempre y cuando estos se encuentren estructurados según el estándar DwC. Para cargar datos en el IPT, debe contar con una cuenta de usuario en uno de los IPT disponibles por el SiB Colombia. Si aún no se tiene una cuenta, puede contactar al Equipo Coordinador del SiB Colombia (EC-SiB) y solicitarla a través del correo electrónico sib@humboldt.org.co.

E. Mapear datos. Una vez se haya cargado el conjunto de datos, se debe verificar que estén siendo leídos en correspondencia con los elementos DwC. El manual de usuario del IPT está disponible para más información o se puede contactar al EC-SiB.
F. Creación de metadatos. La estructura de los metadatos se parece en gran medida a un artículo de investigación tradicional. Estos metadatos mantienen la estructura general de un artículo de datos y facilitan la generación del mismo. En la sección Metadatos del IPT, se debe documentar toda la información que permite dar un contexto a los datos. En total hay 12 secciones para ingresar información que describe el conjunto de datos. El manual de usuario del IPT está disponible para más información o se puede contactar al EC-SiB.

G. Publicar el recurso y notificar al EC-SiB. Una vez completados los pasos anteriores, el IPT activará la opción 'Publicar'. Se debe hacer clic en este botón y enviar un correo a sib@humboldt.org.co para notificar al EC-SiB de su publicación. El correo debe tener como asunto "Recurso publicado" y contener:

- Nombre

- Nombre de organización

- Nombre del recurso publicado

- URL de la vista general del recurso después de publicado

En este punto los datos serán indexados por el SiB Colombia y GBIF, y contarán con un identificador persistente DOI.

\section{Paso 2}

Generación del manuscrito para artículo de datos usando el IPT

El IPT en el cual ha sido publicado el conjunto de datos permite generar un manuscrito RTF que describe al conjunto de datos. El enlace al conjunto de datos aparecerá en el manuscrito bajo el título "Data published through GBIF". A continuación se describe el paso a paso para generar el manuscrito desde los metadatos del conjunto de datos publicado a través del SiB Colombia.

- En la página principal del recurso publicado a través del IPT, se debe hacer clic sobre el botón RTF para descargar una versión del manuscrito en texto enriquecido que se puede abrir en cualquier procesador de texto (por ej: Word) (Figura 2). 


\section{Escarabajos coprófagos de la cuenca alta y media del río Bita, Vichada} (Colombia)

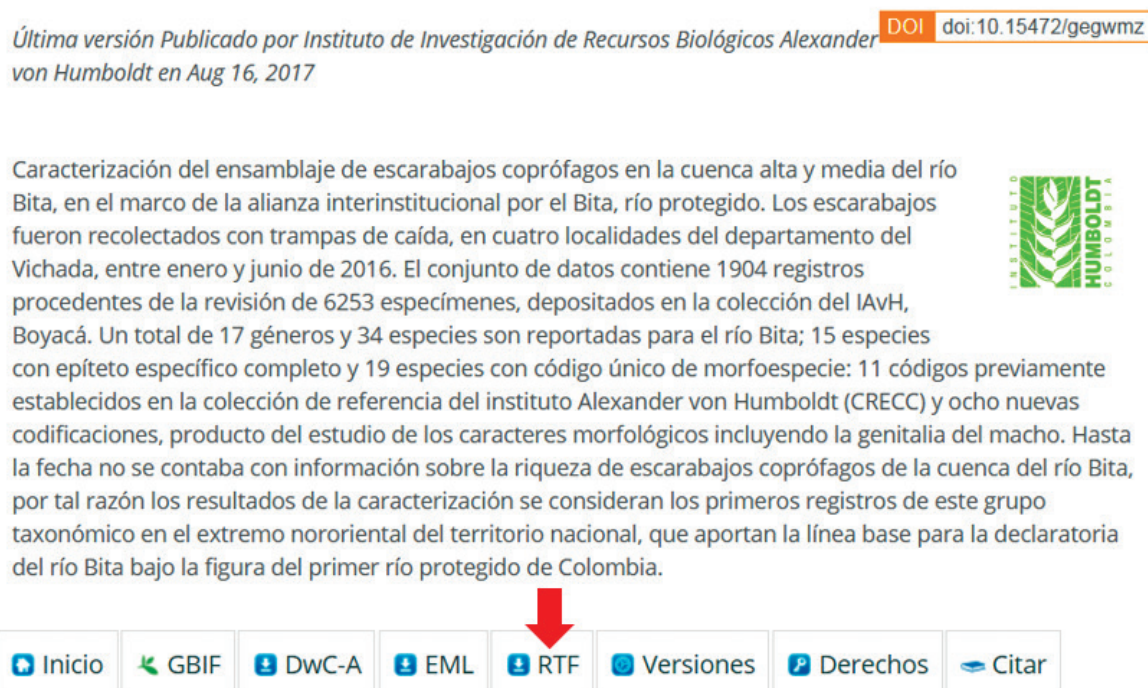

Figura 2. Los metadatos de una conjunto de datos, pueden ser descargados del IPT como archivo RTF, la primera versión del manuscrito para someter a la revista.

- El manuscrito descargado se encuentra en inglés. Los ajustes necesarios de acuerdo a los lineamientos de la revista Biota Colombiana deben ser realizados y la plantilla para artículos de datos se puede descargar aquí.

- Una vez ajustado el manuscrito con los textos adicionales, tablas y figuras, puede ser sometido a evaluación a través del portal en línea de la revista, siguiendo los pasos de registro como usuario. Todo el proceso editorial se desarrolla a través de esa plataforma.

\section{Paso 3}

\section{Ajustes y correcciones del manuscrito para artículos de datos}

Cuando el manuscrito ha sido sometido a evaluación, este se somete a revisión por pares evaluadores de acuerdo a los lineamientos establecidos por la revista para evaluadores de artículos de datos.

Después de evaluado, y en caso de ser aceptado, el manuscrito será devuelto al autor con los comentarios de los revisores y del editor de la revista con el objetivo de realizar las modificaciones antes de publicar. Como autor, deberá realizar todas las correcciones o adiciones recomendadas directamente en los metadatos del IPT y no en el manuscrito del artículo de datos. De esta forma se mejoran también los metadatos del conjunto de datos sometido.

Una vez se hayan mejorado los metadatos en el IPT, se debe actualizar la publicación del recurso para que los cambios se vean reflejados. En la página principal del recurso publicado a través del IPT, ubique el botón RTF y haga clic sobre el mismo para descargar una versión mejorada del manuscrito en texto enriquecido que puede abrir nuevamente en cualquier procesador de texto (por ej. Word).

Después de la re-inserción manual de los textos adicionales y asegurarse que esta versión cumple con los requerimientos de la revista, el manuscrito debe ser enviado nuevamente a la revista.

\section{Secciones de un artículo de datos}

A diferencia de los otros tipos de manuscritos que pueden ser sometidos a la revista Biota Colombiana, los artículos de datos incluyen las secciones estipuladas en la Tabla 1. 
Tabla 1. Estructura del artículo de datos y su correspondencia con los elementos del GMP incorporados en el IPT.

\section{Correspondencia con los elementos del IPT}

Nombre de la sección

\section{Título}

Autores

Afiliaciones

Autores de contacto
Derivado del elemento Título. Centrado sin punto al final.

Derivado de los elementos Creador del recurso, Proveedor de los metadatos y Partes asociadas. De estos elementos, se deriva la combinación nombre y apellido separados por comas. Las afiliaciones de los autores se indican con números $(1,2,3 \ldots)$ al final de cada apellido como superíndice. Centrado.

Derivado de los elementos Creador del recurso, Proveedor de los metadatos y Partes asociadas. De estos elementos, la combinación de organización, dirección, código postal, ciudad, país y correo electrónico, constituyen la afiliación. Si dos o más autores comparten la misma afiliación, se indica con el mismo número.

Derivado de los elementos Creador del recurso y Proveedor de los metadatos. De estos elementos, se deriva la combinación nombre, apellido y correo electrónico. Los correos electrónicos son escritos en paréntesis. Si hay más de un autor como contacto, estos van separados por comas. Si el Creador del recurso y Proveedor de los metadatos es el mismo autor, el Creador del recurso se refleja como el autor de contacto. Texto centrado.

Insertadas manualmente por el Editor Asistente de la revista para indicar las fechas de presentación original del manuscrito, revisión, aceptación y publicación como un artículos de datos en Biota Colombiana.

Fechas de recibido, revisado, aceptado y publicado

\section{Resumen}

Derivado del elemento descripción. El resumen debe incluirse tanto en español o portugués como inglés.

Derivadas del elemento palabras claves. Las palabras van separadas por comas. Las palabras deben estar escritas tanto en español o portugués como inglés.

Palabras Clave

Introducción No se deriva de ningún elemento del GMP y debe ser adicionada manualmente.

Cobertura taxonómica

Derivada de los elementos de la sección cobertura taxonómica: descripción, nombre científico, nombre común y categoría.

Cobertura geográfica

Derivada de los elementos de la sección cobertura geográfica: descripción, latitud mínima, latitud máxima, longitud mínima, longitud máxima.

Cobertura temporal

Derivada de los elementos de la sección cobertura temporal: fecha inicial y fecha final.

Derivada de los elementos de la sección datos del proyecto: título, persona del proyecto, fuentes de financiación, descripción del área de estudio y descripción del diseño.

Descripción del proyecto

Derivada de los elementos de la sección datos de la colección: nombre de la colección,

Descripción de la colección biológica

identificador de la colección, identificador de la colección parental, método de preservación de los especímenes y unidades curatoriales.

Derivado de los elementos de la sección métodos de muestreo: área de estudio, descripción del muestreo, control de calidad, descripción del paso metodológico.

\section{Materiales y métodos}

\section{Resultados}

$--$

Derivado de los elementos de la sección enlaces externos entre otros: nombre, conjunto de caracteres, URL del archivo, formato del archivo, versión del formato del archivo, fecha de publicación, idioma, derechos de propiedad intelectual. Puede adicionar manualmente una descripción adicional de los datos como texto, figuras y tablas.

Información adicional

Derivado del elemento información adicional.

Discusión

No se deriva de ningún elemento del GMP y debe ser adicionada manualmente, enfocada en el potencial de uso de los datos en investigación, educación o toma de decisiones.

Agradecimientos

Referencias

No se deriva de ningún elemento del GMP y debe ser adicionada manualmente.

Derivado del elemento referencia en bibliografía. 


\section{Guidelines for authors}

\section{(http:// revistas.humboldt.org.co/index.php/biota)}

\section{Submitting a manuscript}

Submitting a manuscript implies the explicit statement by the author(s) that the paper has not been published before, nor accepted for publication in another journal or other means of scientific diffusion. Contributions are entire responsibility of the author(s) and not the Research Institute of Biological Resources Alexander von Humboldt, or the journal and their editors.

Papers can be written in Spanish, English or Portuguese, and should not exceed the maximum length of 40 pages (with paragraph lines spaced at 1.5) including tables, figures and appendices. Of particular interest for this journal are descriptions of new species for science, new geographic records, thematic or regional species lists, inventories, databases related to biodiversity, biological collections and sampling reports.

Biota Colombiana receives scientific research articles, as well as notes, reviews, bibliographic novelties and data papers.

Manuscripts must be submitted through the online platform of the journal (http://revistas.humboldt. org.co/index.php/biota) as a registered user. The complete editorial process is managed in this platform.

\section{Evaluation}

Submitted manuscripts will be reviewed by at least two qualified scientific peers. Results of the peer revisions may include any of the following: a) accepted (in this case it is assumed that no change, omission or addition to the article is required and may be published as presented.); b) conditional acceptance (the article is accepted and recommended for publication only if indicated corrections are made; corrections may be minor and a second evaluation is not necessary or major and a second evaluation is necessary); and c) rejected (reviewer considers that the contents and/or form of the paper are not in accordance with requirements of publication standards of Biota Colombiana). For a manuscript to continue its editorial process, it must have been accepted by at least two reviewers.

\section{Preparation of Manuscript}

Any word-processor program may be used to write the text of the manuscript (Word is recommended). Lists or any other type of table must be presented in spreadsheets (Excel is recommended). To submit a manuscript, a cover letter that clearly indicates the following must be sent:

1. Full names, institutional filiations, and e-mail addresses of all authors. (Please note that email addresses are essential to direct communication)

2. Complete title of the article

3. Names, sizes and types of files provided.

4. Concise and clear sustentation of why the presented manuscript is in concordance with the type of articles published in the journal. Such explanation must not surpass a maximum of three lines.

5. List of the names and e-mail addresses of at least four peers who are qualified to review the manuscript.

\footnotetext{
**For information regarding the preparation of data papers, continue to "Details for Data Papers-> Preparation of Data Paper"
} 


\section{Use of Language}

- Manuscripts that are sent to Biota Colombiana have as a minimum requirement for consideration the appropriate use of language in writing, regardless if they are presented in Spanish, Portuguese or English.

- The style should follow the common formalities of scientific writing and be clear, concise and cohesive.

- The use of guides for correct spelling, grammar and style is recommended.

\section{Format}

- Texts must follow the format of standard letter size paper, with $2.5 \mathrm{~cm}$ margins on all sides, 1.5-spaced and left-aligned paragraphs (including title and bibliography).

- All pages must be numbered in the lower right corner.

- Font must be Times New Roman or Arial, size 12, in all parts of the text, except tables (size 10). Manuscript must not exceed a maximum length of 40 pages, including tables, figures and appendices. Avoid the use of bold or underlined font.

- Scientific names of genera, species and subspecies must be in italics, as well as Latin technical terms (i.e sensu, et al.). Avoid underlining any word or title. Do not use footnotes.

- For abbreviations and the metric system, use the standards of the International System of Units (SI). Leave a space between the numeric value and the measure unit (p.e. $16 \mathrm{~km}, 23{ }^{\circ} \mathrm{C}$ ). For relative measures such as $\mathrm{m} / \mathrm{sec}$, use $\mathrm{m} . \mathrm{sec}-1$.

- Write the numbers between one to ten in letters except when it precedes a measure unit (p.e. $9 \mathrm{~cm}$ ) or is used as a marker (p.e. lot 2, sample 7). Numbers greater than ten must be written in Arabic numerals. If in the paragraph both numbers lesser than ten and greater than ten appear, all should be written in Arabic numerals.

- Thousands, millions, etc. should not be separated by commas nor periods (p. e. 54000). Use periods to separate decimals (p. e. 3.1416). In Spanish, use commas to separate decimals (p. e. 3,1416). Hours should be represented in military time from 0:00 to $24: 00$.

- Years should be written without commas or periods (p. e. 1996-1998). In English months and days of the week are capitalized (January, July, Saturday, Monday), whereas in Spanish the first letter of months and days of the week are written with lower-case letters (enero, julio, sábado, lunes).

- Cardinal points (north, south, east and west) must be written in lower case letters, and only be capitalized if used in abbreviation N, S, E, W (O in Spanish) or as part of a proper name ( $p$. e. North Carolina). Correct use of coordinates is: $02^{\circ} 37^{\prime} 53^{\prime \prime} \mathrm{N}-56^{\circ} 28^{\prime} 53^{\prime \prime} \mathrm{O}$. Altitude should be expressed as $1180 \mathrm{~m}$ a.s.l. and $1180 \mathrm{~m}$ s.n.m. in Spanish.

- All abbreviations must be explained the first time they are used.

- When citing in-text references, follow APA citation norms (American Psychological Association Publications Manual, Sixth Edition). Include last names of authors if there are only one or two authors, or the first author followed by et al. (in italics) if there are three or more authors. In the case of two authors, last names must be separated by "\&" (p. e. Cochran \& Goin, 1970). In Spanish, last names of two authors must be separated by " $y$ ". If many references are cited, they must be ordered chronologically and separated by semicolons (p. e. Rojas, 1978; Bailey et al., 1983; Sephton, 2001, 2001). Notice that a comma must be inserted after the authors and before the year (Acevedo, 2009).

- Taxonomic references must not be included in the final list of Literature cited, but they must appear in the text of the manuscript.

- Refer to all figures (graphs, diagrams, illustrations, photos) and tables without abbreviation (p. e. Figure 3, Table 1). All figures and tables should have uniformity in font and letter size. 
- Figures must be clear and have a good quality. Unnecessary complexities (such as 3D effects, frames, etc.) should be avoided. If possible, only use solid colors instead of textures. Letters, numbers or symbols must be in legible sizes.

- All figures must be inserted in the text of the manuscript and sent in a separate file in high quality in the step of "Charge complementary files". For photos and digital figures, files must be in tiff, jpg or png format in a resolution not lower than $300 \mathrm{dpi}$.

- Tables and appendices must have a simple and uniform structure. Footnotes in tables must be as superscript letters. Avoid extensive tables with too much information and dividing lines.

\section{Parts of the Manuscript}

** For information about the parts of data papers, continue to "Details for Data Papers -> Parts of Data Paper".

- Submitted manuscripts must contain the following sections: title, abstract and keywords in English and Spanish, Introduction, Materials and methods, Results, Discussion, Conclusions (optional), Acknowledgements (optional) and Literature cited. At the end of the manuscript, include a list with the tables, figures and appendices.

- Sections subtitles must be written in bold, with only the first letter capitalized. If sections have subtitles, they must be written in bold in the first line of the paragraph, separated by a period from the beginning of the paragraph.

Title: concise and explanatory, must clearly communicate what will be found in the article.

Abstract: a summary of the article, with a maximum length of 200 words. It must include the objectives, methods, results and major conclusions of the study. If the article has a novel or extraordinary finding, it must be highlighted in this section. Abstracts must be written in two languages: Spanish or Portuguese, and English.
Keywords: up to five keywords. They must be complementary to the title (not repeated) and written in Spanish or Portuguese, and English. Words must be separated by periods and presented in alphabetical order. The use of thesaurus to find appropriate synonyms is recommended.

Introduction: presentation of the topic, with enough context to support the rest of the article. The main purpose or objective of the study must be made explicit in this section.

Materials and methods: a detailed description of the procedure, with materials, location, dates, statistics, etc. This description must be sufficiently detailed so that other researchers may replicate the study. If a novel procedure is used, it must be thoroughly explained.

Results: presents major findings in an organized and appropriate manner. Avoids the use of excessively long tables.

Discussion: most relevant, troublesome or novel points of the study are highlighted, and major results are explained in relation to the importance of the study and contributions to its field.

Conclusions: final reflections about the study, with a clear relation to its purpose and objectives, frequently pointing towards future actions and research.

Acknowledgements: Straightfoward and short paragraph between text of manuscript and Literature cited. Mention funding or support of the project. Avoid titles such as Dr., Lic., etc.

Literature cited: Follow APA citation norms (American Psychological Association Publications Manual, Sixth Edition). List of references must only include those that are cited within the text. Order the references in alphabetical order, and chronologically in the case of a sole author. If there are many references of a same author (s) in the same year, add letters a, b, c, etc. to the year. Do not abbreviate names of journals. Include all authors. This section must be at the end of the manuscript. 


\section{Citation examples}

\section{Article in journals:}

Antonelli, A., Nylander, J. A., Persson, C. \& Sanmartín, I. (2009). Tracing the impact of the Andean uplift on Neotropical plant evolution. Proceedings of the National Academy of Sciences, 106(24): 9749-9754.

\section{Books:}

Gutiérrez, F. P. (2010). Los recursos hidrobiológicos $y$ pesqueros en Colombia. Bogotá: Instituto de Investigación de Recursos Biológicos Alexander von Humboldt. 118 pp.

\section{Thesis:}

Cipamocha, C. A. (2002). Caracterización de especies y evaluación trófica de la subienda de peces en el raudal Chorro de Córdoba, bajo río Caquetá, Amazonas, Colombia. (Thesis). Bogotá D. C.: Universidad Nacional de Colombia, Facultad de Ciencias, Departamento de Biología.

\section{Technical reports:}

Andrade, G. I. (2010). Gestión del conocimiento para la gestión de la biodiversidad: bases conceptuales y propuesta programática para la reingeniería del Instituto Humboldt. (Technical report). Instituto de Investigación de Recursos Biológicos Alexander von Humboldt. Bogotá D. C., 80 pp.

\section{Book or report chapter:}

Fernández F., Palacio, E. E. \& MacKay, W. P. (1996). Introducción al estudio de las hormigas (Hymenoptera: Formicidae) de Colombia. In Amat, G. D., Andrade, G. \& Fernández, F. (Eds.). Insectos de Colombia. Estudios Escogidos. Pp: 349-412. Bogotá: Academia Colombiana de Ciencias Exactas, Físicas y Naturales \& Centro Editorial Javeriano.

\section{Congress, symposium or workshop summary:}

Señaris, J. C. (2001). Distribución geográfica y utilización del hábitat de las ranas de cristal (Anura; Centrolenidae) en Venezuela. Presented in Programa y Libro de Resúmenes del IV Congreso Venezolano de Ecología, Mérida, Venezuela. p. 124.

\section{Law or decree:}

Congreso de Colombia. (February 8th 1994) Ley General de Educación. [Ley 115 de 1994]. DO: 41.214.

\section{Web pages:}

Must be clearly included in the text of the manuscript, but not be included in Literature cited section.

\section{Details for Data Papers}

A Data Paper is a type of scientific publication that was designed to stimulate the publication of biodiversity data. Data Papers give academic and professional acknowledgement to those who intervene, in one way or another, in the management of information about biodiversity, as well as highlight the existence and importance of data sets to the rest of the scientific community.

As its name suggests, a Data Paper describes a primary data set. Although a Data Paper is not, strictly speaking, a scientific investigation, it must contain relevant information about the data set (objectives, methods for data collection, funding, taxonomic and geographic coverage, etc.), along with its value and utility (basic or applied) for the scientific community (Chavan \& Penev, 2011) ${ }^{1}$. The great advantage and novelty of this type of manuscript is that it is linked to the data set through a stable and trustworthy repository, the IPT (Integrated Publishing Toolkit). Also, the data set is supported by metadata also available through the IPT and linked to the Data Paper.

A Data Paper must be submitted only when the linked data are primary and original data that have a temporal and methodological restriction and are available in data aggregators such as $\underline{\mathrm{SiB} \text { Colombia }}$ and GBIF. Data must be able to follow the Darwin Core $(\mathrm{DwC})$ standard. Examples of such data sets include:

- Project observations

- Biological collections

- Species lists

\footnotetext{
${ }^{1}$ Chavan, V. y Penev, L. (2011). The data paper: The mechanism to incentivize data publishing in biodiversity science. BMC Bioinformatics 2011, 12(Sup. 15): S2
} 
- Genomic data

- Samples

- Inventories

- Databases

- Functional traits

Data sets that do not comply with the characteristics mentioned above will not be accepted for publication as a Data Paper. Such is the case of compilations of biological records that come from secondary sources (p. e. from published literature).

\section{Preparation of Data Paper (publication of data and creation of manuscript)}

Since the purpose of a Data Paper is to describe all available data resources regarding biodiversity, it must always be linked to the data set it describes through an URL or DOI.

Information about how to generate and submit a manuscript in order for it to be considered as a Data Paper by using the tools and publication model of SiB Colombia is found below. It must be noted, however, that Biota Colombiana also accepts Data Papers that link to data sets published in other known platforms as long as it is linked to a trustworthy repository and has an IPT link. The parts of a Data Paper manuscript are described in Table 1.
As other types of manuscripts that are submitted to the journal, Data Papers will be reviewed by peers and must comply with the same format specifications, citation norms and use of language. Similarly, Data Papers must also be presented with a cover letter, as mentioned in the present Guidelines for authors. Have in mind that as soon as the manuscript is submitted and under evaluation, described data must be available in a public online repository with an adequate license of use and attribution.

\section{Step 1}

\section{Data publication in SiB Colombia}

$\mathrm{SiB}$ Colombia uses a publication model pased on the IPT as its working tool. Using the IPT, the first version of the manuscript may be generated in rich text format (RTF), based on its associated metadata. This tool is available as long as the data set has been indexed by $\mathrm{SiB}$ Colombia and sufficient metadata are linked (more information on publication process of $\mathrm{SiB}$ Colombia may be consulted in https://www.sibcolombia.net/).

A. Registration of organisation. To publish through SiB Colombia, your organisation must be registered as a publishing partner. Consult this link to find already registered organisations. If your organisation is not registered, adding an organisation is easy through the Registration Format.

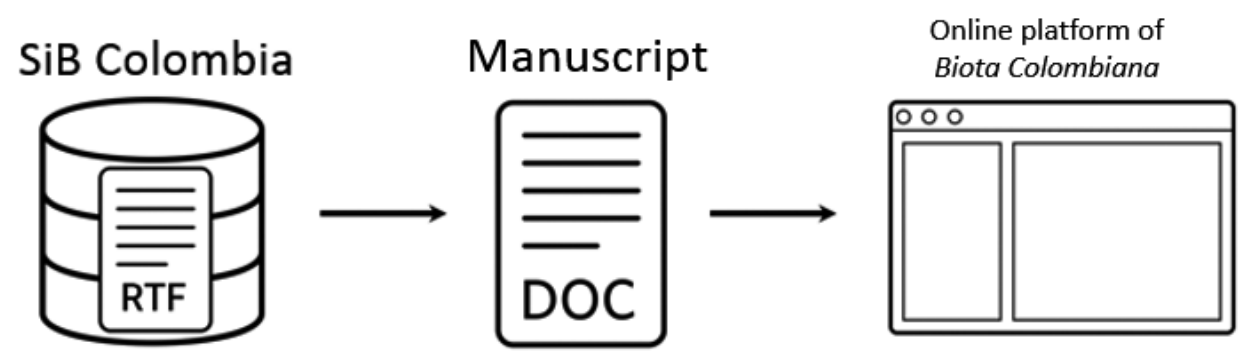

Figura 1. General process to submit a Data Paper from SiB Colombia to the journal Biota Colombiana. 
B. Data standardization. Data must be structured in a table using the Darwin Core $(\mathrm{DwC})$ standard. Download respective template that is appropriate for type of data or generate your template.

C. Data quality. Data quality must be verified and improved using available tools to identify and correct possible geographical, taxonomic or format errors, among others.

D. Online upload of data. IPT is a tool that shares different types of biodiversity data as long as data is structured using DwC standard. To upload data to the IPT, you must have an existing user account in the available IPT of SiB Colombia. If you do not have an account, you may contact the SiB Colombia Coordinating Team (EC-SiB) and request an account to the email address sib@humboldt.org.co.

E. Data mapping. Once the data set is uploaded, verify that it follows DwC elements. For more information, consult the IPT User Manual or contact EC-SiB.

F. Creation of metadata. Metadata structure is similar to that of a traditional research article. In this way, metadata has the same general structure of a Data Paper and thus facilitate the generation of the manuscript. In the metadata section of the IPT, all information that broadens the context of data must be included. There is a total of 12 sections to add information as metadata to describe the data set. For more information, consult the IPT User Manual or contact EC-SiB.

G. Publish resource and notify EC-SiB. Once all previous instructions are completed, IPT will be activate the "Publish" option. Click on the button and send an e-mail to sib@humboldt.org.co in order to notify EC-SiB about your publication. The e-mail must have as subject "Published resource" and include:

- Name

- Name of organisation

- Name of published resource
- URL of general view of resource after publication

Now data are indexed by SiB Colombia and GBIF, and have a digital object identifier, DOI.

Step 2

Creation of manuscript for submission as Data Paper through IPT

The IPT used for publishing the data set generates a RTF manuscript that describes the data set. The link to the data set in the manuscript appears under the title "Data published through GBIF". Here you will find step by step information about how to generate a manuscript based on the data set metadata published in SiB Colombia.

- On the resource homepage published in IPT, click on the RTF button to download the first version of the manuscript in rich text format, which may be opened in any text processor (p. e. Word) (Figure 2).

- Downloaded manuscript is in English. Necessary corrections to follow Biota Colombiana guidelines must be completed on the template. Data Papers template may be downloaded here.

- Once the manuscript is adjusted with additional text, tables and figures, it may be submitted to the journal Biota Colombiana through its online platform, following steps of registry as a user. The complete editorial process is developed through this platform.

\section{Step 3}

Adjustments and corrections of manuscript for data paper

When a manuscript is submitted as a Data Paper, it will go through the same peer review process as other articles of the journal, with specifications for Data Paper evaluation.

After evaluation, and if the manuscript is accepted, it will be returned to the author with the comments of reviewers and the journal's Editor so that respective modifications may be incorporated. 


\section{Escarabajos coprófagos de la cuenca alta y media del río Bita, Vichada (Colombia)}

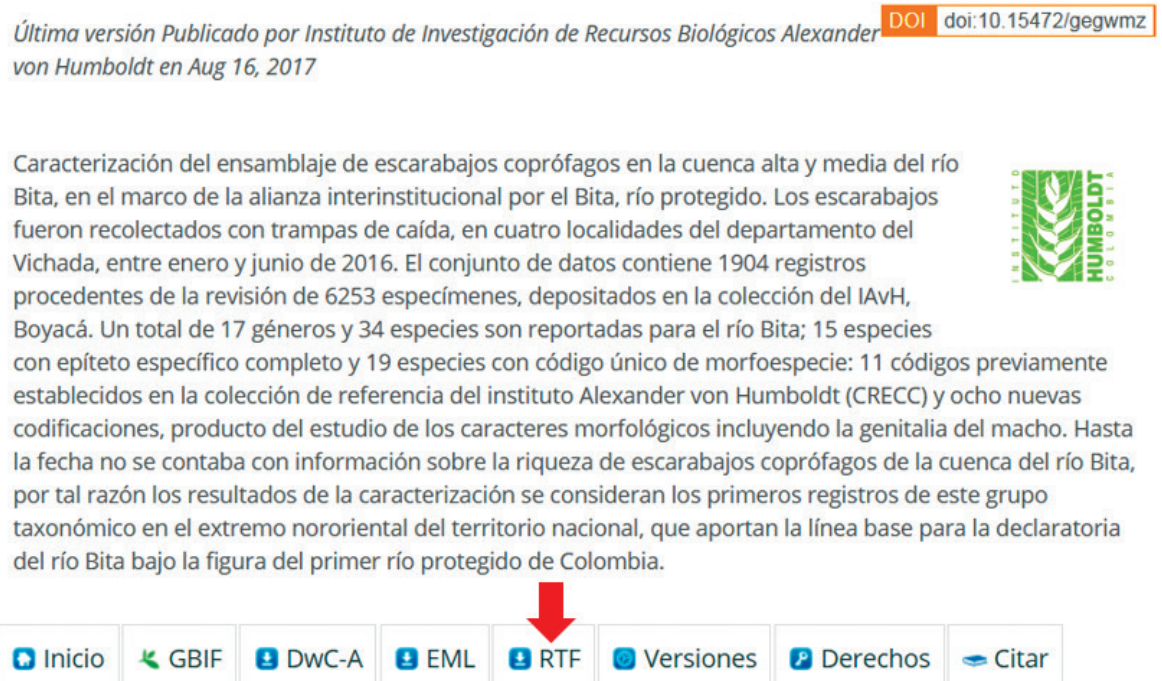

Figure 2. Metadata of a data set may be downloaded from the IPT as a RTF file, giving the first version of the manuscript that will be submitted to the journal.

As the author, you should do all corrections or modifications directly on the IPT metadata and not on the manuscript. In this way, the metadata of the linked data set are also improved by the peer review and editorial comments.

Once metadata in the IPT are improved, the resource publication must be updated so the changes are reflected. On the resource homepage of the published resource, click on the RTF button to download the improved version of the manuscript in rich text format that may be opened in any type of text processor (p. e. Word).
After the manual changes of additional text, figures and tables, and the corroboration that the manuscript follows all of the journal's requirements, it must be sent again through the online platform of Biota Colombiana.

\section{Parts of a Data Paper}

Data Papers differ from other articles that are published in the journal Biota Colombiana in the sections it should include and are mentioned in Table 1. 
Table 1. Structure of a Data Paper and correspondence with GMP elements of IPT.

Name of section

\section{Title}

Authors

Affiliations

\section{Correspondence with IPT elements}

Derived from the element Title. Centered and without period at the end.

Derived from the elements Resource creators, Metadata providers and Associated Parties. From the elements, the combination of name and last name, separated by a coma, is created. Author affiliations are indicated with numbers $(1,2,3 \ldots)$ at the end of each last name with a superscript. Centered.

Derived from the elements Resource creators, Metadata providers and Associated Parties. From these elements, the combination of organisation, address, postal code, city, country and email address constitute the complete affiliation. If one or more authors share the same affiliation, it is represented with the same number.

Derived from the elements Resource creators and Metadata providers. From the elements, the combination of name, last name, and email address is created. Email addresses are inside parentheses. If there is more than one author as contact, authors are separated by comas. If the Resource creator and Metadata provider is the same author, the Resource creator is assumed to be the contact. Text is centered.

\section{Dates of received, revised, accepted and published}

Manually incorporated by the editorial assistant of the journal to indicate respective dates of when the manuscript was received, revised, accepted and published as a Data Paper in Biota Colombiana.

\begin{tabular}{|c|c|}
\hline Abstract & $\begin{array}{l}\text { Derived from the element description. Abstract must be included in Spanish or } \\
\text { Portuguese, and English. }\end{array}$ \\
\hline Keywords & $\begin{array}{l}\text { Derived from the element keywords. Words are separated by comas. Keywords must be } \\
\text { written in Spanish or Portuguese, and English. }\end{array}$ \\
\hline Introduction & Not derived and must be added by the authors manually. \\
\hline Taxonomic coverage & $\begin{array}{l}\text { Derived from section of taxonomic coverage: description, scientific names, common names } \\
\text { and category. }\end{array}$ \\
\hline Geographic coverage & $\begin{array}{l}\text { Derived from section of geographic coverage: description, minimum latitude, maximum } \\
\text { latitude, minimum longitude, maximum longitude. }\end{array}$ \\
\hline Temporal coverage & Derived from section of temporal coverage: description, start date, end date. \\
\hline Project description & $\begin{array}{l}\text { Derived from section of project data: title, project personnel, funding, study area description, } \\
\text { design description. }\end{array}$ \\
\hline Collection data & $\begin{array}{l}\text { Derived from section of collection data: name of collection, collection identifier, parental } \\
\text { collection identifier, specimen preservation methods, curatorial units. }\end{array}$ \\
\hline Materials and methods & $\begin{array}{l}\text { Derived from section of sampling methods: study extent, study description, quality control, } \\
\text { step description. }\end{array}$ \\
\hline Results & --- \\
\hline Data description & $\begin{array}{l}\text { Derived from external links, among others: name, file URL, file format, version of file format, } \\
\text { publication date, language, copyright. An additional description of data such as text, figures } \\
\text { and tables may be added. }\end{array}$ \\
\hline Additional information & Derived from element of additional information. \\
\hline Discussion & Not derived and must be added by the authors manually. \\
\hline Acknowledgements & Not derived and must be added by the authors manually. \\
\hline Literature cited & Derived from element of citations. \\
\hline
\end{tabular}




\section{Biota Colombiana}

Volumen 19 (Sup. 1) - Colombia Bio y otras novedades científicas

Una publicación del / A publication of: Instituto de Investigación de Recursos Biológicos Alexander von Humboldt

En asocio con / In collaboration with:

Instituto de Ciencias Naturales de la Universidad Nacional de Colombia

Instituto de Investigaciones Marinas y Costeras - Invemar

Missouri Botanical Garden

\section{TABLA DE CONTENIDO/ TABLE OF CONTENTS}

Editorial

Una nueva especie de barniz de pasto Elaeagia (Rubiaceae), de la cordillera Oriental de Colombia. A new species of Elaeagia (Rubiaceae) from the cordillera Oriental of Colombia. Humberto Mendoza-Cifuentes y José Aguilar-Cano

Una nueva especie de Allomaieta (Melastomataceae - Cyphostyleae) del piedemonte amazónico de los Andes de Colombia. A new species of Allomaieta (Melastomataceae-Cyphostyleae) from the Amazonian foothills of the Colombian Andes. Humberto Mendoza-Cifuentes

Dos nuevas especies de Miconia (Melastomataceae) del piedemonte oriental de la cordillera Central de Antioquia, Colombia. Two new species of Miconia (Melastomataceae) from the eastern foothills of the Cordillera Central of Antioquia, Colombia. Humberto Mendoza-Cifuentes, Julián Aguirre-Santoro y Álvaro Idárraga

Dos nuevas especies de árboles molinillo (Magnolia: Magnoliaceae) de la serranía de los Yariguíes, departamento de Santander, Colombia. Two new species of "molinillo" tree (Magnolia: Magnoliaceae) from Serranía de los Yariguíes, Santander, Colombia. José Aguilar-Cano, Humberto Mendoza-Cifuentes y Melisa Ayala-Joya

Catálogo de la flora de los Parques Nacionales de Colombia: Parque Nacional Natural El Tuparro. Catalogue of the flora of the National Natural Parks of Colombia: El Tuparro National Natural Park. Humberto Mendoza-Cifuentes y Mireya P. Córdoba-Sánchez .

Primer registro del efemeróptero Oligoneuria (Oligoneurioides) amazonica (Demoulin, 1955) (Insecta: Ephemeroptera, Oligoneuriidae) para Colombia. First record of Mayfly Oligoneuria (Oligoneurioides) amazonica (Demoulin, 1955) (Insecta: Ephemeroptera, Oligoneuriidae) from Colombia. Cristian E. Granados-Martínez, Carlos A. Lasso y Juan M. Fuentes-Reinés .....

Variaciones morfológicas y algunas notas bioecológicas del cangrejo de agua dulce Neostrengeria charalensis Campos y Rodríguez, 1985 (Decapoda: Pseudothelphusidae), en ambientes exo y endocársticos de los Andes colombianos. Morphological variations and some bioecological notes of the freshwater crab Neostrengeria charalensis Campos \& Rodríguez, 1985 (Decapoda: Pseudothelphusidae), in exo and endocárstic environments of the Colombian Andes. Martha R. Campos, Ada Acevedo, Carlos A. Lasso y Jesús Fernández-Auderset

Ectoparásitos (Argulidae, Cymothoidae, Corallanidae) en rayas de agua dulce (Potamotrygonidae) de la Orinoquia colombiana. Ectoparasites (Argulidae, Cymothoidae, Corallanidae) in freshwater rays (Potamotrygonidae) of the Colombian Orinoquia. Carlos A. Lasso, Martha R. Campos, Mónica A. Morales-Betancourt y David Castro .....

Trichomycterus rosablanca (Siluriformes, Trichomycteridae) a new species of hipogean catfish from the Colombian Andes. Trichomycterus rosablanca (Siluriformes, Trichomycteridae) una especie nueva de bagre hipogeo de los Andes colombianos. Lina M. Mesa S., Carlos A. Lasso, Luz E. Ochoa y Carlos DoNascimiento

A new species of cave catfish, genus Trichomycterus (Siluriformes: Trichomycteridae), from the Magdalena River system, Cordillera Oriental, Colombia. Una nueva especie de bagre de caverna, género Trichomycterus (Siluriformes: Trichomycteridae), del sistema río Magdalena, cordillera Oriental, Colombia. César A. Castellanos-Morales

Una nueva rana de huesos verdes del género Scinax (Anura: Hylidae) asociada a los bosques subandinos de la cuenca del río Magdalena, Colombia. A new frog with green bones of the genus Scinax (Anura: Hylidae), associated with the sub-Andean forests of the Magdalena River basin, Colombia. Andrés R. Acosta-Galvis

Una nueva rana nodriza (Anura: Dendrobatidae) de los bosques de niebla asociados a la cuenca del Orinoco de Colombia. A new nurse frog (Anura: Dendrobatidae) from the cloud forests of the Orinoco basin of Colombia. Andrés R. Acosta-Galvis y Adrián Pinzón

\section{Notas}

Nuevos registros de plantas acuáticas para la región Guayana y notas sobre las islas flotantes en el río Guaviare, Guainía, Colombia. New records of aquatic plants from the Guayana region in Colombia, with notes on floating islands in the Guaviare River, Guainía. Anabel Rial

Primer registro del hemíptero Strudivelia cinctipes Champion, 1898 (Hemiptera: Veliidae) para ambientes cavernícolas de Colombia. First record of the hemiptera Strudivelia cinctipes Champion, 1898 (Hemiptera: Veliidae) for cave environments in Colombia. Hernán Aristizábal-García, Natalia Herreño-Castellanos y Carlos A. Lasso 